\title{
THE ROLE OF INTERMEDIARY ORGANISATIONS IN THE UTILISATION OF RESEARCH
}

JAAMIAH GALANT

\section{crest}

Centre for Research on Science and Technology 
C 


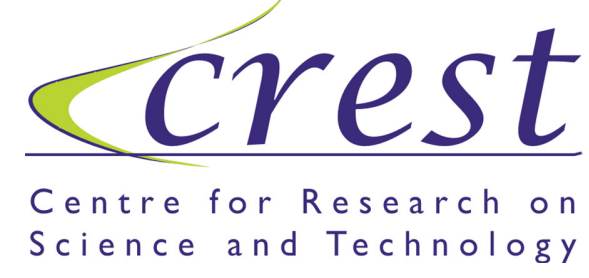

THE PRODUCTION AND UTILISATION OF KNOWLEDGE IN HIGHER EDUCATION INSTITUTIONS IN SOUTH AFRICA

Volume 5

The role of intermediary organisations in the utilisation of research

Jaamiah Galant

(C)2005 Centre for Research on Science \& Technology

All rights reserved 
The Production and Utilisation of Knowledge in Higher Education Institutions in South Africa (Volume 5): The Role of Intermediary Organisations in the Utilisation of Research

Published by SUN PReSS, a division of AFRICAN SUN MeDIA, Stellenbosch 7600

www.africansunmedia.co.za

www.sun-e-shop.co.za

All rights reserved. Copyright $\odot 2005$ Centre for Research on Science \& Technology, Stellenbosch University

No part of this book may be reproduced or transmitted in any form or by any electronic, photographic or mechanical means, including photocopying and recording on record, tape or laser disk, on microfilm, via the Internet, by e-mail, or by any other information storage and retrieval system, without prior written permission by the publisher.

First edition 2005

ISBN 1-919980-73-3

Set in $11 / 13$ Lucida Sans Unicode

Cover design by Dewald van Zyl

Typesetting by Marthie van Niekerk

SUN PReSS is a division of AFRICAN SUN MeDIA, Stellenbosch University's publishing division. SUN PReSS publishes academic, professional and reference works in print and electronic format. This publication may be ordered directly from http://www.sun-e-shop.co.za 


\section{CONTENTS}

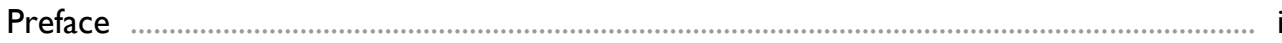

Introduction

Focus and structure of mini-case study reports

2 Overview of organisations ....................................................................... ।

3 Summary of organisations and activities f .............................................. 7

3.I Nature of organisation .................................................... 7

3.2 Research-related activities ……........................................... 7

$4 \quad$ General observations …............................................................... 10

Mini-case study I: National Wool Growers' Association of South Africa (NWGA) .... I3

Acronyms ................................................................................................... 13

I Introduction ................................................................................ 14

$2 \quad$ NWGA and the wool industry .................................................. 14

Management and funding .................................................. 15

Membership .................................................................... 16

Relationship with government …..................................... 16

Activities/services offered ................................................. 16

$3 \quad$ NWGA's involvement in research ................................................ 18

$4 \quad$ Promoting research utilisation ........................................................ 20

5 A researcher's view: Dr AC Geyer, Department of

Agriculture, Port Elizabeth Technikon ……..................................... 21

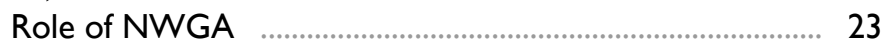

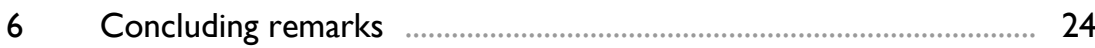

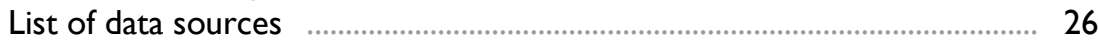

Telephonic interviews .................................................... 26

Publications and documents …........................................ 26

Websites …................................................................... 26

Mini-case study 2: South African Avocado Growers' Association (SAAGA) ................ 27

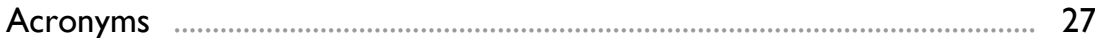

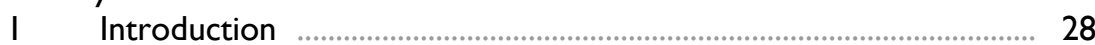

2 SAAGA and the avocado industry .............................................. 28

Management, funding and membership ........................... 28

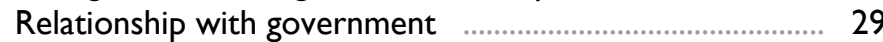

Activities/services offered ................................................. 29

3 SAAGA's involvement in research ................................................... 31

Commissioning research ................................................... 31

Relationship with researchers ........................................ 32

$4 \quad$ Promoting research utilisation ............................................................ 33

5 A researcher's view: Dr B Manikom, Institute for Tropical and Sub-Tropical Crops, Agricultural Research Council ................ 34

Role of SAAGA ......................................................... 35 
$6 \quad$ Concluding remarks .............................................................. 36

List of data sources …........................................................................... 38

Telephonic interviews ........................................................ 38

Document ……................................................................. 38

Website ……............................................................... 38

Mini-case study 3: National Association of Automotive Component and Allied Manufacturers (NAACAM) …………………………….......................................... 39

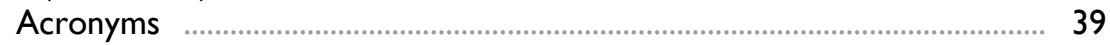

I Introduction ..................................................................................... 40

2 NAACAM and the motor industry ................................................... 40

Management and funding ........................................................ 40

Membership ......................................................................... 4 I

Relationship with government ............................................. 4 I

Activities/services offered ............................................... 4I

$3 \quad$ NAACAM's involvement in research .............................................. 42

4 A researcher's view: Dr R Barnes, School of Development Studies, University of Natal ................................................................... 43

Benefits to industry ................................................................ 46

Role of NAACAM

$5 \quad$ Concluding remarks …......................................................................... 47

List of data sources ………............................................................................... 49

Telephonic interviews _....................................................... 49

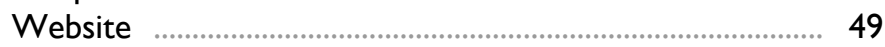

Mini-case study 4: Cotton SA _....................................................................................... 50

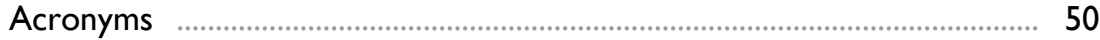

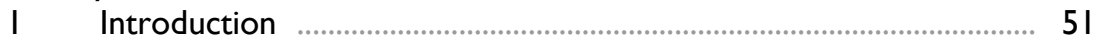

2 Cotton SA and the cotton industry ………………........................ 5 I

Management and funding …………….................................. 52

Relationship with government ............................................ 52

Activities/services offered .................................................... 53

3 Involvement in research ......................................................... 53

4 A researcher's view: Ms A Swannepoel, Institute for Industrial Crops, Agricutural Research Council ....................................... 56

Role of Cotton SA ............................................... 57

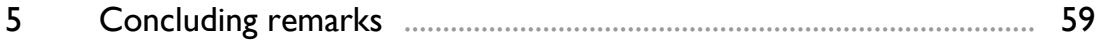

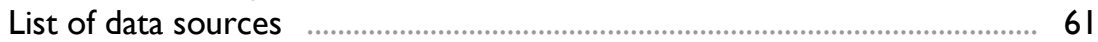

Telephonic interviews ………………………………...... 61

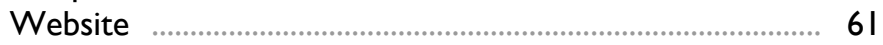


Mini-case study 5: South African Advertising Research Foundation (SAARF)

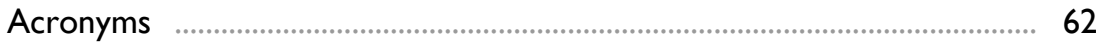

I Introduction ...................................................................................... 63

2 SAARF and the media, advertising and marketing industries .......... 63

Management and funding ................................................. 64

Relationship with government ........................................ 64

Activities/services offered ............................................... 65

3 SAARF's involvement in research .................................................66 66

Managing research .............................................................. 66

Research networks …....................................................... 67

Nature of research …....................................................... 68

Quality assurance ............................................................ 68

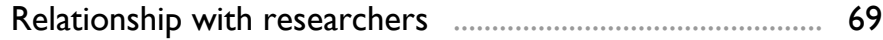

$4 \quad$ Promoting research utilisation ....................................................... 70

5 A researcher's view: Mr HA Steenkamp, Bureau for Market Research, UNISA ........................................................................... 7I

Utilisation of the research by SAARF …........................... 72

Role of SAARF …....................................................... 74

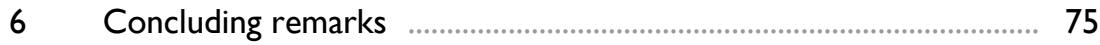

List of data sources …...................................................................... 76

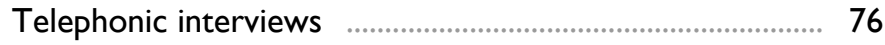

Website …................................................................... 76

Mini-case study 6: Waste Minimisation Clubs ................................................................. 77

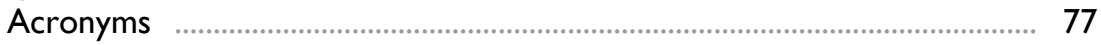

I Introduction ............................................................................. 78

$2 \quad$ Waste Minimisation Clubs .......................................................... 78

Waste Minimisation Clubs and industry ........................... 78

Management and funding ................................................. 78

Activities/services offered .............................................. 79

3 Engagement with research in Clubs ….......................................... 80

$4 \quad$ Promoting research utilisation ......................................................... 8I

$5 \quad$ A researcher's view: Prof C Buckley, Pollution Research

Group, University of Natal ......................................................... 82

Role of Waste Minimisation Clubs …............................... 84

$6 \quad$ Concluding remarks …...................................................................... 85

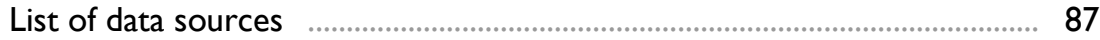

Telephonic interviews .................................................. 87

Publication …..................................................................... 87

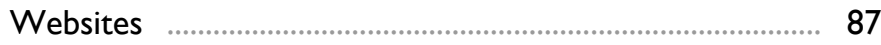




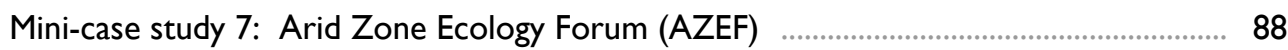

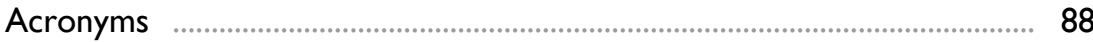

I Introduction .................................................................................. 89

$2 \quad$ Arid Zone Ecology Forum ............................................................... 89

AZEF and the NRF .......................................................... 89

Management and funding ….............................................. 89

Participants ................................................................... 90

Relationship with government .......................................... 90

3 Involvement in research: AZEF Annual conference ........................ 91

Location and format ......................................................... 91

Nature of research presentations ...................................... 92

Purpose and value of the annual conference ..................... 93

$4 \quad$ Promoting research utilisation ............................................................ 93

5 A researcher's view: Professor JD Skinner, University of Pretoria ………............................................................................. 95

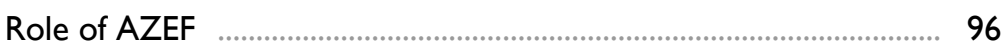

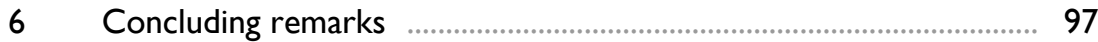

List of data sources $\ldots$

Telephonic interviews ..................................................... 99

Website …........................................................................ 99

Mini-case study 8: South African Community Epidemiology Network on

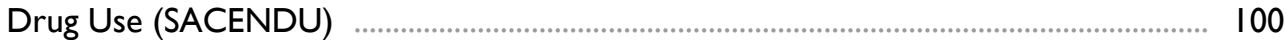

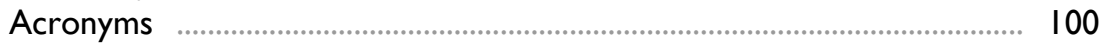

I Introduction ................................................................................. 10 |

2 South African Community Epidemiology Network on

Drug Use .................................................................................... I0

SACENDU and the MRC ........................................... I0I

Management and funding ............................................... 102

Members of the network ............................................... 102

Relationship with government ...................................... 103

Activities/services offered …............................................. 103

3 SACENDU's involvement in research ......................................... 105

Collecting data ............................................................ 105

Reporting on the data .................................................. 107

$4 \quad$ Promoting research utilisation ......................................................... 108

5 A researcher's view: Mr R Matzopoulos, National Injury

Mortality Surveillance System, Medical Research Council ............. III0

Interaction with SACENDU …........................................ $1 / 2$

$6 \quad$ Concluding remarks .................................................................. 13

List of data sources …...................................................................... II5

Telephonic interviews ................................................ II5

Publications and documents ......................................... 115

Websites …................................................................... II5 


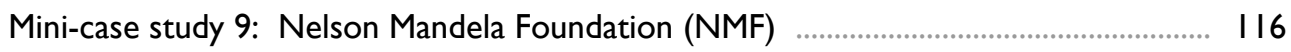

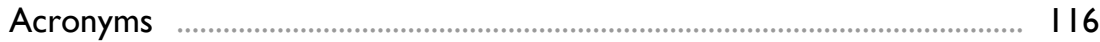

I Introduction .............................................................................. 117

$2 \quad$ Nelson Mandela Foundation …................................................... 117

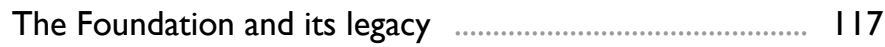

Management and funding .............................................. 118

Relationship with government ..................................... 118

Activities ....................................................................... 118

3 The Foundation's involvement in research ................................. 120

Commissioning research ............................................. 120

Involvement in the research process ............................. 121

$4 \quad$ Promoting research utilisation ...................................................... 122

5 A researcher's view: Prof LC Simbayi, Human Sciences

Research Council .................................................................... 125

Role of the Foundation ............................................... 127

$6 \quad$ Concluding remarks ...................................................................... 127

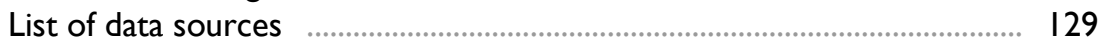

Telephonic interviews ................................................... 129

Publication ...................................................................... 129

Website ….............................................................. 129 


\section{PREFACE}

In June 2002, the Carnegie Corporation of New York awarded a substantial grant to CREST - then the Centre for Interdisciplinary Studies - to conduct research on the production and utilisation of research in higher education in South Africa.

In the original proposal to Carnegie, we described the context and rationale behind this project as follows:

With the advent of the new democracy in 1994, it was expected that the higher education institutions in the country would and should play a major role in the transformation of South African society. On the one hand, South African universities and technikons were expected to transform themselves; on the other hand, as major actors within the national system of innovation, it was also expected that they would make a significant contribution to the new society in various ways, including the production of relevant and useful knowledge.

The focus in the project is on the R\&D function of higher education institutions; on the knowledge produced by scientists and scholars at these institutions. In terms of this focus, the overarching aim of the proposed project is to analyse and assess to what extent South African universities and technikons are engaged in a transformative agenda in the production and utilisation of scientific knowledge.

Two major research questions will drive the project:

$<$ To what extent has the production of scientific knowledge at SA universities and technikons changed over the past seven years?

C To what extent is the knowledge produced at SA universities and technikons used, particularly in the interest of new national goals?

At the same time as we commenced our work on this project, the National Advisory Council on Innovation placed on tender a national study on the state of research utilisation in South Africa. CREST was awarded a grant to conduct a survey of public sector R\&D as well as a separate interview-based study of industry views on research utilisation. We subsequently integrated our work on the Carnegie project and the $\mathrm{NACl}$ commission into a two and a half year study. By the end of December 2004 we completed our research.

The findings of this study have been organized into six separate reports:

Volume I: A review of models of research utilisation

Volume 2: A survey of research utilisation

Volume 3: An industry study of the utilisation of public R\&D

Volume 4: The dynamics of knowledge production and utilisation: Fifteen case studies

Volume 5: The role of intermediary organisations in the utilisation of research

Volume 6: Knowledge for transformation: Modes of knowledge production and utilisation in post-apartheid South Africa 
I wish to thank all the participants in the individual projects for their co-operation and generous time. Without them, these studies would obviously not have been possible. I also wish to thank Marthie van Niekerk and the other support staff at CREST for their assistance in the completion of this report.

JAAMIAH GALANT

Stellenbosch 
Following the survey on knowledge production and utilisation, reported on in Volume 2, we identified a number of interesting examples where researchers reported that they were engaged in research projects that utilised innovative organisational forms in engaging with funders, users and other stakeholders (e.g. practitioners). These organisational forms seemed to act as intermediary agencies between researchers and users.

We selected nine of these examples as the focus of the mini-case studies presented in this Volume. The mini-case studies describe how non-standard organisational forms, which include forums, networks and associations, have become involved in the production and utilisation of research in a range of diverse scientific and institutional contexts. The minicase studies seek to illustrate new modes of 'interactive engagement' between users, intermediary agencies and researchers, that impact on the production, dissemination and utilisation of research.

This introductory section provides an executive summary of the nine mini-case studies in which we outline the structure and focus of the case study reports, give an overview of the focus organisation in each case study, summarise the organisations and activities, and make general observations about the features and practices that emerge from the cases.

\section{Focus and structure of mini-case study reports}

Each case study report presents two perspectives on the organisation. The first perspective is a view from within the organisation. The report starts with this perspective by contextualising the organisation within a field and then describes the nature of the organisation, with specific reference to its mission, management, funding, membership and internal structures relating to research. The report goes on to describe the core activities of the organisation with a special focus on research related activities; interactions with researchers, government and users; and dissemination strategies.

The perspective then shifts to that of the researcher. In each case study a prominent researcher, who has regularly interacted with the organisation, was interviewed to get his/her perspective on the organisation. Here, the focus of the case study report is on the nature of the interaction between the researcher and the organisation, and the mutual benefits they have derived from these interactions.

The case study reports conclude with some general remarks regarding the role of the organisation as an intermediary agency and its involvement in the production, dissemination and utilisation of research.

\section{Overview of organisations}

Summaries of the organisations focused on in each mini-case study are presented in the order that they appear in this volume. The organisations, except for one, can be loosely grouped into industry-based associations, or networks and forums of researchers and practitioners. The exception is the Nelson Mandela Foundation, which is a nongovernmental organisation (NGO) supporting social development research and 
programmes. The summaries provide a brief description of the nature of the organisation and its primary activities.

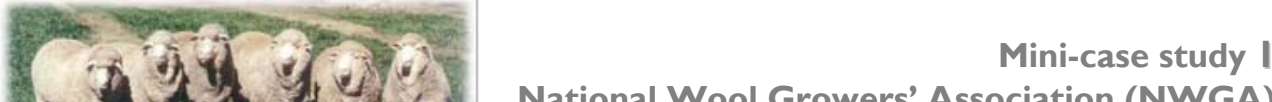

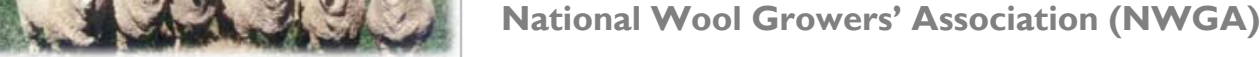

NWGA is a wool industry association that is dedicated to the promotion of sustainable and profitable wool sheep farming. It provides a wide range of support and extension services to its members, who include commercial and communal wool sheep farmers. NWGA does not actually commission or fund research, but it has a research committee that evaluates the quality and progress of existing research projects and identifies new areas of research, in order to make recommendations for funding to Cape Wools SA. It has also established many relationships and networks with a range of stakeholders that enable it to influence production research in the industry as well as policies that will impact on the farming practices and livelihoods of its members. NWGA makes use of different strategies to disseminate and promote the utilisation of research. It publishes research results in its own monthly publication and encourages and facilitates on-site practical demonstrations of new research and technologies and organises regular information days for farmers to which researchers are invited to make presentations of their research findings. From a researcher's perspective, NWGA plays an important role in conveying research needs of farmers to researchers. NWGA production advisors act as a communication channel between researchers and farmers, and they often provide crucial logistical support to researchers.

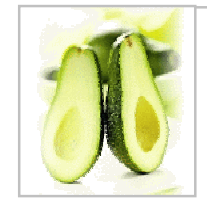

Mini-case study 2 South African Avocado Growers' Association (SAAGA)

SAAGA is an organisation driven by growers' needs to improve the economic viability of producing, promoting and marketing avocadoes. SAAGA commissions and funds research with clear objectives that will benefit its members directly and sustain the industry in the long term. The growers themselves through their representatives on SAAGA technical and research committees determine research priorities. The research committee puts out tenders for research projects and determines the brief and time frame for the tender. Over the years, SAAGA has established many long-term relationships with a small network of researchers in the field. SAAGA organises an annual research symposium for all industry members where researchers are invited to do formal presentations of their research. SAAGA encourages researchers to present their research in ways that bring out the practical implications of the research. The research papers are published in full in an annual SAAGA Yearbook. In addition, SAAGA field officers report summaries and recommendations of the research in a newsletter that is distributed to growers every six weeks. SAAGA actively promotes the utilisation of research through its field officers, who interact directly with growers on-site and serve as conduits for the transfer of research knowledge from the researchers to the growers. 
NAACAM represents the interests of motor component manufacturers in South Africa and is dedicated to keeping its membership abreast with new developments, research, legislations, and initiatives affecting the industry. NAACAM keeps in touch with members' needs through on-site visits and use these visits as opportunities to promote and evaluate the utilisation of policy and research recommendations. NAACAM does not fund research, nor undertake big research projects itself, but it does get involved in reviewing and commissioning industry relevant research through its participation in the Motor Industry Development Council. Within this Council NAACAM gets together with other industry players to put together research briefs, to nominate research team members and to review and comment on research results. From a researcher's perspective, NAACAM is an important conduit through which to gain access to, and credibility from, industry members. If NAACAM endorses the research, it encourages its members to either participate in the research if appropriate, or to use and apply the research recommendations. NAACAM also facilitates interactions between its members and researchers, by regularly inviting researchers to present at regional meetings of the association.

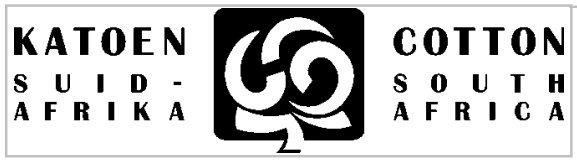

Mini-case study 4 Cotton SA

Cotton SA is an umbrella body that represents all the role players in the cotton industry. It acts as an industry forum and advisory body to various government departments and in turn, keeps its constituency informed of policies regulating the industry. Cotton SA tries to be responsive to cotton growers' research needs by prioritising and funding mainly research projects that have direct application possibilities for farmers. Cotton SA strives to keep in touch with farmers' needs through a series of regional 'study groups' involving farmers, government extension officers, researchers and a representative from Cotton SA. In addition, it collaborates with the Institute for Industrial Crops (IIC) at the ARC, to organise big annual meetings of cotton growers in different regions, where growers are given the opportunity to raise problems and identify potential areas for research. Industry relevant news and research is published by Cotton SA in a monthly Market Report; in a Cotton SA journal published every second month; and in other media popular amongst farmers. Researchers contracted to Cotton SA are expected to produce regular articles in these publications and are urged particularly to simplify their language to make it accessible to growers. Researchers benefit primarily from the financial support provided by Cotton SA for their research. Although researchers produce the research plans independently and are left alone to carry out those plans, their accountability to Cotton SA compels the researchers to pay particular attention to the benefits, applicability, and feasibility of implementation of the research, to farmers. 


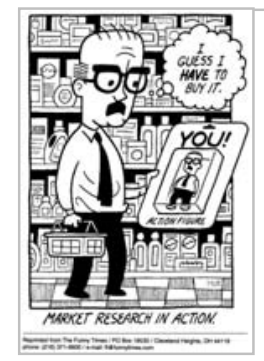

Mini-case study 5 South African Advertising Research Foundation (SAARF)

SAARF is an organisation that is committed to directing and publishing media and product research that is of benefit to the media, advertising and marketing industries. SAARF funds, commissions and manages research, which it subcontracts to independent marketing research companies. In consultation with various media committees and councils, SAARF provides very clear briefs to researchers of what data should be collected and how and actively monitors the research progress to make sure that researchers adhere to the brief. SAARF contracts out and then publishes three of the most widely used media and product surveys in the country, namely the AMPS', RAMS2 and TAMS 3 surveys. It also employs a range of external and internal validation procedures to ensure the quality of the research produced. The active involvement of stakeholders in various SAARF media committees and councils ensures that the needs of the primary users of the research are taken into account when setting up the research briefs. SAARF publishes its survey results in a variety of ways that make them accessible and 'user friendly'. In recognition of the wide range of potential users of the research and the varying capacities they have for interpreting the research results, SAARF produces special Technical Reports that contain a comprehensive "readership research methodology" that assists readers to use the data for their media and advertising planning. In addition, SAARF offers ongoing training courses in the use of the data as well as offering customised in-house courses for members on request. Researchers are encouraged to participate in stakeholder meetings organised by SAARF and whenever necessary, are expected to elaborate on their research directly to industry members.

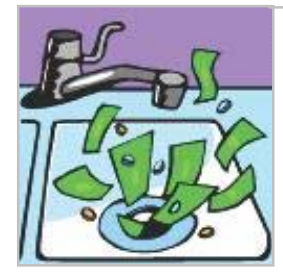

\section{Mini-case study 6 Waste Minimisation Clubs}

Waste Minimisation Clubs constitute groups of companies committed to sustainable industrial development working together to exchange information, ideas and experiences in waste minimisation. Clubs are generally managed and facilitated by consultants or researchers who are drawn from organisations and institutions that have expert knowledge in waste management strategies. The main activities that Club members engage

\footnotetext{
I All Media and Products Survey

2 Radio Audience Measurement Survey

3 Television Audience Measurement Survey
} 
in are waste minimisation assessments in their own companies and regular meetings for information sharing and learning opportunities. Waste Minimisation Clubs do not fund, commission or conduct research. However, through the initiative of the facilitator, Clubs do provide access to, disseminate and engage constantly with research that can contribute to improving waste management. Clubs rely on facilitators to bring relevant research to their attention and facilitators often have to filter the research to highlight practical aspects applicable to members of the Club. Researches are sometimes invited to make presentations to Club members. Facilitators also assist companies to conduct on-site waste minimisation assessments. These on-site visits are used as opportunities to promote and evaluate the utilisation of waste minimisation research and practices.

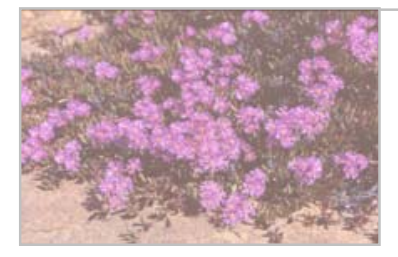

\section{Mini-case study 7 Arid Zone Ecology Forum (AZEF)}

AZEF is an informal network that provides a forum for arid zone researchers and practitioners to get together to share ideas around innovations and debate solutions to commonly experienced problems within arid regions. Its primary activity is hosting an annual conference where participants include researchers, government officials from agricultural, environmental and conservation departments, and a small percentage of arid zone farmers. Much thought is given to the location and format of the annual conference. The conference is usually located in small rural towns, with little to distract participants from conference activities. Formal and informal interactions between participants are equally valued and hence many opportunities for both forms of interaction are created. These include formal presentations, field trips, formal and informal round-table discussions and general socialising. The informal and intimate nature of the annual conference contributes towards establishing a community of researchers and practitioners interested in arid zone issues, as well as integrating young researchers, like post-graduate students, into this community. Conference activities are only reported in a booklet with abstracts of the research papers and it is only recently that AZEF is beginning to develop space on its website to publish some of the research papers and compile CDs of full conference proceedings. With respect to promoting research utilisation, AZEF sees its role as encouraging and suggesting ways in which individual researchers can go about promoting their research and making it accessible to those who should implement it. 


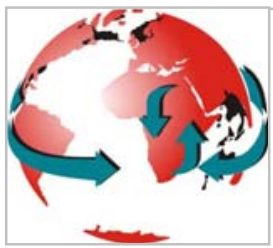

Mini-case study 8

South African Community Epidemiology Network

on Drug Use (SACENDU)

SACENDU is a network of researchers, practitioners and policy makers concerned with the uses and consequences of abuse of alcohol and other drugs. The network is driven from within by a strong research group at the Medical Research Council of South Africa (MRC), which accounts for the emphasis that SACENDU places on the systematic collection of appropriate data and the analyses of patterns and trends of the uses and consequences of abuse of alcohol and other drugs. SACENDU collects, collates and analyses primary and secondary data from a range of sources. Data sources include members within the network and researchers outside of SACENDU. Updated SACENDU data are reported at specially organised meetings in different regions across the country every six months. At these meetings researchers, practitioners and policy makers have the opportunity to interact with each other and network, as well as discuss and critique SACENDU data and research results. The interaction with network members at these meetings provides valuable feedback from users and enables SACENDU to be responsive to comments and suggestions from network members. This often results in the addition of new data or the initiation of new research projects. Subsequent to these meetings, SACENDU data are disseminated on its website in three different forms: two-page summaries; longer overviews of results by sites and by drugs; and full proceedings containing all the raw data. In the past few years, several journal articles have been written based on SACENDU data and the data are also regularly reported on in the popular media. Researchers often benefit from co-publications with SACENDU researchers. With respect to policy makers, SACENDU prepares special policy briefs and makes explicit policy recommendations based on its data.

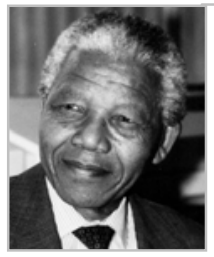

Mini-case study 9 Nelson Mandela Foundation (NMF)

The Nelson Mandela Foundation is an organisation committed, amongst other things, to supporting social development research and programmes and creating platforms for dialogue between different social groups and agencies. It encourages social alliances and partnerships that will foster community engagement, community project-ownership and community benefit. The Foundation commissions and funds research that is innovative and will have some impact on social development policies and interventions. It considers the researchers to be its partners and where possible, it actively participates in the development phases of the research and monitoring research progress. The Foundation is instrumental in disseminating and promoting the utilisation of its research. One of its main strategies is to involve key stakeholders at the outset of a research project, getting their 
input at the research design stage, and then keeping them updated throughout the research process. Once the research is completed, the Foundation makes special efforts to tailor reports for specific groups of stakeholders and specifically targets different pillars of government that it feels can utilise the research to make a difference to the future of the country.

\section{Summary of organisations and activities}

Table I provides a summary of the nature of the organisations and the research-related activities that they engage in.

\subsection{Nature of organisation}

The organisations have been categorised into the following three groups:

a) Industry-based associations

These organisations are initiated by specific industries and are therefore driven by industry needs and interests. Memberships to the organisations are quite formal and are usually open to all practitioners and stakeholders within the particular industries. The organisations are funded primarily through industry levies or membership fees and are dedicated to meeting the practical and research needs of their members.

b) Clubs / networks / forums

These are more informal self-organised bodies that are driven by researchers and their scientific interests, who place a strong emphasis on the applied value of their research. Membership is not formalised and participants include practitioners, policy makers and researchers. Funding sources vary to include science councils, funding agencies and industry.

c) Non-governmental organisation

Only one organisation falls into this category. This is an organisation that develops from within civil society - by people outside of industry or government. It does not have any form of membership, but rather establishes formal and informal relationships and partnerships with a range of stakeholders that include policy makers, researchers and community forums or organisations. It is donor funded from a range of funding sources including overseas donor agencies.

\subsection{Research-related activities}

The range of research-related activities in the table reflects different phases in the cycle from knowledge production to knowledge utilisation. These phases can be described as follows:

(a) Planning

This is usually the starting point in the cycle from knowledge production to knowledge utilisation. During this phase, research priorities are identified and research agendas are set. Organisations involved during this phase thus influence the outcomes of research agendas to reflect the needs and priorities of their constituencies. 
b) Resources

This phase involves the access and availability of resources to carry out research. Organisations contribute to access and availability of research resources in two ways:

- they provide financial resources by funding research carried out by independent researchers or

- they provide human resources in the form of researchers who have the time and capacity to conduct research.

c) Dissemination

This phase involves making research public. Organisations contribute to this phase by using a range of strategies to disseminate research either to their immediate constituency only or also beyond their immediate constituency.

d) Utilisation

The final phase in the cycle involves uptake or utilisation of the research.

Organisations involved during this phase mediate the research through direct interaction with primary users. In other words, this phase involves more than simply providing access to the research - it involves processes whereby organisations facilitate the interpretation and implementation of research results by primary users.

We should point out that this phase is also often associated with the impact of research and in our case studies; there are numerous accounts where organisations report on the impact of research. However, since we did not interview any primary users we have refrained from commenting on any measures of impact of the research. 


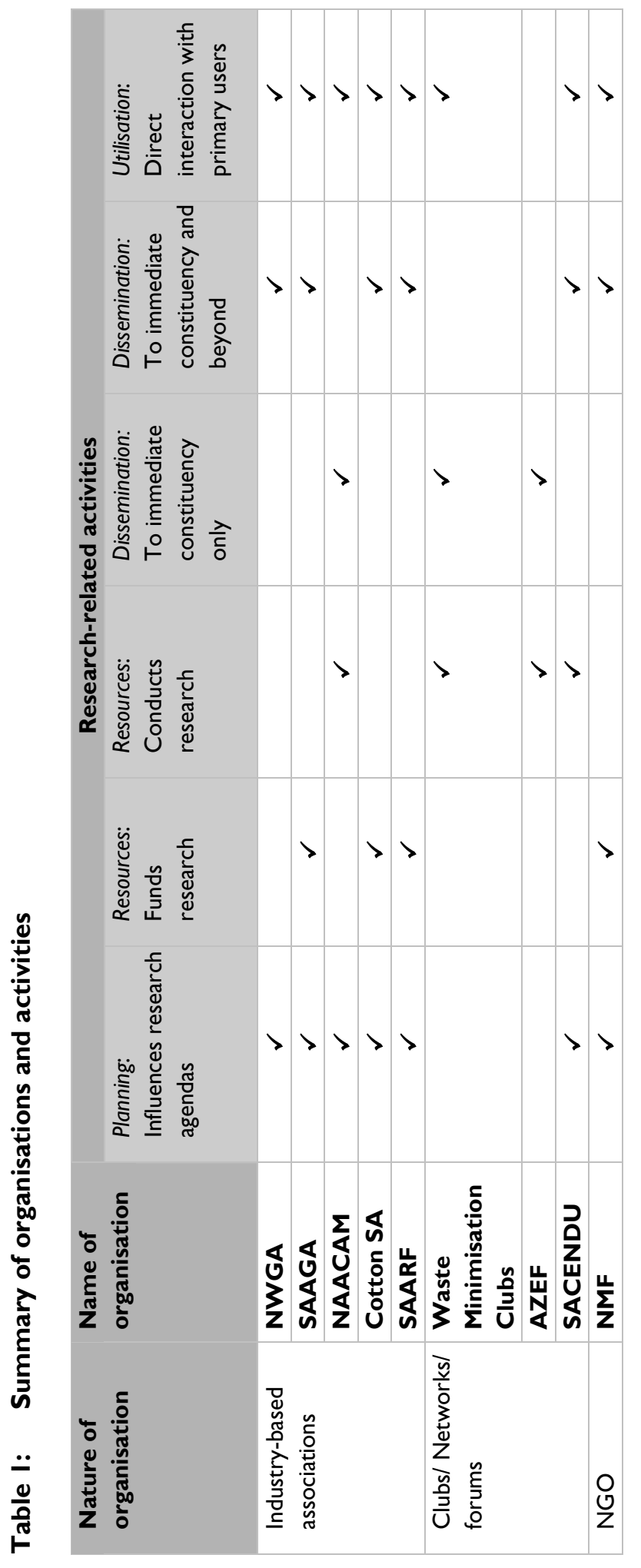




\section{$4 \quad$ General observations}

The mini-case studies are illustrative of how non-standard organisational forms, which include networks, forums, NGOs and industry-based associations, act as intermediary agencies between researchers and users in the production and utilisation of research. They are 'non-standard' organisational forms in that they are not directly related to government initiatives geared at steering or directing research agendas. These organisations either develop from their respective constituencies (as in the case of the five industry-based associations), or are driven by researchers sensitive to the needs of primary users (as in the case of AZEF, Waste Minimisation Clubs and SACENDU). The NMF is perhaps unique as an organisation that developed from the vision and commitment of its founder, Nelson Mandela, to the economic, political and social transformation of South Africa.

We see in these case studies, organisations that perform a strategic function in bringing together a wide range of knowledge producers and knowledge users, with the latter ranging from practitioners to policy makers. The nature of the engagements facilitated by these organisations is such that the research interests of its members (who are often diverse) arise "naturally" from these interactions. There does not seem to be much central steering or top-down directives. The articulation of research demand occurs in self-organising systems that in turn are embedded in other related networks.

These case studies reflect what Arie Rip (1996) refers to as 'aggregation' in his description of post-modern research systems. Rip posits that there are two important systemic aspects of research systems, namely 'steering' and 'aggregation'. 'Steering' refers to "the extent to which the system is sensitive to attempts of a principal, generally the state, to implement its own goals" (Rip, 1996:343). Where steering occurs, scientists and scientific communities tend to work towards goals of the state. This has the concomitant effect of the increasing homogenisation of research demand in the system to serve the interests of government. In contrast, 'aggregation' refers to "the organisation of processes of agenda building within the system" (Rip, 1996:343). Generally, he argues, these involve bottom-up processes in organisations that lead to de facto priorities in research (Rip, 1996:347). It is particularly these 'bottom-up' processes involving researchers and practitioners in dialogue that are illustrated in our case studies.

With respect to the industry-based associations, for example, in the case of NWGA, a network of regional planning structures that include NWGA production advisors, researchers and farmers; avocado growers interacting directly with researchers on SAAGA technical and research committees; researchers interacting with manufacturers at NAACAM regional meetings; regional 'study groups' facilitated by Cotton SA involving farmers, government extension officers and researchers; the involvement of stakeholders and researchers in various media committees and councils of SAARF. These are all examples of different modes of engagement through which research demands are articulated and research agendas are set.

The case studies also highlight the varied strategies the organisations employ in disseminating and mediating research to users. For example, some of the organisations have their own publications in which they regularly report on research results to their 
constituencies. These publications include newsletters (Waste Minimisation Clubs, NAACAM), newspapers and magazines (NWGA), yearbooks (SAAGA), research abstracts (AZEF) and research reports (Cotton SA, SAARF, SACENDU, NMF). Several of the organisations also report on research results in other popular media (NWGA, SAAGA, Cotton SA, SAARF, SACENDU, NMF) thus disseminating research results beyond their immediate constituencies. With respect to mediating research, we have for example, organisations that facilitate field visits and on-site demonstrations of research results and new technologies by researchers directly to the users (NWGA, NAACAM, SAAGA, Cotton SA, Waste Minimisation Clubs), as well as examples of organisations that 're-package' research reports so that they can be more accessible to users (SAARF, SACENDU, NMF).

SACENDU and the NMF present perhaps the best cases of how intermediary agencies target policy makers as a special group of knowledge users. For example, SACENDU specifically invites policy makers to its six-monthly regional meetings that also include researchers and practitioners, and prepares special policy briefs and makes explicit policy recommendations based on its data. One of the NMF's main strategies is to involve key stakeholders at the outset of a research project and once the research is completed, it makes special efforts to tailor reports for different groups of stakeholders and specifically targets different pillars of government that it feels can utilise the research to make policy decisions.

From the researchers' perspective, these organisations play a crucial role as intermediary agencies facilitating access to users and modes of dissemination that the researchers would not have been able to achieve on their own. In all the cases, it is the organisation that sets up the forums and networks for researchers to interact directly with users, thus creating opportunities for the researchers to disseminate their research wider than just to the research community; to promote the utilisation of the research directly to the primary users and, to respond to the research needs of the users. We see that the organisations clearly support and endorse research that will have strategic value (NAACAM, SAARF, Cotton SA, SACENDU, NMF) as well as applied value (NWGA, AZEF, Waste Minimisation Clubs) to benefit its constituencies. The applied research includes research around new technologies and new practices.

In conclusion, these case studies illustrate how research demand can be articulated and developed in ways that complement and strengthen more formal government-driven mechanisms, such as policy statements, funding programmes, evaluations and reviews, and performance related measures. In these case studies, research demand and agenda setting occur through novel forms of 'interactive engagement' between researchers, primary users and other stakeholders. These forms of engagement challenge the effects of central steering in the research system, by generating a demand for research that is driven from the bottom-up, is heterogeneous in terms of the range of interests served, and more representative of the range of actors who have a direct interest in the research being produced. We see further how non-standard organisational forms function as intermediary agencies between researchers and users, playing a significant role in disseminating and promoting the uptake and utilisation of research. 
We conclude by listing the distinctive features that characterise the intermediary bodies described in the case studies:

$<$ They are focused on a specific domain that is defined primarily by the users/practitioners within that domain.

$<$ These organisations are "hybrid" in that they combine the functions of funding agencies, research management organisations, dissemination agencies and so on.

$<$ The 'proximity' between these agencies and the knowledge producers on the one hand and the users on the other hand seems to be a major reason for the 'success' of these organisations in getting their 'message' across in both directions.

$<$ All of the above means that these agencies are very well positioned to 'translate' the research needs and interest not only of their knowledge producers, but more importantly, of their users/practitioners very quickly and are able to adapt to changes in the demand environment quite quickly. This has the added benefit of representing a diversity of demands that performs a very important function in the national system of innovation.

$<$ They draw on a range of resources that enable them to disseminate research widely and to promote and facilitate the uptake and utilisation of research. 
MINI-CASE STUDY 1

NATIONAL WOOL GROWERS' ASSOCIATION OF SOUTH AFRICA

(NWGA)

A wool industry association dedicated to the promotion of sustainable and profitable wool sheep farming through the provision of enhanced production technology research and extension.

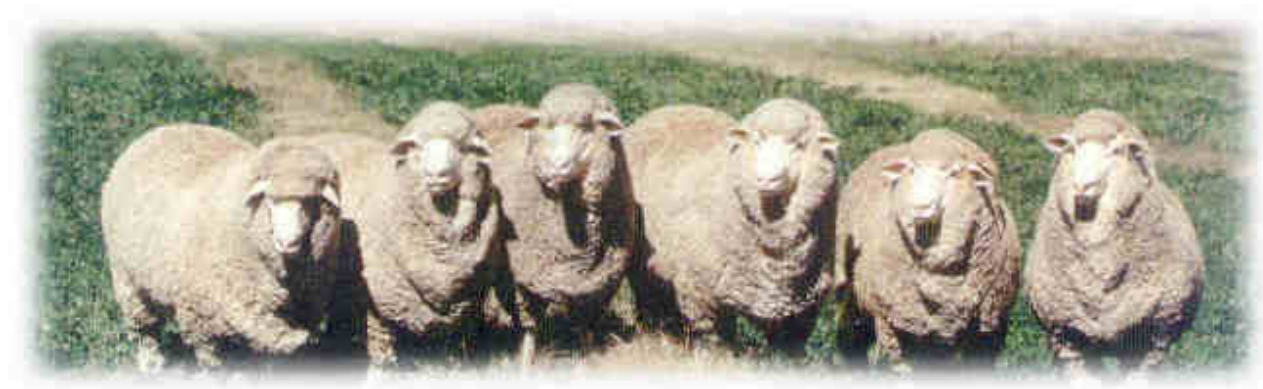

Photograph courtesy of National Wool Growers' Association of South Africa website [http://www.nwga.co.za/]

\section{Acronyms}

NWGA

National Wool Growers' Association

CWSA

Cape Wools SA

ARC

Agricultural Research Council

PE Technikon Port Elizabeth Technikon 
1 Introduction

The sheep and wool industry is one of the oldest agricultural industries in South Africa. It plays an important economic role as an earner of foreign exchange for the country, and provides employment to some 250000 people. This industry became established on a commercial basis under British colonial rule (1806-1910). During the whole of its colonial period, the Cape Province remained the most important wool-producing area in Southern Africa. Although the sheep industry spread rapidly throughout virtually the whole country during subsequent years, "Cape wools" has become the international generic trade term for all wools produced on the sub-continent (Cape Wools SA, website).

The National Wool Growers' Association (NWGA) is an organisation that focuses on the wool farmers and their interests. They focus specifically on providing production technology services to wool sheep farmers. These services include production advisory services, training and development, and production research and development.

In this case study report we describe the activities of NWGA and reflect on the nature of the organisation and the contribution it makes towards dissemination and utilisation of research within the industry. We then step back and get a view from a researcher. We consider the relationship that one prominent researcher has established with NWGA. In particular, we describe his involvement in production research in the wool industry and reflect on the benefits his relationship with NWGA has had on his ongoing research.

\section{$2 \quad$ NWGA and the wool industry}

NWGA are contracted to Cape Wools SA, to provide production technology services to wool sheep farmers. Cape Wools SA (CWSA) is a section-2I service company established by the Wool Industry Forum of South Africa. One of the objectives of the Forum is to "promote the proficiency of the production, processing and the demand for South African wool and wool products". Accordingly, one of the main objectives stated in the Memorandum and Articles of Association of CWSA is to "perform research in connection with the improvement, production, manufacture, processing, storage and marketing of South African wool". To enable CWSA to fulfil its obligations in terms of the strategic functions allocated to it by the Forum, CWSA receives funding from the Wool Trust, which, amongst others, also identifies as one of its main objectives, to generate income from its capital base to provide funding for "research in connection with the improvement, production, manufacture, processing, storage or marketing of South African wool" (Cape Wools SA, website).

There is, therefore, alignment between industry structures that underpins access to funding from the Trust for the strategic identification, funding and management of Research and Development for the wool industry. This alignment also ensures that an appropriate and necessary framework for identification, prioritisation and an audit system exists within the industry to ensure that optimum use of funds from the Trust remains a priority (Cape Wools SA, website).

It is to this end that Cape Wools SA, with a mandate from the Wool Industry Forum and funding from the Wool Trust, has contracted NWGA to manage its production research portfolio and provide production technology services to wool farmers. 


\section{Management and funding}

NWGA was founded during a Wool Conference in Middelburg on 26 May 1926

when delegates from 19 Wool Growers' Associations (16 from the Cape and 3 from the Free State) formally accepted its constitution and rules. Since then, NWGA has developed into a countrywide organisation, consisting of six Area Branches, with more than 600 sub-branches (NWGA website). Activities of NWGA are managed by a National Chairman and General Manager, Dr Arno Moore, who is supported by a national executive, production advisors spread across the country, and several committees with specific focus areas.

In 2003, NWGA operated on a budget of RI 8 million. NWGA generates funds through a number of different channels: firstly, through membership fees, and secondly through contracts for development and training projects, both in commercial and communal areas 4 . These development contracts always include 10\% management or consultation fees, which accrue to the organisation. A third form of generating funds is through sponsorships from private companies. They are usually invited to become partners in development projects and agree to the partnerships because of the "commercial value" they get from it (Dr Moore, interview). These sponsorships most frequently involve sponsoring shearing demonstrations and shearing competitions ${ }^{5}$. A fourth, and significant form of generating funds, is through advertising in the monthly publication of NWGA, The Wool Farmer. According to Dr Moore, The Wool Farmer "generates between 20 and 30 thousand Rand a month returns on advertisements" (Dr Moore, interview).

In addition to these different sources of funding, NWGA also gets substantial funding from Cape Wools SA, to whom they are contracted to deliver production technology services to wool farmers. Despite these many sources of funds, Dr Moore points out that NWGA still struggles to generate funds specifically for research. Currently, research funding comes mainly from the Wool Trust, via Cape Wools SA. Dr Moore describes some of the ideas that have been raised to address the issue of research funds:

There is resistance in the wool industry towards statutory levies and if you don't have these levies then it's very difficult to have a blanket approach towards funding. So we are looking at creative ways to have a bigger possible contribution basis towards research, if we don't go the statutory levy route. [ ] We want to get together in NWGA, a virtual research centre, we can call it that, where we think we can have one body who can generate research funds from where ever, to add value to the funds that we have. But to have a research programme that is run on business principles. We're trying to get something like that going (Moore, interview)

The statutory levy would be a levy imposed by government on all wool sheep farmers, which would then be used for research to benefit the industry. Getting funds through a statutory levy would mean that NWGA would be able to use the money flexibly, since it would not be tied into a specific development or research project.

4 In 2003, NWGA received funding for shearer training from the Department of Labour (manpower rebate), the National Skills Funds and New Zealand Aid, which financed the costs of a New Zealand expert in hand shearing to assist NWGA training team (NWGA website).

5 The two main NWGA sponsors have been Intervet South Africa (Pty) Ltd and Voermol Feeds (NWGA website). 


\section{Membership}

Membership of NWGA is voluntary, although there is a membership fee. The members are commercial farmers (mostly white) and communal farmers (mostly black) with membership evenly distributed, "like 50\% of each of those categories" (Moore, interview). Dr Moore explains the difference between these two categories of farmers:

The main difference is land tenureship. The commercial farmer is the farmer who farms in the commercial areas with his own land. The communal farmers are farmers who farm on communal land. So there is not one person who owns the land and this is a major constraint in the communal set-up. So in the communal set-up we work with wool farming communities. In the commercial areas we work with individual farmers, but on a group basis (Moore, interview).

Communal farmers, who are part of the same community, take up individual membership within NWGA. At present, NWGA boasts a voluntary membership of approximately 7500 wool farmers.

\section{Relationship with government}

NWGA interacts regularly with government through the provincial and national Departments of Agriculture. It has always maintained good relationships with these departments resulting in several wool sheep-related partnership projects, in which the provincial departments provide the funding and NWGA provides the service. In one such project in the Eastern Cape, the provincial department of agriculture has also seconded eight of their extension offices to NWGA to work on the partnership project. As testimony to the good relationship with provincial governments, Dr Moore quotes the Member of the Executive Council (MEC) for Agriculture in the Eastern Cape, as saying that, the relationship between NWGA and the Eastern Cape Department of Agriculture is "not a partnership, but a marriage".

\section{Activities/services offered}

The activities of NWGA are organised through provincial structures and sub-structures that draw in as many of their members as possible:

We have six provincial offices with Production Advisors and they work through about sixty, what we call farmer planning committees, which consists of farmers and all experts that you can have on that planning committee where they identify needs for a specific area and an execution plan to deliver on that needs (Moore, interview).

The "experts" on those planning committees sometimes include researchers from tertiary institutions or the Agricultural Research Council (ARC).

The activities and services of NWGA, as described by Dr Moore, fall into four broad strategic areas aimed at the benefit of their members, namely, production technology services, effective marketing of wool, influencing policy and harnessing financial resources. 


\section{a) Production technology services}

A unique feature of the production technology services offered by NWGA is to take proven technology and demonstrate it practically on private commercial farms and government sponsored experimental farms. According to Dr Moore, NWGA has "in the commercial area 35 on-farm-trial demonstration units" (Moore, interview).

Through its activities, particularly the production technology services, NWGA boasts approximately 6000 commercial farmer contacts per year. These farmer contact sessions take on different forms, as reported in the 2003 Annual Report:

In total 6079 individuals [commercial farmers] were reached during 2002/2003. The vast majority of farmers (74\%) were reached through group actions such as information days, project open days, study group meetings and training courses (NWGA Annual Report, 2003).

In the communal wool farming areas, production technology services comprise mostly training and development of the farmers in key areas such as genetic improvement, shearer training, wool classing training, training and support with packing and marketing of wool, training in sheep management and training in sheep handling and selection (NWGA website).

An important component of production technology services is to "initiate appropriate priority production research" (NWGA Business Plan, Production Technology Services: 2003/4). In section 4, how NWGA achieves this is discussed in detail.

\section{b) Effective marketing of wool}

NWGA has a marketing committee that considers various strategies for the effective marketing of wool. In June 2004, NWGA hosted an industry symposium on wool marketing. Effective marketing of communally reproduced wool is given special attention and offers particular challenges as Dr Moore points out:

[For] more effective marketing of communally reproduced wool [ ] we need infrastructure like shearing sheds, etc. to get wool in a form where you can actually market it according to industry standards otherwise it's worthless (Moore, interview).

According to the 2003 Annual report, since 1997, 72 communities have been provided with infrastructure and / equipment enabling them to harvest and market wool through the auction system (NWGA Annual report, 2003).

\section{c) Influencing policy}

NWGA interacts with the policy environment not only through its relationships with national and provincial departments of agriculture, but also through its affiliation to Agri SA, the commercial farmers' union (Moore, interview). Through Agri SA, NWGA made significant inputs regarding production research and technology, and prioritising implementation needs, in the National Plan for South African Agriculture (NWGA Annual report, 2003). 


\section{d) Harnessing financial resources}

NWGA has had a good success rate in terms of its ability to harness financial resources for the benefit of its members. This is largely owing to the wide pool of organisations and institutions that NWGA has access to:

We have a very effective network that includes the involvement of the ARC, government department, provincial and national departments and other bodies like the CSIR and privately like European money, through Britain and the USA, those are all sources of funds that we use (Moore, interview).

In addition to all the activities described above, NWGA also produces a monthly publication, The Wool Farmer, which is produced in three languages, namely, English, Afrikaans and Xhosa. The paper contains industry-specific information and is distributed widely "to members and to people that we want to send it to, with whom we feel we can promote ourselves with and who will gain from the paper, like agricultural businesses and colleges, extension officers from the Department, policy and decision makers in government, etc." (Moore, interview).

The activities described above are typical of industry associations, as far as it facilitates access to information for all its members, provides individual support when and where necessary and contributes to policy making within the industry.

\section{$3 \quad$ NWGA's involvement in research}

As part of its contract with Cape Wools SA to provide Production Technology Services to the wool industry, NWGA manages the production research portfolio on behalf of Cape Wools SA. This means that, while they do not commission research, they evaluate progress of existing projects as well as the potential of new research projects and recommend to Cape Wools SA which research projects to fund. The research portfolio is managed primarily through a research sub-committee of the National Production Advisory Committee, set up by NWGA, with some inputs from the farmer planning committees. Dr Moore explains how research needs are identified and dealt with:

[We get research ideas] from various ways, like the network of planning committees that we just spoke about 6 . If you have 50 or 60 planning committees throughout the country and you are involved with practical farming and that type of thing all the time then you can easily identify needs in the knowledge gap and that then flows to the National Production Advisory Committee and then to the research committee. That's one way and then secondly, all our top researchers in the country are involved with this planning committee so they are knowledgeable, they have all the expertise and they can then put some innovative ideas regarding research on the table as well (Moore, interview).

According to the 2003 Annual Report, the National Production Advisory Committee held two meetings to evaluate progress and determine priorities for research funding for 2003/2004. Seven ongoing research projects are managed by NWGA while two additional projects were accepted for funding by Cape Wools SA. The research is

\footnotetext{
6 See first quote in section 3 , describing the activities of NWGA.
} 
undertaken mostly by researchers from tertiary institutions as well as from national research facilities like Onderstepoort [Veterinary Institute] and Grootfontein [Agricultural Development Institute], and of course the ARC. Occasionally, production advisors from NWGA also get involved in research projects, most often by providing access and logistical support. Researchers usually have to tender for the research projects and enter a contract with Cape Wools SA, but are managed by, and held accountable to, the research committee of NWGA. Dr Moore describes what expectations NWGA has of these contract researchers:

We want two things mainly, the one is to present us with properly planned research which we will field from our side since we've got experts sitting on our committee to ensure as far as possible that it is a good investment we're making and that we will get the results, that's number one and number two, we want them to give proper reports and then we want them to go the extra mile and say that they will be involved with making this information available to the farmers through information days or whatever or visits to trials or to be involved with our demonstration sites on farms where some of these results get taken further in the practical adaptation (Moore, interview).

The above comment shows that NWGA are clearly concerned with issues around the dissemination and utilisation of the research it supports. It is not surprising therefore, that most of the research that they do support is applied research that will have a visible impact on production systems when implemented:

We look at [the research] in terms of whether it will produce results that are practical and applicable, which will fulfil a need. We don't sit with results and ask - what are we going to do with it now - there is already need for the results. [ ] So when you evaluate it, it is very difficult to say how are you going to do it, but it's all about the applicability of the results and the influence it will have on the profitability of the systems (Moore, interview).

Although Dr Moore admits that sometimes they have to make assumptions about the value of the research, mostly NWGA relies on the research experts that they have on their research committee to provide realistic evaluations of current and potential research projects and hence contribute to making recommendations to Cape Wools SA regarding which projects to fund.

In addition to the above descriptions of research involvement by NWGA, the 2003 Annual Report also lists other "actions" that NWGA are involved in that are aimed at maintaining "a competitive, but cost-effective agricultural research system for South Africa", i.e.:

i) NWGA National Chairman holds the position of Chairman: Research and Technology in Agri SA. In this capacity he is able to positively influence the policy and institutional environment relating to production research.

ii) NWGA, through Agri SA, made significant inputs regarding production research and technology in the National Plan for South African Agriculture. 
iii) NWGA plays a major role in the "Overarching Action Committee for Sheep" focussing on prioritising implementation needs in the National Plan for South African Agriculture.

iv) NWGA represents wool farmers on the Advisory Committee of the ARC Livestock Business Division, focussing on livestock research matters.

v) NWGA represents wool farmers on the Project Committee of the Red Meat Research and Development Trust of SA. This ensures co-ordination with NWGA National Production Advisory Committee and a number of projects are currently co-funded.

(NWGA Annual Report, 2003)

The above report suggests that NWGA takes its research portfolio very seriously and clearly strives towards leading the production research agenda in the wool industry. NWGA itself does not undertake or commission research, but it evaluates the progress of current research projects and the potential of new research projects, in order to recommend financial support from Cape Wools SA. The main criterion used in the evaluation of these research projects is the applicability of the research results.

\section{$4 \quad$ Promoting research utilisation}

Dr Moore argues that the way NWGA structures relationships between farmers and researchers and organises its activities, contribute significantly towards promoting the dissemination and utilisation of research:

I think we are fantastically positioned to form the link between the farmer and research, it's unique, there is nothing else like it because we have this network of planning committees and the bodies, the production advisors, link them with the researchers. Firstly, the planning committees have their aligned farmers who are directly involved from the beginning in the research, either the execution or identification of the research. Secondly is the fact that l've mentioned all this information that we have and the expertise we have from the experts who are co-opted on our planning committee. So through these numerous group actions we have, there is a constant flow of the newest information and then thirdly through our monthly publication, the Wool Farmer. Whenever there are new promising research results available, it will be published in the Wool Farmer (Moore, interview).

An additional activity, that also plays an important role in disseminating and promoting the utilisation of research, is the use of practical demonstrations:

It is through repetition, through practical demonstration [that we make the research accessible]- which is very important, visits, taking them out to places where that technology works. [ ] For instance if you have veld management projects, you will demonstrate there on the ground, you will put in place a system where you can actually demonstrate say resting of veld. [ ] In our ram breeding project for instance we will take farmers, the decision makers, the top guys in communities we will take on a study tour to the commercial breeders (Moore, interview). 
As described in section 3, such practical demonstrations are ongoing, on private commercial farms as well as government- sponsored experimental farms.

NWGA contributes to its own publication, the Wool Farmer, and also contributes to other publications:

We make use of all obvious publications through which we can spread our message better, papers like the Barkley Report, you know small papers or bigger ones like Die Burger or the Eastern Cape Herald Farmer's Weekly and the Landbouweekblad. And there are various others (Moore, interview).

According to the 2003 Annual Report, during 2002/2003, 53 articles related to NWGA's Production Technology Services were published in the Wool Farmer, Landbouweekblad, Farmers Weekly, Landbou Burger, etc. (NWGA Annual report, 2003).

Beside the efforts to promote research utilisation described above, in the previous section we also saw that NWGA expects researchers, whose research they have supported, to become involved in information days and participate at demonstration sites as ways of encouraging the dissemination of the research and promoting utilisation of the research by wool sheep farmers. In this regard, Dr Moore only has praise for the researchers they have worked with, describing them as "very supportive", with not one researcher turning down an invitation to participate in information days or practical demonstrations.

One researcher who has had an ongoing relationship with NWGA is Dr Antonie Geyer, formerly a senior lecturer in the Department of Agriculture at Port Elizabeth (PE) Technikon. He led a research project that investigated the establishment of an effective farming system for the Allen Waters communal area in the Eastern Cape. Through this research project, he worked in close co-operation with NWGA production advisor for the region, as well as researchers from the ARC and the University of Pretoria. Dr Geyer has recently been appointed into a research management position at NWGA.

In the next section we give a brief description of Dr Geyer's research project in the Allen Waters community. We consider how NWGA views his research and also reflect on Dr Geyer's interaction with NWGA, the benefits he has derived from this interaction and its impact on the industry, and what he sees as the role and value of NWGA to other researchers in the field.

\section{A researcher's view: Dr AC Geyer, Department of Agriculture, Port Elizabeth Technikon}

In 1999 Dr Geyer got funding from the NRF, through a research programme at Port Elizabeth Technikon, to undertake a research project focusing on the Allen Waters community in the Eastern Cape. NWGA production advisor working in that region first highlighted the need for some kind of intervention in that community. However, as Dr Geyer explains, NWGA does not have the capacity to undertake research itself, and so the research project was initiated by the technikon. 
The project involved a research team that included Dr Geyer, one researcher from the Eastern Cape Department of Agriculture and one from the University of Pretoria, research assistants from the ARC, extension officers from the Eastern Cape Department of Agriculture and NWGA production advisor in the region. The production advisor played a "logistical type of role in the research process apart from his usual job as an NWGA production advisor"(Geyer, interview).

The research project developed in two phases:

The first phase of the research consisted of a typology study, that we could see the composition of the community. [ ] That was the first aim to just understand the diversity of the community. [ ] The second phase followed the first phase where we said now we concentrate on the stock farmers. So those people that weren't stock farmers weren't involved in phase 2. [] The objective [of the second phase] was to determine a management strategy for the stock farmers (Geyer, interview).

Dr Geyer explains that the first phase was important in order to identify how many of the community were in fact involved in stock farming. Once the stock farmers had been identified, the research project moved into the second phase. This phase involved more than just introducing "more improved type of management practices". It also provided training in general farming skills that resulted in increased income to the community:

We physically helped them to apply the farming practice. For instance an animal health program, selection of ewes, selection of rams, culling of animals. Things that weren't done there. And we also gave them access to formal marketing opportunities. For live stock to sell the cold animals and also for their wool production. Instead of the traders coming around and picking up the stock for next to nothing and the farmers stay poor. [ ] We arranged with the brokers to come down and collect the wool and they waited a bit longer for their money but they got lots and lots more money than previously (Geyer, interview).

The research project clearly had a very significant development focus as well. Dr Moore from NWGA acknowledges the value of the dual focus of the project:

It gave us valuable norms on results that can be obtained; perhaps that's the first part. I look at it that the research is a very small part of the project. The project itself is about making a communal farming community effective and Allen Waters the way it stands now is a star project, they produce wool and it fetches prices that is very competitive with commercial farmers. So the project is hugely successful, the value of a research project like that is always two-fold, as I see it. The one is there is a value in the norms, the results, the indicators that you get in that you can actually use it in other ways as well. The second one is that you can't do research there without expertise and knowledge rubbing off on the community, because you usually get some knowledgeable guys in there and it helps, but it forms part of a huge development project (Moore, interview). 
According to Dr Geyer, some of the practices and lessons learnt from the Allen Waters project are now being applied by NWGA, through their production advisors in other communities. This includes genetic improvement projects, training of communal farmers and specifically marketing skills. With the genetic improvement projects, NWGA introduces genetically improved rams into farming communities and takes out "cold rams". The farming communities then take responsibility for caring and managing those rams and reaping the benefits from its progeny.

The results from the research project were widely disseminated, both formally and informally:

When we finished the first phase I read three papers at international conferences. One in South Africa and two in Australia at different occasions. Brian [the other researcher] read a paper in one of the African countries - I think it was Malawi. That was more on the formal side. Then more on the informal, were articles in the Farmers Weekly and I think there was in the Department Of Agriculture in their monthly Agri User or something. And then NWGA published it in their newspaper the Wool Farmer and that was the written part. Then we had what we call information days and open days like a farmers day at Allen Waters itself which was attended by the surrounding community and we also, because Brian worked as a lecturer at the [agricultural] college there he also bought the students from time to time to show them the actual thing (Geyer, interview).

From the above comment, we see that Dr Geyer and his team made many efforts to disseminate the research results. In this regard, they got some support from NWGA, through the organisation of the information days and their monthly publication. In the next section we consider Dr Geyer's views on the role of NWGA in the research process.

\section{Role of NWGA}

Dr Geyer explains that, from the outset of the research project, he sought the involvement of NWGA, who at the time had a production advisor working in the Allen Waters communal area:

I think it is important for research that you realise once you do industry research that the industry must be aware and there must be partnerships in such research. And this is why NWGA for wool was a very important role player in this research. I didn't want to do this research in isolation. It wouldn't have worked (Geyer, interview).

While NWGA did not provide any financial support to the project, they contributed "manpower capacity". NWGA production advisor acted as a "communicator" between the research team and the community because he was already well known in the area. $\mathrm{He}$ played a "logistical role" and facilitated their initial access to and interactions with the community. The production advisor, however, did not get involved in actual data gathering. During the second phase of the project, NWGA made a special contribution:

In the second phase it was possible for NWGA to help us to introduce better quality rams to the project. Again - it wasn't possible for us to do that alone. 
NWGA organised the rams. We had an open day there. We all had the marketing value but NWGA supported us that whole day (Geyer, interview).

In a sense, NWGA were making an investment in a project without knowing what the outcome would be. As Dr Geyer says, "we didn't really know what to expect about the genetic improvement of the project" (Geyer, interview). Even though it might seem like risk taking on the part of NWGA, there were benefits of this project to them from the first phase already:

The moment we could establish these stock farmers they [NWGA] could focus their service on the stock farmers. Now what happened right at the end we could see the progeny of the ram that was introduced and initiated by our project. And that progeny was genetically in a very good condition compared to what they had there. So immediately the advantage to NWGA was that they could focus on the stock farmers and secondly that they had a far better wool product to deliver to the formal market at the end of the day. So the quality of the product improved considerably at the end of the day (Geyer, interview).

The project was a calculated risk that paid off for NWGA, the community and, ultimately, the industry. In addition to the role they played in introducing the new rams, NWGA also assisted in arranging the open days, specifically the days that the ram breeders were invited. Since this research project did not receive any financial support from NWGA or Cape Wools SA, there were no obligations to present the research results at NWGA forums. Nonetheless, through the efforts of the researchers and the close involvement of NWGA production advisor in the project, the research results have been noted and NWGA production advisors in other communities have applied the methodology.

\section{$6 \quad$ Concluding remarks}

NWGA is an organisation that is dedicated to the promotion of sustainable and profitable wool sheep farming. It provides a wide range of support and extension services to its members. NWGA does not actually commission or fund research, but it has a research committee that evaluates the quality and progress of existing research projects and identifies new areas of research, in order to make recommendations for funding to Cape Wools SA. In addition, the networks and relationships that NWGA establishes with other stakeholders places it in a favourable position to influence production research in the industry, as well as policies that will impact on the farming practices and livelihoods of its members. For example, NWGA Chairman is also the Chairman for Research and Development in Agri SA, and NWGA made significant inputs into the National Plan for South African Agriculture.

NWGA makes use of different strategies to disseminate and promote the utilisation of enhanced production technology research that will benefit its members, who consist of commercial, as well as communal, farmers. Research results are published in NWGA's own monthly publication, and research articles are regularly published in other popular media. NWGA actively tries to bridge the gap between researchers and farmers through its network of regional planning structures that include NWGA production advisors, researchers and farmers. NWGA further encourages and facilitates on-site practical 
demonstrations of new research and technologies and organises regular information days for farmers to which researchers are invited to make presentations of their research findings. The on-site demonstrations are used as opportunities to both promote utilisation of research and to evaluate whether effective utilisation is possible.

From a researcher's perspective, NWGA plays an important role in conveying research needs of farmers to researchers. Researchers usually have to tender to Cape Wools SA for research projects that have been recommended by NWGA research committee. NWGA has clear expectations of researchers to produce research that can be practically applied by farmers. It has therefore established many long-term relationships with experienced researchers in wool farming. In the field, the production advisors act as a communication channel between researchers and farmers, and they often provide crucial logistical support to researchers. Besides their interactions with production advisors, researchers are also encouraged to participate in some of the farmer planning committees and of course, to interact with farmers at the information days organised by NWGA.

This case study suggests that NWGA fulfils a significant role as an intermediary agency that: promotes the research needs of the primary users of the research, in this case, wool sheep farmers; uses a range of strategies to disseminate research results; actively promotes and evaluates the utilisation of research; and sets up channels of communication between farmers and researchers. 


\section{List of data sources}

Telephonic interviews

Dr A Moore, General Manager, National Wool Growers' Association (July 2004)

Dr AC Geyer, formerly Port Elizabeth Technikon (July 2004)

Publications and documents

NWGA Annual Report, 2003

NWGA Production Technology Services Business Plan, 2003

Websites

http://www.nwga.co.za/

http://www.capewools.co.za 


\section{MINI-CASE STUDY 2}

\section{SOUTH AFRICAN AVOCADO GROWERS' ASSOCIATION (SAAGA)}

An association committed to act in growers' interests to improve the economic viability of producing, packing and marketing avocados.

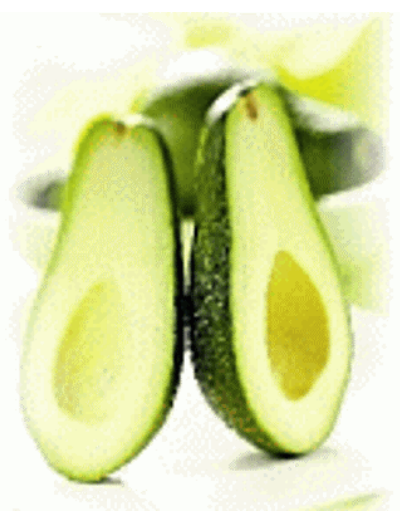

Photograph courtesy of South African Avocado Growers' Association website [http://www.saaga.co.za/]

\section{Acronyms}

SAAGA

ITSC

ARC

ASBV
South African Avocado Growers' Association Institute for Tropical and Sub-Tropical Crops Agricultural Research Council Avocado Sun Blotch Viroid 


\section{$1 \quad$ Introduction}

Avocado production in South Africa is an export-orientated industry, aimed primarily at the European market. The main production areas are in the warm sub-tropical regions of the Northern and Mpumalanga Provinces in the North East of the country. Since 1973, South African avocado exports have shown a linear growth. It is estimated that approximately $55 \%$ of the total avocado crop is exported. As a result, the industry is always under pressure to ensure the quality of the crops they export and maintain high annual crop yields. Consequently, much attention is given to orchard practices such as pruning, tree nutrition, fertilisation and preventing crop diseases (Donkin, 2003).

The South African Avocado Growers' Association (SAAGA) was formed in the late 1960s to promote the interests of avocado farmers in South Africa. It is the mission of SAAGA to act in the grower's interest to improve the economic viability of producing, packing and marketing of avocados. To this end, the association funds research, market development both locally and in the European Union, provides extension services and facilitates coordination between exporters (Donkin, 2003).

In this case study report we describe the activities of SAAGA and reflect on the nature of the organisation and the contribution it makes towards dissemination and utilisation of research within the industry. A researcher's perspective on SAAGA is provided. We consider the relationship that one prominent researcher has established with SAAGA. In particular, we describe his involvement in avocado crop research and reflect on his relationship with SAAGA and its impact on the industry.

\section{$2 \quad$ SAAGA and the avocado industry}

SAAGA is the largest organisation representing growers in the sub-tropical fruit sector. Unlike the deciduous and citrus industries in South Africa, marketing of avocados has never been subject to statutory control. Growers export their fruit through exporting companies - the majority of which operate on a commission basis. Quality standards for export are determined by SAAGA in association with the National Department of Agriculture. Quality inspections are carried out by a parastatal organisation, the Perishable Products Export Control Board (PPECB) on a consignment basis prior to shipping. The PPECB also ensures that standards for refrigerated road transport and refrigerated containers, for sales to local markets, are met (Donkin, 2003).

\section{Management, funding and membership}

The first avocado orchard was established in the 1920s and the number of avocado farmers grew steadily from then onwards. Farmers first discussed the need for a grower's association in the 1960s when there was a growing awareness of the potential for the export of avocados. After forming some ad hoc associations, SAAGA was officially established in 197I. Currently, SAAGA has a voluntary membership of about 450 growers, accounting for $90 \%$ of avocado production in South Africa. The major avocado export companies are also members of the association (Donkin, 2003). 
A General Manager, Mr Derek Donkin, and two Technical Officers, who do field work with farmers, and administrative support staff, manage SAAGA activities. However, the growers steer the organisation:

SAAGA is a voluntary organisation, to represent the interests of growers. It's "grower" run. The board consist of grower members that are representative of the various regions (Donkin, interview).

Growers are organised into five geographical production areas and each area nominates one or two technical representatives to also serve on SAAGA technical and research committees. All SAAGA's funding is derived from a voluntary levy paid by members on exported fruit as well as fruit sold locally. A quarter of its budget is spent on funding research (Donkin, interview).

\section{Relationship with government}

SAAGA interacts with the National Department of Agriculture around two major areas of common interest, namely, export and import regulations, and market access. Mr Donkin describes SAAGA's interaction with government:

On the export side, there are export regulations, which are determined by the Department of Agriculture. And that's normally related to the regulations of the main import market. Once a year we have a meeting with Department of Agriculture, the sub-directorate that has to do with plant health and quality, and we go through the export regulations and see whether they still meet requirements of the industry. Taking into account we have to meet the requirements of the European Union, for import of avocadoes. We also liaise with them on the local market regulations in the same way. And then on a different level we liaise with the government through the market access working group in the Department of Agriculture and that is looking at issues at accessing new markets for us, the United States is one that we are trying to access. And we have meetings, I think it is every two months with the Department of Agriculture (Donkin, interview).

Beyond these interactions, there are no other formal relationships with government.

\section{Activities/services offered}

SAAGA undertakes a range of activities to serve its members. These include activities relating to research and farmer practices, extension services, disseminating information to its members, marketing and promotion of avocadoes and co-ordinating other industry activities.

SAAGA uses its resources to fund and commission research for the benefit of the industry:

In that area [technical area] we determine research priorities through various committees that are represented by the growers. Then the funding that comes from the levies is used to find institutions and researchers that can carry out research to meet the needs, or the research needs. We fund research projects (Donkin, interview). 
Researchers who are funded by SAAGA have to report their research findings to all the members at the annual research symposium organised by SAAGA.

SAAGA interacts directly with farmers through its two "field officers" who are qualified horticulturalists. These field officers provide extension services to farmers that entail the following:

[We have] two horticulturists that are in the field that assist growers with fertiliser recommendations, nursery practices, pack house practices. Everything from nursery production right through to the pack house, they assist there. And that includes food safety and things like EUREPGAP [European Good Agricultural Practice] (Donkin, interview).

Communication with farmers is maintained via regular e-mails as well as a newsletter, AVO Info, which SAAGA produces every six weeks. The newsletter contains some technical information around farming practices, but concentrates more on providing marketing information:

We coordinate export volumes, we gather information on what's being exported and estimates from our various exporters. We also have information sharing from other countries in the world that supply the European market. The European market is our major market. [ ] What we do is, provide good information to allow people to make good decisions. So we provide market information and statistics and some recommendations so that people can make marketing decisions (Donkin, interview).

SAAGA also has a local marketing campaign, which is mainly based on promotions and public relation strategies:

[We have] publications in magazines and that kind of thing. To make public aware of avocadoes and their health benefits. In the United Kingdom, we have a similar program, where we do mainly PR through the media and we do have some activities with people that supply supermarkets as well. And that again is to create awareness of avocadoes and to encourage people to go out and buy them because they are healthy and good fruit to eat (Donkin, interview).

In addition to all the above, SAAGA also co-ordinates industry activities, like liaising with port authorities on behalf of the industry and with government around export and import regulations.

The activities described above are fairly typical of industry associations, in so far as it facilitates access to information for all its members, provides individual support when and where necessary and co-ordinates industry activities. 


\section{SAAGA's involvement in research}

\section{Commissioning research}

SAAGA commissions and funds industry related research. To do this it has put mechanisms in place to ensure that the growers themselves determine research priorities:

The research priorities are determined by the various area representatives. In each area we've got one or two technical representatives. And they sit on the technical and research committee once a year. And those people that represent their areas then go to their study groups normally in their areas and ask for growers what their problems are, what they think needs to be researched. And they bring those needs to the meetings, those are prioritised and also we look at current things that need doing (Donkin, interview).

In addition to the area representatives, SAAGA General Manager and the two field officers also sit on the research committee. Occasionally, outside researchers are also invited to participate in the meetings, but their role is mostly advisory:

Obviously if we feel that there is somebody that has some expertise that can sit on that committee we invite them. So sometimes there are researchers on that committee but when it comes to making decisions as to what the priorities are, it's more within the hands of the growers, because the researchers are obviously vying for business. And so they would very often push their strong points or their area of expertise as a point, which should be researched. So when it comes to priorities we take their advice into account but the determination of the priorities lies with the growers (Donkin, interview).

Once the research priorities have been identified, SAAGA puts out tenders for the submission of project proposals. The tenders are sent to researchers and institutions that already have a record of accomplishment of doing industry related research. SAAGA research committee determines the brief and time frame for the tender and, once proposals are accepted, agrees on the budget for the research project.

Given the strong voice that growers have in determining the research priorities, it is not surprising that most of the research projects deal with solving of immediate problems that avocado farmers have to overcome. However, Mr Donkin points out that SAAGA is also aware of the need for "strategic research" that will keep the industry "viable in the future":

Strategic is something, if we don't do it today it won't make a difference tomorrow. But in the long term, for the viability of the industry it will make a difference. For example, breeding rootstocks that are more tolerant to root rot. Root rot is a problem in the avocado industry. At the moment we've got chemicals to reduce the problem, but we only have one. So there may be resistance developing. So we say, let's have a rootstock that is more tolerant, [ ] Or give us a better yield in quality, which will help us to be more competitive in the long run (Donkin, interview).

These kinds of strategic research projects are also discussed at the technical and research committee meetings and are often included as part of the research priorities for the year. 


\section{Relationship with researchers}

In commissioning their research, SAAGA tends to tap into an existing network of researchers:

The avocado world is quite small, the same with the sub tropical fruit. We generally tend to have a good network and know of people. The main researchers in the sub tropical region are the University of Natal, University of Pretoria, and then Merensky Technological Services, which are a private set up. We use the ARC ITSC [Institute for Tropical and Sub-tropical Crops] obviously in Nelspruit and then there are some private consultants that do certain research, for example entomology or pathology or their area of expertise. And then the University of Stellenbosch we've made use of, but that is more on the post harvest side (Donkin, interview).

SAAGA does not get involved in daily aspects of the research process, but it does support the researchers when necessary:

The researchers are pretty much then left on their own to carry out their project. But knowing that they have to report on what they have done. The rest is maybe a bit of guidance or for example if they need assistance to get fruit or a plot to do their trials we assist them. But they really do it on their own; we don't really manage the process from day to day (Donkin, interview).

Mr Donkin describes SAAGA's relationship with researchers as "very good" in that researchers always feel free to raise problems or ask for advice throughout the year and they are in regular contact with at least one of the field officers. Researchers are expected to make formal and informal presentations, as well as to publish their research:

Often we ask them to do a progress report prior to the technical committee and/or make a presentation at that committee on what they are doing very briefly. And then once a year we have a research symposium, and the whole industry is invited to that. Proper presentation is then made of the research they have done and after that their research is written up in scientific format and is published every year in our Avocado Grower Association Yearbook. The research is then published (Donkin, interview).

While researchers are encouraged to publish the research results in scientific journals, they have to seek SAAGA's permission before doing so:

There is a clause to say before they publish they must just check with us whether they can do it. Because say for example the research is of a sensitive nature, and it may jeopardise for example our access to a market because somebody could close it off, or there may be some intellectual property. Then we want to hold on to that. For example if we are looking at developing a new process product, and we are funding that research and there is intellectual property written there, and then we like to hold on to that. So it has to be checked with us before it is published (Donkin, interview). 
It is evident then that SAAGA takes its research portfolio very seriously. The growers themselves determine its research priorities, and it funds and commissions industry related research to researchers with a good record of accomplishment. Researchers are held accountable for the progress of the research and intellectual property that arises from the research is held by SAAGA.

\section{$4 \quad$ Promoting research utilisation}

Comments by Mr Donkin suggest that SAAGA is very sensitive to the difficulties that farmers may have in interpreting research results and thus utilising them. As a result, SAAGA embarks on specific strategies that facilitate and promote the utilisation of the research. One of its most powerful strategies is using the field officers as conduits for the transfer of research knowledge from the researchers to the growers:

We've got extension officers who are very up to date with research - they are technical people. They take those results and convert them to easy terms of language if we can. And then help farmers to apply that research. Making recommendations. Say for example there's been a trial that shows that you need to hypothetically water your avocadoes three times a day in summer time when you have $x, y$ and $z$ conditions. They'll go then as a study group on individual farm visits, when making recommendations they'll include that kind of thing. So that farmers are kept up to date with developments that have been made in research so that they apply those on the farm. Extension is basically conduits to the growers from the academic side to the growing side (Donkin, interview).

SAAGA ensures that all its members have access to the research results through the publication of the annual SAAGA Yearbook. The Yearbook contains full scientific papers of all the research projects funded by SAAGA. Given the volume of reading that the Yearbook requires, SAAGA reports on some of these research results in its more frequent newsletter, where it tries specifically to draw out the practical implications of the research. SAAGA field officers mainly write these newsletter reports.

There is also an expectation that researchers who present their research results at the annual research symposium will do so in a way that brings out the practical applications of the research:

When you present you must understand that your audience is a bunch of growers and although you have to be able to prove statistically that your trial was done correctly and it is right, there still has to be a practical spin-off. So what are the practical implications? There is a lot of practical stuff involved in the research that is done. And so the farmers then can make use of it. For example they have done research on what affects the quality of the fruit, what should the fruit mineral content be when the fruit is golf ball size up until a couple of a weeks before harvest. What will the various levels of nutrients be? That's been converted into practical things where people can send their fruit in for analysis and change their management according to what the results are. Most of it is very practically orientated (Donkin, interview). 
In this way, SAAGA encourages the researchers they work with to contribute to the promotion of utilisation of the research by avocado farmers.

One researcher who has had an ongoing relationship with SAAGA is Dr Barry Manikom, Manager of the Institute for Tropical and Sub-Tropical Crops (ITSC) - Disease Management, at the Agricultural Research Council (ARC). Dr Manikom developed a reliable indexing method to test for Avocado Sun Blotch Viroid (ASBV), which all avocado farmers are now using. He received funding from SAAGA for this research and presented the results at their research symposiums.

In the next section, we give a brief description of Dr Manikom's research project into ASBV. We consider how SAAGA views his research and also reflect on Dr Manikom's interaction with SAAGA and its impact on the industry, and what he sees as the role and value of SAAGA to other researchers in the field.

\section{$5 \quad$ A researcher's view: Dr B Manikom, Institute for Tropical and}

\section{Sub-Tropical Crops, Agricultural Research Council}

The Disease Management section at the ITSC had been investigating the incidence of ASBV since it first appeared in crops in South Africa. The researchers were aware of a test that was being used overseas, but there was no "consistent reliable service locally" to detect the presence of ASBV (Manikom, interview). In 1998, Dr Manikom submitted a proposal to SAAGA for a research project that would develop a "reliable indexing method for ASBV". The proposal was accepted and he received funding from them for two years.

Even though Dr Manikom's research project was initiated by himself and was not necessarily identified by SAAGA as a research priority at that time, the value and strategic nature of the research is appreciated by SAAGA:

The Nursery Association identified that sun blotch viroid was a problem even with the tests that they had. [ ] Sun blotch viroid is quite a problem in the avocado industry because you can graft butt wood onto it - a nursery tree that looks healthy. The tree looks healthy for the first year or two and then year 3 or 4 you see that the tree is not bearing. So you basically waste three or four years and the costs you could have recouped from the harvest. So there is a problem there. Now this testing is for testing of butt wood that is used in a nursery program and because it is more sensitive it could pick up sun blotch more easily, I think whereas the older tests, weren't as accurate and as sensitive. But it has meant a lot to our industry in being able to produce clean or relatively clean nursery trees, which is the foundation of the industry. So it [the research], is very important for the industry (Donkin, interview).

Mr Donkin admits that receiving proposals from researchers, as happened with Dr Manikom, was more common six or seven years ago, than it is now. The reason, he says, is that researchers then were not as dependent on industry funding as they are now, and hence could pursue their own research interests. 
Six or seven years ago, SAAGA was less conscious of intellectual property rights and commercial spin-offs of research:

At that stage people weren't thinking about owning intellectual property or that kind of thing. At that stage there would have been no contract or agreement to say that the commercial application has some benefit. The way industry looked at it was you could have a commercial [benefit] but it benefits us too so we are happy. Whereas we say now, if people are going to make money out if it [the research], we'd have to look at the proportions as to how it was funded by various organisation and say we want a cut in proportion as to what we funded. That's how it would work nowadays. At that time I know there was nothing. It was a verbal agreement, they do the project and that was it (Donkin, interview).

This meant that once Dr Manikom had developed a reliable test to detect ASBV, he was able to charge growers for every sample they brought in for testing. The intellectual property rights of the test reside with Dr Manikom and the ITSC. As such, "sensitive detection of ASBV" is a service the ITSC continues to offer to avocado growers at a cost. This service is supported by SAAGA and they now, through a nursery accreditation scheme, insist that all avocado trees be tested by the ITSC:

SAAGA will endorse a number of nurseries, there are 6, 7 on the list at the moment, and they have 2 field officers, SAAGA does, and part of their duties is to visit the nurseries, take samples, they'll check for documentation, [to see if they have been tested for ASBV], they'll look at the soil mix, they'll look at the water supply, they will look at whether it is fenced off and covered in, and whether people have to go to through water baths etc. They have a ranking system, a points system then they pass it and then they are an affiliated SAAGA nursery (Manikom, interview).

In practice, the growers or nurserymen send samples for testing directly to the ITSC at their own costs and the ITSC simply administers the test:

Normally it is the nurserymen, they will send their mother material in. [ ] I give them the test results. [ ] I just tell them whether they have the disease or not, and they have to sort out the problem (Manikom, interview).

The ITSC thus does not do any follow up work with farmers whose crops have the disease. This is left to the farmers and the advice and support they get from SAAGA field officers.

\section{Role of SAAGA}

As an agricultural researcher, Dr Manikom has interacted for many years with farmer organisations like SAAGA. He describes how the role of these organisations has changed and their impact on researchers:

We go back prior to '94. Actually, before the ARC, before 91, we were totally funded by the government and we used to just go out and work on what we felt like. We see a problem and we will go out and attack it. At the same time, every farmers' organisation had a group of leading farmers who were called an advisory committee, and once a year they'd come 
and have a meeting and say, well, we've got a major problem with this, and a big problem with that, and we used to listen and see if we could sort out those problems. But they were non-statutory bodies, they were just a bunch of leading growers and they called themselves an advisory body. After the ARC came into being, our budget from central government got reduced, so we said you guys [farmer organisations], have to chip in and on the other side you guys can have a committee or something that can direct the research. So, for very little money, they have far too much influence (Manikom, interview).

The comment above supports Mr Donkin's comment quoted earlier, that researchers today are more dependent on funding from industry, and hence research agendas are driven more by industry needs than researchers' own interests. Organisations like SAAGA play a significant role in this regard. This is not to say that strategic research, with more long-term benefits, are not funded occasionally, as was pointed out by Mr Donkin in an earlier quote.

As part of his funding obligation, Dr Manikom presented his research results at two of SAAGA research symposiums and published papers in SAAGA Yearbook. Dr Manikom notes with some concern, that symposium participants have changed over the years:

There's been change over the last few years, it used to be, you get 250 growers or so. In the last year or two l've noticed, now they're getting maybe 50 growers and the rest are consultants and chemical companies, people that sell the chemicals, which is not good, but anyway (Manikom, interview).

Despite this seeming change in the audience, Dr Manikom claims that the presentations at the research symposiums have remained standard scientific papers that describe methodologies, results and conclusions. He believes that; even though they are not researchers themselves, the growers and members do absorb the research.

\section{$6 \quad$ Concluding remarks}

SAAGA is an organisation driven by growers' needs to improve the economic viability of producing, promoting and marketing avocadoes. Its funding is derived from a voluntary levy paid on exported fruit as well as fruit sold locally. SAAGA commissions and funds research with clear objectives that will benefit its members directly and sustain the industry in the long term. The growers themselves through their representatives on SAAGA technical and research committees determine research priorities. The research committee puts out tenders for research projects and determines the brief and time frame for the tender.

SAAGA has established many long-term relationships with a small network of researchers in the field. Although it does not get involved in daily aspects of the research process, when necessary, it does assist researchers to get access to fruit or farms for conducting research trials. SAAGA organises an annual research symposium for all industry members where researchers are invited to do formal presentations of their research. The research papers are published in full in an annual SAAGA Yearbook. In addition, SAAGA field officers report summaries and recommendations of the research in a newsletter that is 
distributed to growers every six weeks. SAAGA actively promotes the utilisation of research through its field officers, who interact directly with growers on-site and serve as conduits for the transfer of research knowledge from the researchers to the growers. Site visits are also used as opportunities to evaluate how effectively research ideas and technologies have been implemented.

From a researcher's perspective, SAAGA is a much-needed source of financial support for industry related research. Researchers funded by SAAGA are expected to make formal and informal presentations to SAAGA research committee as well as at the annual research symposium. SAAGA encourages researchers to present their research in ways that bring out the practical implications of the research. The annual symposium provides researchers with an opportunity to disseminate their research and to interact directly with growers.

This case study suggests that SAAGA fulfils a significant role as an intermediary agency that: promotes the research needs of avocado growers; funds research that benefit its members directly and sustain the industry in the long term; encourages researchers to draw out the practical implications of their research for growers; disseminates research in a variety of ways; actively promotes and evaluates the utilisation of research; and facilitates interaction between researchers and growers. 


\section{List of data sources}

Telephonic interviews

Mr D Donkin, General Manager, South African Avocado Growers' Association (July 2004)

Dr B Manikom, Institute for Tropical and Sub-tropical Crops - Disease Management, Agricultural Research Council (July 2004)

\section{Document}

Donkin, D (2003) An Overview of the South African Avocado Industry

\section{Website}

http://www.saaga.co.za 
MINI-CASE STUDY 3

NATIONAL ASSOCIATION OF AUTOMOTIVE COMPONENT AND ALLIED

MANUFACTURERS (NAACAM)

A motor industry association concerned with policies, research and development related to automotive component manufacturing.

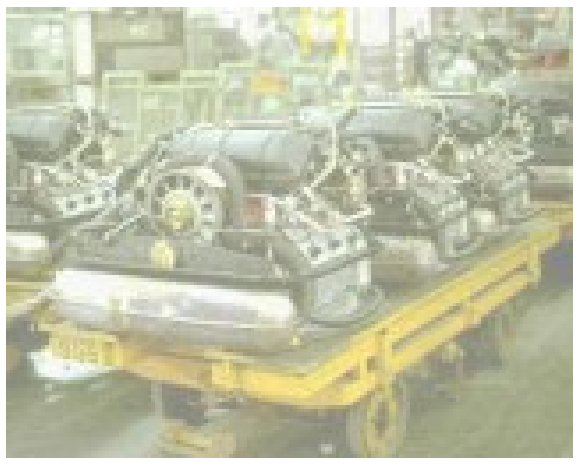

Photograph courtesy of National Association of Automotive Component and Allied Manufacturers website [http://www.naacam.co.za/]

\section{Acronyms}

NAACAM National Association of Automotive Component and Allied Manufacturers MIDP Motor Industry Development Programme

MIDC Motor Industry Development Council

NAAMSA National Association of Automobile Manufacturers in South Africa

UN University of Natal

DTI Department of Trade and Industry

NUMSA National Union of Metal Workers of South Africa 


\section{$1 \quad$ Introduction}

The motor industry tends to be a highly regulated industry in most countries. In South Africa, the rules governing the motor industry are set out in a piece of Government legislation that resides at the back of the Customs Act and is called The Motor Industry Development Programme (MIDP). It was promulgated in September 1995 with the objective of making the local motor industry internationally competitive over a reasonable time. The MIDP is administered by the Department of Trade and Industry (DTI), with the help of customs officials (Williams, NAACAM website). The motor industry associations and unions sit together on the Motor Industry Development Council (MIDC) to strategise and discuss implementation of the MIDP.

The National Association of Automotive Component and Allied Manufacturers (NAACAM) is an association that represents the interests of motor component manufacturers in South Africa. It participates in the MIDC and is dedicated to keeping its membership abreast with new developments, research, legislations, and initiatives affecting the industry.

In this case study report we describe the activities of NAACAM and reflect on the nature of the organisation and the contribution it makes towards dissemination and utilisation of research within the industry. We also consider the relationship that one prominent researcher has established with NAACAM. In particular, we describe his involvement in motor industry research and reflect on the benefits his relationship with NAACAM has had on his ongoing research.

\section{$2 \quad$ NAACAM and the motor industry}

NAACAM is one of two motor industry associations. NAACAM represents those companies involved in manufacturing vehicle components. The other association is the National Association of Automobile Manufacturers in South Africa (NAAMSA). The NAAMSA represents those companies that actually make the vehicles, that is, put the vehicle components together. Along with the National Union of Metal Workers (NUMSA), these two associations represent all the companies working in this industry.

\section{Management and funding}

NAACAM was established in 1980 and has only three full time members - an Executive Director, Mr Clive Williams, an executive assistant and a secretary - that make up NAACAM office. NAACAM is funded solely through membership fees, which amount to R5 000 per member. Funds are spent on rent, salaries and travel expenses. The NAACAM office acts as a central co-ordinating body between members. The executive director nominates members to work together in project teams. The participating members carry the costs of running these projects. Since the executive director ensures that all members 'get a turn' at some stage to run projects, the financial costs are shared amongst all members. NAACAM itself therefore does not have a dedicated research budget, and project teams, consisting of members, undertake research on behalf of NAACAM. 


\section{Membership}

All companies in the country that make parts for vehicles are eligible for NAACAM membership. According to Mr Williams, the bulk of the industry employees are already NAACAM members, which amounts to "just under I 50 companies, representing over 200 factories" (Williams, interview). NAACAM executive is elected out of this membership. NAACAM executive consists of a president, two vice-presidents, treasurer and six elected members. All members pay an annual membership fee of R5 000 as previously mentioned. A list of all members is published in an annual directory that NAACAM office produces. These directories are distributed to members as well as, worldwide to the South African embassies and Trade offices (Williams, interview).

\section{Relationship with government}

NAACAM interacts with government directly through the Automotive Directorate within the Department of Trade and Industry (DTI). According to Mr Williams, the NAACAM Executive Director, he has virtually daily contact with that directorate. Communication with government revolves around manufacturing and trade legislations and policies governing the local industry, as well as participation in overseas missions and international trade fairs and interacting with delegations from foreign component manufacturers. In addition to the daily contact, NAACAM also interacts with government through the MIDC, which is co-ordinated by the DTI.

\section{Activities/services offered}

One of the main services offered by NAACAM is to distribute information and put members in touch with each other or other role players in the industry:

Typically, two years ago, three years ago people would say the bulk of the benefit is the information we provide. Whereas now I am told by members that the primary benefit is the networking. If they want something instead of going and trying to find it themselves, we say: phone us because we know where they can get it straight away or else somebody will get it for them. And this is the power of clustering, power of an association. If it works for one it invariably works for a bunch of other people. So, don't reinvent the wheel (Williams, interview).

NAACAM office sends out three e-mails per day to all members that contain information varying from "someone looking for parts, someone advertising services, or about a show in Korea, [as well as] research results" (Williams, interview). They also assist with conferences that they endorse by "providing speakers and putting a note out to everybody saying what is happening, if you want to go, this one is okay" (Williams, interview).

In addition to this co-ordinating function, NAACAM office also facilitates meetings of members within different provinces. Mr Williams explains what happens at these meetings: We have four meetings a year for the Gauteng region, five in Durban, four in the Eastern Cape, four in the Western Cape. We just get together for a few hours. We go through a guy's factory and spend two or three hours talking about what's happened over the past three months and what's coming up in the future (Williams, interview). 
Mr Williams himself also spends time doing site visits. These visits are meant to provide on-site support to companies:

The last third of my time I try to spend on the road, physically meeting people face to face. There is a huge need for that; simple things like what are the government incentives to helping people with what the bigger picture is in the world. If their strategy is different to the one that we can now recommend as we developed a strategy for the people, either they better change it or understand why they are going differently to everybody else (Williams, interview).

More formally, NAACAM executive meets every second month and they hold an Annual General Meeting.

The activities described above are typical of industry associations, as far as they facilitate access to information for all its members, and provide individual support when and where necessary.

\section{$3 \quad$ NAACAM's involvement in research}

NAACAM does not fund research, but it does get involved in commissioning research through its participation in the MIDC. Mr Williams explains how this happens:

We have a forum called the Motor Industry Development Council, which meets every six to eight weeks where the major players are NAACAM, NAAMSA, the RMI, South African Tyre Manufacture Conference (SATMC), and DTI and NUMSA sit together. That group of people work cooperatively to coordinate what happens in the industry. So if government or anybody wants us to find out more about it that committee will collectively take responsibility for requesting research or actions and individuals will be charged with going and making sure it happens. Then we get the results that get fed back in that forum, so everybody gets that information (Williams, interview).

Four executive members from NAACAM represent the component manufacturers in this forum. They are then responsible for identifying people from amongst their membership to participate on research project teams that might include members from the other associations on the forum. These project teams are given a comprehensive "terms of reference", which includes writing up a report. Most of the research projects that come out of this forum are funded through government grants from the DTI. One such project for example, involved doing a census on the number of employees in the industry. NAACAM, NAAMSA, NUMSA and DTI were involved in this project, which had a government grant of R730 000 (Williams, interview).

Research results are obviously fed back to the MIDC, and NAACAM takes responsibility for disseminating the results directly to their members. They do this in different ways:

If it is a short report one could just send it to everyone [via e-mail]. If it's bulky, but people need to see the whole thing we will put it on the website. If the people just need to know the gist of it then I can summarise it. But 
really it is so case dependent. We do all three and we do it and we can do it (Williams, interview).

While project teams made up from the various associations conduct most of the industryrelated research, occasionally outside researchers are commissioned by government to do research. In such cases, NAACAM and the other associations who participate in the MIDC, review and comment on the research and give feedback directly to the researchers in this forum. If appropriate, NAACAM also facilitates access to its members for the researchers. Mr Williams describes how NAACAM responds to, and interacts with research done by outside researchers:

We set them up with whom they should go and see. If they are not getting a good sample we say that is not good enough - you are not asking the right questions. [ ] We have an input into the study definition, we have a consultant looking at studies done and we have a comment on the results and recommendations. So it's not just us, the other members in that forum has that same right of comment. That's why I think it worked so well in the industry (Williams, interview).

The above comment suggests that NAACAM engages constructively and, when necessary, intensely, with industry related research. It is interesting therefore, that in describing how he spends his time as executive director of NAACAM Mr Williams does not mention research. He reports that a third of his time is spent "interfacing with government", another third is spent in his office, disseminating information and setting up networks between people, and the last third of his time is spent "on the road, physically meeting people face-to-face". It seems then that research is only really focussed on in the context of the MIDC. It is within this forum that NAACAM gets together with other industry players to put together research briefs, to nominate research team members and, to review and comment on research results.

One researcher who has undertaken many research projects related to the motor industry is Dr Raymond Barnes, formerly from the School of Development Studies at the University of Natal. He has become a leading researcher in the field and now runs his own company that does regular consultancy work for government and companies in the motor industry. Through his work he has had to interact regularly with NAACAM and other associations in the motor industry.

In the next section we provide a brief description of one of Dr Barnes' research projects. We consider how NAACAM views his research and also reflect on Dr Barnes' interaction with NAACAM and its impact on the industry, the benefits he has derived from this interaction, and what he sees as the role and value of NAACAM to other researchers in the field.

\section{A researcher's view: Dr R Barnes, School of Development Studies, University of Natal}

In 1995 Dr Barnes was appointed as the automotive researcher within the Industrial Restructuring Project run by the School of Development Studies at the University of Natal. This broad project, funded initially by the IDRC of Canada and later by the Department of 
Trade and Industry", focused on "trying to understand what the competitive challenges were for firms, what they needed to do in order to upgrade their competitive capabilities, their levels that would ensure their survival and future success" (Barnes, interview).

Within this broad project, researchers were given specific industries to focus on, which included automotive, textile, clothing and furniture industries.

Dr Barnes describes some of the broad aims and objectives of the project as follows:

The broad aims were to generate detailed sectoral knowledge on the respective industries that we were researching. And the way to build up sectoral knowledge is to codify it in the forms of reports and presentations and the other is to ensure that the researchers become recognised over that period of time as sort of important intellectuals in relation to those industries. So, they ${ }^{8}$ sent us overseas, they put a lot of time and energy into ensuring that we were given a global orientation. [ ] We had a very close link with the University of Sussex, the Institute of Development Studies; we spent a lot of time studying there. So what they really tried to do was to create an intellectual think tank for the industry at the university (Barnes, interview).

It seems then that the Industrial Restructuring Project was not only about gathering sectoral information, but also about developing the expertise of the researchers. Part of the reason for this is that the project also included an "action research" component, which involved researchers running workshops and "interface sessions" with industry members. Dr Barnes describes the nature of the research that was undertaken:

It included basic research. We obviously had to understand the sectors, basic scoping exercises, trying to profile the industry, we had to administer a couple of surveys at a regional level. In terms of how we structured the research project, which was that it had to be an action orientated research project. For people to involve themselves in action research, they need to be led. [ ] So it was very important for us to upscale ourselves as researchers in relation to strategic challenges confronting industry. So we started involving ourselves quite early in strategy and trying to understand where industry is going and why it is going in that direction. What the options were and then applying it - we spent a lot of time inside of the factories, spent a lot of time feeding back to management teams. [ ] We went to every single firm and presented to their management team. So we would give up to 60,80 presentations per researcher per year (Barnes, interview).

Within two years of the start of the project, demands from industry for Dr Barnes and the research team to undertake strategic research, not only at the provincial level, but also at the individual firm level, led to two spin-off initiatives. The first was the emergence of automotive benchmarking clubs and the second was the establishment of a

7 The project started as a KwaZulu-Natal based project funded by the IDRC for three years. After that, funding for three more years was obtained from the DTI and the project was extended to a national project. (Barnes, interview)

${ }^{8}$ The Project Leader was Prof Mike Myers at the University of Natal. 
private consulting company run by Dr Barnes and a group of researchers and engineers?. Dr Barnes explains how this happened and what the role of the clubs were:

What basically happened on the benchmarking club side is we sort of identified global issues that impacted on industry and we identified what needed to be done. Firms needed to improve their conversion processes, upgrade their production facilities and move towards lean production processes etc. The government then launched something called the Sector Partnership fund. We identified it as a possible funding conduit through which we could establish a continuous improvement network for the automotive component industry in the province. On the basis of that we invited all the firms to a big workshop, they all attended and they voted that they wanted a benchmarking structure created. And when the benchmarking structure was created with $65 \%$ funding from the sector Partnership fund, that was our cue to set up a separate company. The service of the benchmarking club was to benchmark each firm individually against international competitors (Barnes, interview).

Dr Barnes' PhD related to the development of the methodology of the first benchmarking club. An outcome of the first benchmarking club was the establishment of the "Durban Automotive Cluster". Dr Barnes explains what this is:

The benchmarking club evolved in this very strong network of firms working with one another in an intimate way. And when that happened we basically evolved the benchmarking club into a public private sector partnership between the local government and ourselves. They fund $50 \%$ and industry funds 50\% - [the Durban automotive cluster] is another legal body with a board of directors etc. We [the private company] are the service provider to that structure (Barnes, interview).

We see from the comments above that strategic research in the industry happened concurrently through the private consulting company as well as the School of Development Studies. During this period, Dr Barnes acknowledges, there was always a feeling of walking a tightrope between doing academic research on the one hand for the School of Development Studies, and applied research for industry through the private company. Eventually, the project ended and the private company took over the role of the university project, providing better resources (Barnes, interview). Dr Barnes chose to continue doing the applied research with the consultancy. In fact, Dr Barnes admits "in essence what I am doing now is not that different from what I was doing at the university, except I no longer do it for the university but for myself' 10.

9 Dr Barnes is currently one of the Director's of this company, established in 1997.

10 According to Dr Barnes, the benchmarking clubs have all been merged into one structure called the South African Automotive Benchmarking Club. It used to be three structures, now it is one legal entity, government does not fund it anymore, industry funds it. There are 69 firms involved - component manufacturers, and it is one of the national programmes, we've got offices here in Durban, but we also have offices in Port Elizabeth and we, [the private company], run the benchmarking club structure and we run the cluster structure. (Barnes, interview). 


\section{Benefits to industry}

Close linkages between the researchers and industry were encouraged as part of the original vision of the research project. As such, Dr Barnes describes some of the efforts made to communicate and disseminate their research and what the benefits of these were to industry members:

Every research piece that we produced was fed back to the industry. We wrote up little newsletters, we ran workshops; we went to each of the individual firms. I made a point of going to them every three or four months, but firms, small firms. Presenting to them, telling them what we are doing and what the key issues are and what I learned from my recent trip to the UK or Brazil or wherever I went. So we really tried to build up an intimate relationship with industry. Because of that personal dynamic they stopped seeing the research as sort of abstract academic thinking and started seeing how it could be grounded in their own operations. And because we were working so closely with them and spending so much time on their factory floors and inside of their firms I think they started viewing us in a more serious light as well. [ ] So we spent a lot of time on the shop floor with the firms as well. And I think that built up credibility. So the benefit to them was they started to get some practical real information, whilst also getting longterm strategic insights. We never lost sight of that (Barnes, interview).

The broader impact of Dr Barnes' research on the motor industry is summed up by Mr Williams from NAACAM:

What happened was that Barnes and [Prof] Black [project], was the government saying to two independent consultants you go and tell us what happens in the industry, what are the facts. They then go and interview a whole lot of our members and come back with a picture and then they paint a picture. They then say to government based upon that picture we have the following recommendations and then government would enact laws or whatever (Williams, interview).

We see then that Dr Barnes' research appeared to be significant at both the level of the individual firm and at an industry wide policy level.

\section{Role of NAACAM}

Dr Barnes describes his relationship with NAACAM as a "very good one", that was established at the outset of the project and that was based on a clear contract of accountability and performance:

Remember I said at the beginning I had to go and meet with all the major firms, I met with the head of the association and region. We met with NAACAM upfront. We had a clear business plan; our research programme for two years was clearly articulated. We went to them and we said to them - we are going to deliver on this mandate. We are going to deliver on this business plan; we need your help to do so. But we will be held accountable in relation to what we want to deliver in two years. So, Clive Williams got a copy, his board, all of the representatives of industry got copies. Every firm I visited got a copy. So we stuck to the letter of the law. We said we would do 
things; we did it exactly as we said we would to the time lines specified and that brought us national credibility quickly (Barnes, interview).

The research process as described by Dr Barnes clearly involved close interactions with the motor industry, and in this regard, he acknowledges the valuable role that NAACAM played in facilitating these interactions:

[NAACAM's] involvement was a gate keeping one. They are gatekeepers with regards to industry. So if they said "no" to anything they could have damaged the research. But they opened gates for us. [ ] Originally we only focused on KwaZulu Natal, then we were focused on the Eastern Cape, then we went to Joburg. Whenever we were going to launch into a new area with new research I would approach Clive Williams (Executive Director of NAACAM), and say to him, Clive this is what we are doing. He will say l've heard about the great things you are doing in Port Elizabeth, I will open up the doors for you in Johannesburg and Pretoria and wherever you want to go. He will invite us to give a presentation at the next meeting of the association in the region. We would go along, present and he'd give us half an hour to answer questions from the floor and then he'd publicly endorse us. And state these guys have done a good job in KwaZulu Natal, I've seen what they done in $K Z N$, l've seen what they've done in $P E-I$ would recommend that you participate in the research (Barnes, interview).

Not only did NAACAM endorse and support Barnes' research, it also made every effort to invite him to make presentations of the research at association meetings in various regions. In addition, according to Mr Williams, NAACAM's critical engagement with Barnes' research has led to further research being undertaken in a similar area in which NAACAM and other industry members will be involved:

It's an area that hasn't been looked at for almost nine years. They turned up some figures, made some assumptions. And we said we clearly need to do a lot more work in this area. The arena that they were given in this last study wasn't broad enough, we came in and [said] you've made a whole lot of recommendations based on thin research, it is not good enough. We believe it should be a proper study and that's what happened. In fact we will within the next two months embark on a much broader study in that particular area - the medium and heavy commercial vehicles (Williams, interview).

The description of the nature of the research and the research process given by Dr Barnes indicates that primarily the researchers drove the research agenda, but there was also a strong drive to get feedback and participation from industry. With respect to the latter, they received the full support of NAACAM who not only assisted them with access to industry members, but also with forums for disseminating the research.

\section{$5 \quad$ Concluding remarks}

NAACAM represents the interests of motor component manufacturers in South Africa and is dedicated to keeping its membership abreast with new developments, research, legislations, and initiatives affecting the industry. It is funded solely through membership fees. NAACAM office acts as a central co-ordinating body between its 
members by facilitating channels of communication and a constant flow of information dissemination. It keeps in touch with members' needs through on-site visits and use these visits as opportunities to promote and evaluate the utilisation of policy and research recommendations.

NAACAM does not fund research, nor undertake big research projects itself, but it does get involved in reviewing and commissioning industry relevant research through its participation in the Motor Industry Development Council. Within this Council NAACAM gets together with other industry players to put together research briefs, to nominate research team members and to review and comment on research results.

From a researcher's perspective, NAACAM is an important conduit through which to gain access to, and credibility from, industry members. If NAACAM endorses the research, it encourages its members to either participate in the research if appropriate, or to use and apply the research recommendations. NAACAM also facilitates interactions between its members and researchers, by regularly inviting researchers to present at regional meetings of the association. These meetings are valuable forums for researchers to promote or disseminate their research directly to potential users of their research.

This case study suggests that NAACAM fulfils a significant role as an intermediary agency that: influences what research is undertaken for the benefit of the industry; evaluates and promotes utilisation of policy and research recommendations; endorses and promotes research that will benefit its members; and facilitates access and interactions between industry members and researchers. 


\section{List of data sources}

Telephonic interviews

Mr C Williams, Executive Director, NAACAM (July 2004)

Dr R Barnes, formerly School of Development Studies, University of Natal (July 2004)

Website

http://www.naacam.co.za/ 
MINI-CASE STUDY 4

COTTON SA

A representative body of all role players in the cotton industry concerned with stimulating production and usage of cotton as well as enhancing the marketability of cotton through research.
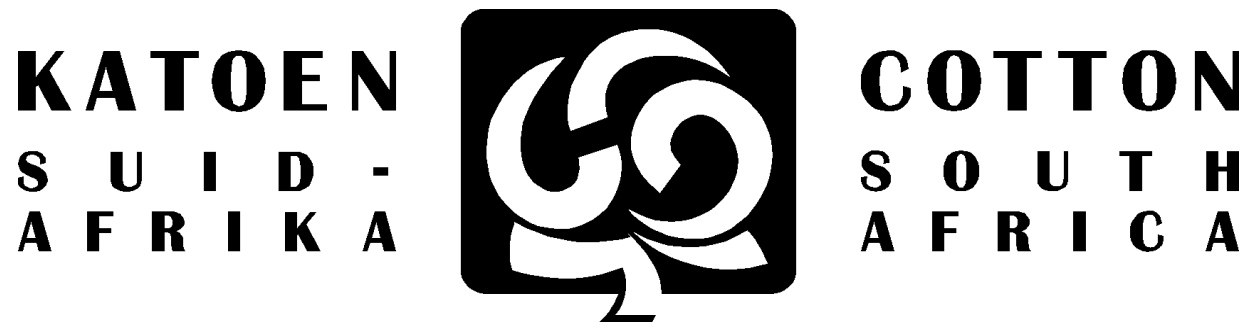

Logo courtesy of Cotton SA

\section{Acronyms}

IIC

Institute for Industrial Crops

ARC

Agricultural Research Council 
1 Introduction

Approximately 200 denim jeans or $650 \mathrm{~T}$-shirts can be produced from one $200 \mathrm{~kg}$ bale of cotton lint. South Africa's 1999/2000-production year crop of 224630 cotton lint bales represents 45 million pairs of denim jeans or 150 million T-shirts (Cotton SA website).

The first cottonseed was planted in 1690 in the Western Cape Province. Cotton, however, prefers a warm climate and requires a substantial amount of moisture for the seed to germinate. Hence, cotton cultivation from 1900 onwards flourished in the Northern and Eastern parts of South Africa. In the early stages of its cultivation, cotton played an important role in the manufacture of explosives. 'African Explosives' established the first ginnery in 1924 (Cotton SA website). Cotton was officially declared an agricultural crop only in 1939.

The cotton industry involves many different role players, from growers to ginners, spinners, weavers and textile manufacturers, all of who have their own specific interest group associations. Cotton SA was established in 1996 as an article-2I company, to bring all these associations under one body that represents all role players in the industry. The role of Cotton SA, amongst other things, is to act as an industry forum and advisory body to various government departments, and to stimulate the production and usage of cotton and the enhancement of the marketability of cotton through research, quality standards and norms as well as training (Cotton SA website).

In this case study report we describe the activities of Cotton SA and reflect on the nature of the organisation and the contribution it makes towards dissemination and utilisation of research within the industry. We consider the relationship that one prominent researcher has established with Cotton SA. In particular, we describe her involvement in research in the cotton industry and reflect on the benefits and difficulties her relationship with Cotton SA has had on the ongoing production and utilisation of her research.

\section{Cotton SA and the cotton industry}

As a representative body of the cotton industry, the Board of Cotton SA consists of representatives from the cotton producers' association, the cotton ginners' association, the cotton spinners and weavers association, the textile manufacturers' association and the cotton textile workers' union. Cotton SA is thus an umbrella body for all these associations. The member associations do not have to pay membership fees because Cotton SA is funded through a statutory industry levy on cotton crops.

Dr Sarel Broderyk" from Cotton SA explains how the levy works:

When cotton is grown, you ultimately harvest seed cotton. It's the fibre and the seed together. The ginner separates the seeds from the fibre and the fibre is the valuable component. It is going between $R 8$ and RIO per kilogram and on that the levy is taken. It is roughly $17 \mathrm{c} / \mathrm{kg}$ of fibre that comes to Cotton SA (Broderyk, interview)

"Dr Broderyk is a retired researcher who has been part of the Cotton SA family for "more or less a lifetime". 
Government support for the establishment and funding of Cotton SA is seen as part of a broad industry plan:

This levy is government instigated and supported. Cotton SA is part of a national cotton strategy which the Department [of Agriculture] has drawn together to get a number of role players to work towards the betterment of the [cotton] crop like grading, marketing and all that (Broderyk, interview).

One important function that Cotton SA fulfils for the industry is keeping its constituency informed, especially with respect to regulatory aspects relating to pricing and marketing developments and picking requirements of the crop. Another equally important function that Cotton SA fulfils for the industry is funding research that "has direct potential for benefiting cotton growers" (Broderyk, interview).

\section{Management and funding}

\section{A Chief Executive Officer, who is supported by a Quality Control Manager, an}

Administrative Manager and a Promotions Manager, manages Cotton SA. Together they manage and co-ordinate the activities of Cotton SA through a series of sub-committees, which consists of representatives from the various role players in the industry. One such sub-committee, for example, is the research sub-committee that is responsible for approving funding and commissioning research projects.

As mentioned above, funding is derived solely from an industry levy on cotton fibre. A percentage of the levy is used for research - this is usually approximately about $2,8 \mathrm{c} / \mathrm{kg}$ (Broderyk, interview). Being dependent on an industry levy means that financial resources can vary greatly which affects long-term planning:

I might just mention to you that the crop has dwindled to a very, very low level. And the research money that is available - we will be particularly lucky if there is about R300 000 this year. In the past it has been over a RI million a year. [ ] And that is surely a great difficulty because planning ahead becomes very difficult if you can't count on funding (Broderyk, interview).

The fluctuations in available funds have affected particularly the range and scope of research projects that have been funded by Cotton SA.

\section{Relationship with government}

Cotton SA interacts regularly with the National Department of Agriculture around regulations and policies that affect the cotton industry. In this capacity, it acts as a cotton industry advisory body to government. For example, Cotton SA has instigated a revision of the law that stipulates that cotton must be cut and destroyed once a year by about August and the fields must be kept clean for about a month (Broderyk, interview).

At a provincial level, Cotton SA collaborates with local government structures to support the training and development of small scale or emergent farmers. 


\section{Activities/services offered}

Cotton SA activities are geared towards fulfilling the three main aspects of its mission, namely, to provide an information service to its members, to promote the usage of cotton and to enhance the marketability of cotton through improved production research. Information around pricing and marketing is disseminated primarily through a monthly Market Report that is made available to all growers and members from the industry. This report "is a monthly update on how the world pricing is set up and changing” (Broderyk, interview).

Information related to other aspects of cotton production is disseminated through a series of monthly 'study groups' that are run in different cotton growing regions and involve mostly cotton growers, and occasionally commercial companies, government extension officers and researchers also participate. Dr Broderyk describes what these study groups do:

They follow a program. And this program is based on what activities are currently happening. So in August you will have budgeting and arrangement for funds, September you have land preparation, in October you have planting and so it proceeds through the year (Broderyk, interview).

Cotton SA co-ordinates these study groups through a specific 'spokesperson', who is responsible for bringing any requirements of the crop to the attention of the group, for facilitating the sharing of information and for bringing to the attention of Cotton SA any concerns or problems raised in these study groups.

Another regular strategy for information dissemination used by Cotton SA staff is publishing articles in popular media such as the Farming Newspaper and African Entrepreneur. Many of these articles discuss recent research results and often address issues related specifically to emerging farmers. These articles are also frequently used to promote cotton as a product:

As you will probably be aware, synthetic fibres is giving cotton stiff competition for various reasons. And the one idea is that cotton must be promoted on its points of superiority so that the usage can increase (Broderyk, interview).

As part of its commitment to enhancing the marketability of cotton, Cotton SA maintains a fibre laboratory where "advanced equipment" is used to "measure various characteristics of cotton fibre, like length, strength and maturity" (Broderyk, interview).

\section{Involvement in research}

Cotton SA, in collaboration with the Institute for Industrial Crops (IIC), at the Agricultural Research Council (ARC), organises an annual "circus" of meetings with cotton growers in every cotton-growing region. At these meetings, growers are invited to "state any problems that they experience that are not catered for by the present level of knowledge" (Broderyk, interview). These problems are then compiled into a list of research needs that are submitted to the research sub-committee of Cotton SA, as well as the IIC. The reason for the involvement of the IIC is that they are the main body responsible for undertaking cotton research. 
Dr Broderyk describes what happens once the research needs of the growers have been listed:

These needs are listed and then depending on the availability of money, funds that are allocated to specific projects and the priority of these projects are decided by a sub- committee on research. [ ] The researchers at the Institute for Industrial crops have their opportunity of drawing up the projects that suit their particular field of endeavour. They will come and defend these projects to the sub committee. [ ] Actually the management of the Institute for Industrial Crops will discuss it with the particular people in their different disciplines and so on. They will formulate proposals if they are in line with what merit they think it has. They draw up a project plan [with a budget] and they defend it with this [research] committee (Broderyk, interview).

In other words, the researchers draw up the actual research proposals and budget plans. They influence what research is undertaken and how, but ultimate approval of the research projects lies with the research sub-committee of Cotton SA. This sub-committee tends to favour the funding of applied type research projects:

The underlying principle at the moment is to only fund those projects that have direct potential for benefiting the growers. That means basic research gets a back seat (Broderyk, interview).

Very occasionally research projects that will have more long term benefits, rather than immediate applications, are also funded:

At the moment if it doesn't formulate or lead to an extension or recommendation then that research is really not very welcome. But that are exceptions. The verticillium project [is an example] where it is of strategic importance to have the verticillium resistant cotton line - without which the industry could be wiped out in a single season unless one has some genetic material to fall back on (Broderyk, interview).

In the past, researchers from a range of institutions were involved in cotton research, but for the last few years, the IIC has been the leading institution in cotton research. Researchers who undertake research with the financial support of Cotton SA are expected to produce an annual progress report as well as articles in the Cotton SA 'journal', which appears every second month:

When progress has been made that can be used and brought to the attention of the growers an article is expected that will be in a language that the growers will understand. And it must be published. And when the project terminates, certainly it must result in an article or perhaps more than an article in Cotton SA that will be a benefit for the growers (Broderyk, interview).

There is thus a keen awareness of the need to make research results and reports accessible and applicable to the end users of the research - that is, the growers. It is surprising therefore that Cotton SA no longer facilitates forums in which researchers 
present their research directly to growers, except in cases where study groups invite researchers:

Yes, that [presentation forums] unfortunately has fallen by the wayside in the last year too. But we strongly encourage that. At the moment we have interaction with the research people on a committee level and the growers are not particularly exposed to them. Unless there is a need to involve the study groups and they are invited (Broderyk, interview).

According to Dr Broderyk, not all researchers meet their expectations to produce research that can be easily applied by farmers:

Yes, the true situation is that we've had a lot of difficulty creating a realisation amongst some of the research people of the need to produce something practically useful to the point where we have to return articles to them, which do not have a message or do not in any way contribute to the growers' situation. If there isn't a research message how can we use growers' funds for that? (Broderyk, interview).

Another concern related to researchers is a perceived lack of new knowledge being produced for the industry:

The other thing, with all due respect to the Institute for Industrial Crops, has been rather lacking in producing new information that we could use to stimulate interest and get more interaction with farmers. They have really been lacking in that aspect and that is a major thing. If you don't have information coming from the back to keep on supporting you in the front then eventually your story dries up (Broderyk, interview).

The comments in this section suggest that Cotton SA strives, insofar as its resources allow, to be responsive to growers' research needs by funding certain types of research projects. It constantly monitors what happens in the field of knowledge production and is not necessarily only concerned with applied knowledge, but is also concerned when the 'frontiers' of science in its domain are not pushed forward. However, Cotton SA's control over the knowledge production process is limited because it does not actually commission the research or provide a research brief. It provides the financial resources and suggests topics for research, but then relies on the researchers to submit workable proposals that address the research needs of growers. Consequently, Cotton SA sometimes has difficulty with what research is produced and how to make the research accessible to growers.

Ms Annette Swannepoel, a Senior Researcher at the Institute for Industrial Crops, has had a long association with Cotton SA is. She has been involved in cotton research for 18 years and since 1994 has led a research project, funded by Cotton SA, investigating infection threshold values for verticillium wilt in cotton. Verticillium wilt is a soil disease that impacts on the sustainable use of agricultural land for cotton production.

In the next section we provide a brief description of Ms Swannepoel's research. We consider how Cotton SA views her research and also reflect on Ms Swannepoel's interaction with Cotton SA, the benefits she has derived from this interaction and its 
impact on the industry, and what she sees as the role and value of Cotton SA to promote the production and utilisation of research in the industry.

\section{$4 \quad$ A researcher's view: Ms A Swannepoel, Institute for Industrial Crops, Agricultural Research Council}

Ms Swannepoel's research project on verticillium wilt was initiated through a request from Cotton SA to the IIC to investigate a problem that a specific farmer had been experiencing with verticillium wilt. It was soon realised that this problem, if it became widespread, could affect the industry negatively:

The reason why they asked for it was that this disease is strategically important for cotton in South Africa for sustainable use of agricultural land for cotton production. This specific disease is soil born, so it infects the soil and it can persist in the soil for many years. If your [verticillium wilt] concentration goes up too high in the soil, the farmers won't be able to use that soil for cotton production (Swannepoel, interview).

Following the process described in the earlier sections, Ms Swannepoel considered the request from Cotton SA and then drew up a project protocol and budget and submitted it for approval to the research sub-committee of Cotton SA. The proposal was approved and Cotton SA agreed to contribute to the operational costs of the project, while the IIC covered salaries and overheads.

Cotton SA views this research as different to most of the other research projects they fund, because it lies somewhere between strategic and applied research:

The benefits for that project [on verticillium wilt] will not be directly measurable. It is more of a strategic exercise that makes sure of the genetic material of having a situation, which could otherwise be quite disastrous. And this lady has certainly produced noteworthy results and we have seen some plants growing where others certainly wouldn't. It is something to have up your sleeve if you are responsible about the industry (Broderyk, interview).

Ms Swannepoel, on the other hand, sees this research as more applied or "extension research". By this she means, "we take known principles and we assess it under our conditions, and tailor make it to be applicable for specific areas or farming conditions" (Swannepoel, interview). The applied nature of the research is reflected in her description of the research aims and objectives:

The first thing that we did is we did a survey to determine what is the extent of the problem. At what levels are we looking at in the soil and at what levels are we starting to experience economic losses. I can refer back to the title: that is the infection threshold value. That was the first aim to determine that - to what extent the soil is infected and at what level. From thereon, this disease cannot be controlled with chemicals, it is a disease that should be manipulated through cultural practices. And I investigated several cultural practices that are within the capabilities of farmers ... like planting dates, irrigation schedules. So I looked at the impact 
of those on the [crops] and then to end off with a workable plan or solution for the farmer (Swannepoel, interview).

Her determination to produce research that can be applied by the cotton farmers can be attributed to the approach to research adopted at the IIC, as well as her understanding of the expectations that Cotton SA has of researchers:

We [at the IIC] have a process that we go through when we initiate research or when Cotton SA approaches us. We all sit around the table and discuss how we are going to do it and what we expect from the work and how we are going to disseminate the technology or answer back to the farmer (Swannepoel, interview).

[Cotton SA] expects of us that at the end of the project that we would present a farmer with recommendations or a very clear package on how to deal with the problem that they have identified. So it must be workable, it must be practical. It shouldn't be - many principles in disease control for instance are very textbook and very idealistic. They want a practical approach that the farmer can work with on the farm. They require that from us. (Swannepoel, interview).

Ms Swannepoel's commitment to making her research practical and accessible is reflected by the range of strategies she uses to engage farmers and to disseminate her research:

We do on farm trials. Part of the research or experiments we do as a demonstration show on farms - usually in the early stages of the research. We also have yearly farmers' day where we would release some of the results or progress and give them that pieces of information as they evolve. Then also we publish our work with recommendations in the Cotton SA magazine. It's a quarterly magazine and they have a certain number of pages that are dedicated to cotton research results. And the other way is Cotton SA has a yearly "rondomtalie" (the circus). [ ] They have all the cotton producing areas, all the study groups- the farmers are organised into study groups and I usually go with them (Swannepoel, interview).

It is evident that Ms Swannepoel clearly meets the expectations that Cotton SA has of researchers that it funds. Her research "has direct potential for benefiting cotton growers" (Broderyk, interview), she interacts face-to-face with farmers and regularly publishes her research results with recommendations for implementation.

In the following section we look more closely at her interaction with Cotton SA and how she views their role in the ongoing production and utilisation of her research.

\section{Role of Cotton SA}

Ms Swannepoel distinguishes very clearly between the role of Cotton SA and that of the researcher:

The people at Cotton SA aren't scientists. They are more administrative people so they rely on us [researchers] to do the project protocol and the scope of the project (Swannepoel, interview). 
These different roles, according to Ms Swannepoel, make for a mutually beneficial relationship:

From our side it is definitely financial. We need the money to keep on going of course. And on their side we can solve some of the farmers' problems, which should increase production. Cotton SA aims to increase production because they are below the national requirement of the crop. We need to import fibre, so they are constantly on the aim to improve production by controlling diseases or pests or whatever the research problem is. Their primary aim in the end is to increase production (Swannepoel, interview).

Even though Ms Swannepoel describes the role of Cotton SA as largely an administrative one, she also acknowledges its role in assessing the quality and progress of the research:

Usually what happens is we need a report back session with Cotton SA where they visit us. We sit around the table and we tell them what the progress on the work is and what our aims are for the next year. Maybe six months later there will be another meeting. Sometimes it is once a year. [ ] They are usually evaluating the work to see if it is on track with their aims, which should be applicable to the farmers. They ask questions and they pry. They are not afraid to say if they are not satisfied if they think your approach is not right or whatever. We have an open discussion about the whole project. The progress is continuously measured against the aims and objectives of the project (Swannepoel, interview).

In this regard, Cotton SA acts as an accountability structure - researchers are held accountable for what they produce. It would seem that the accountability relates particularly to the benefits, applicability, and feasibility of implementation, of the research to farmers. Ms Swannepoel, however, believes that Cotton SA does not always have its ears to the ground, when it comes to the research needs of farmers:

They have what is called a technical committee that was set up to look at the research and to see that we are sort of on track. And then they established the sub committee in the technical committee to work more closely with the researchers. [ ] What happened is annually all the different regions have a meeting where they put on the table their research needs. Usually me or our rector would attend this meeting. We hear directly from the farmers what their problems are, but none of the members of the sub committee who should make the recommendations to the technical committee attends those meetings. And then a month after that, the sub committee comes here to our institute to discuss what happened at those regional meetings, but none were present. So I come back with a message from such meetings and say listen the farmers need this and this and this. And they don't see the urgency or the importance around it because they didn't attend the meetings (Swannepoel, interview).

More seriously, she claims that, at times self-interest drives the research agenda at Cotton SA:

There is a lot of personal stuff going on, because some of the members that sit on the technical committee are consultants that are hired by Cotton SA to 
do certain work. Like for instance there would be an entomologist consultant that is an entomologist, but we [the Institute] also have entomologists so of course he would be rooting for his own business. So he would shut down a project on entomology so perhaps he can do it. I feel they are biased. [ ] Because they are looking out for their own interests (Swannepoel, interview).

Ms Swannepoel is also critical of Cotton SA's sometimes shortsighted view of research:

As a researcher you think ahead, and you see this might be a small problem now, but with my knowledge I know in about $5-7$ years this is going to be a threat to the industry. Cotton SA doesn't always see it that way. They think just about the financial implications for now. It's not a problem now, so we will not spend any money on it now. They don't think towards the future (Swannepoel, interview).

Despite her criticisms of Cotton SA, Ms Swannepoel admits that she still advises farmers to use the forums provided by Cotton SA to raise issues:

With some farmers there is direct contact and others are through Cotton SA. What we usually advise the farmers is if they have a problem contact Cotton SA and they will channel it through to us. But there is also direct contact. [ ] You build up a personal relationship with farmers over the years. (Swannepoel, interview).

The comments by Ms Swannepoel on the role of Cotton SA suggest that the financial support it provides is perhaps the most valuable contribution it makes with respect to research. As an experienced cotton researcher, Ms Swannepoel stays in touch with research needs of cotton farmers and is able to anticipate potential problems. While she has enjoyed generous support from Cotton SA, she is critical of the ongoing contribution it can make to meet, particularly, the strategic research needs of the industry.

\section{$5 \quad$ Concluding remarks}

Cotton SA is an umbrella body that represents all the role players in the cotton industry. It acts as an industry forum and advisory body to various government departments and in turn, keeps its constituency informed of policies regulating the industry. It derives its funding solely from an industry levy on cotton fibre.

Cotton SA is an organisation committed to stimulating the production and usage of cotton and the enhancement of the marketability of cotton through funding research that has strategic or applied value within the industry. It tries to be responsive to cotton growers' research needs by prioritising and funding mainly research projects that have direct application possibilities for farmers. Cotton SA strives to keep in touch with farmers' needs through a series of regional 'study groups' involving farmers, government extension officers, researchers and a representative from Cotton SA. In addition, it collaborates with the Institute for Industrial Crops (IIC) at the ARC, to organise big annual meetings of cotton growers in different regions, where growers are given the opportunity to raise problems and identify potential areas for research. 
However, Cotton SA's ability to be responsive to growers' research needs is limited by the fact that it only makes suggestions for research topics, but relies on contracted researchers to come up with the actual research proposals and budget plans. Its research sub-committee, which approves all research proposals, does not provide any research brief, except to state its expectation that the research must have direct potential for benefiting cotton growers.

Cotton SA publishes industry relevant news and research: in a monthly Market Report; in a Cotton SA journal published every second month; and in other media popular amongst farmers. Researchers contracted to Cotton SA are expected to produce regular articles in these publications and are urged particularly to simplify their language to make it accessible to growers. The study groups and annual growers' meetings are also used as opportunities for information dissemination.

Cotton SA is fortunate that the IIC is the leading institution that undertakes cotton research. As such, it has at its disposal a pool of researchers from which it can readily draw. The involvement of these researchers in some of the study groups and the annual growers' meetings, means that the researchers often have first hand knowledge themselves of growers' research needs and strategic needs of the industry. Established researchers thus also build up personal contacts and relationships with farmers that are often sustained beyond Cotton SA activities. Researchers benefit primarily from the financial support provided by Cotton SA for their research. Although researchers produce the research plans independently and are left alone to carry out those plans, their accountability to Cotton SA compels the researchers to pay particular attention to the benefits, applicability, and feasibility of implementation of the research, to farmers. From a researcher's perspective, the continued prioritising of applied research by Cotton SA is sometimes viewed as shortsighted and indicative of a lack of strategic thinking with respect to the industry.

This case study suggests that Cotton SA fulfils a significant role as an intermediary agency that: promotes the research needs of cotton growers; funds research that has direct potential for benefiting growers; pressurises researchers to publish in simplified language and forms that are accessible to growers; disseminates research in a variety of ways; and encourages and facilitates interaction between researchers and farmers. 
List of data sources

Telephonic interviews

Dr S Broderyk, Consultant, Cotton SA (July 2004)

Ms A Swannepoel, Senior Researcher, Institute for Industrial Crops, Agricultural Research Council (July 2004)

Website

http://www.cottonsa.org.za/ 
An organisation that directs and publishes media and product research for the media, advertising and marketing industries.

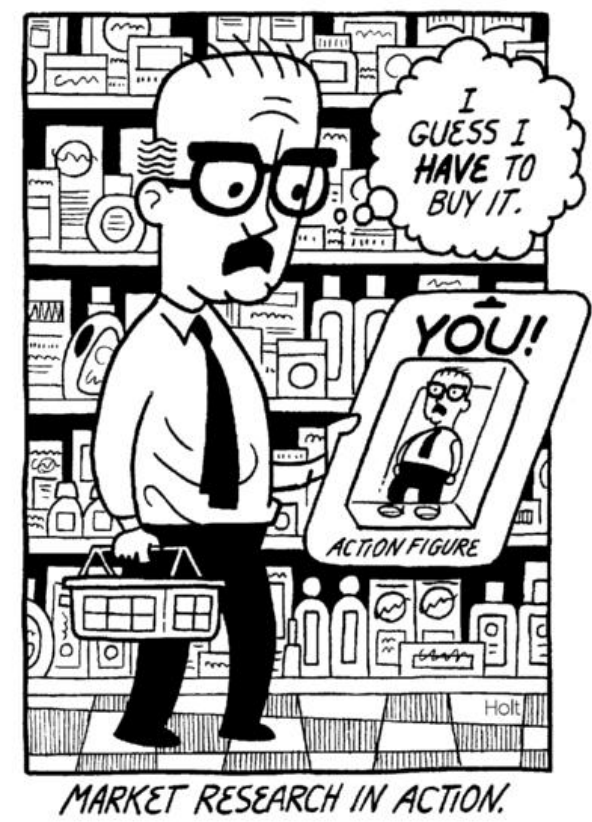

Reprinted from The Funny Times / PO Box 18530 / Cleveland Heights, OH 44118 phone: (216) 371-8600 / e-mail: ft 6 funnytimes.com

Cartoon courtesy of The Funny Times website [http://www.funnytimes.com/]
Acronyms
SAARF
South African Advertising Research Foundation
GCIS
AMPS
Government Communication Information System
RAMS
All Media and Products Survey
TAMS
Radio Audience Measurement Survey
LSM
Television Audience Measurement Survey
SAMRA
Living Standards Measure
UNISA
South African Marketing Research Association
DRU
University of South Africa
Stats SA
Demographic Research Unit
MIT
Statistics South Africa
Marketing Industry Trust 
The structure of the media industry in South Africa has changed enormously over time, as it has in most parts of the world. Generally, these changes have resulted in the introduction of new media such as television, suburban "free sheets" (also known as community newspapers), and the Internet. Interactive media, like the Internet and its World Wide Web, have also added new media dimensions to an increasingly complex, multi-media environment (SAARF website). The end result is a wide range of media choices for both the consumer and for the advertiser: the owner of the product has to decide how to market the product and to whom; the media owner has to decide who to sell advertising space to; and the consumer is either already a regular user of particular media and products or becomes seduced by the advertising, marketing and media industries to make different choices. For all of the above choices to be made by the advertising, marketing and media industries, they rely on data about the use of the mass media, and the consumption of products and services by users of the mass media.

The South African Advertising Research Foundation (SAARF) was established as a joint industry body specifically to provide this data via "comprehensive, unbiased, reliable, regular and technically excellent" consumer surveys. Its purpose is to provide data about the use of the mass media, and about the consumption of products and services by users of the mass media. The data is such that it can be used for target marketing and aid advertisers and their advertising agencies in taking decisions about the selection of media for their advertising campaigns. Media owners are able to use it for selling media space or airtime, and for strategic editorial and/or programme planning (SAARF website).

In this case study report we describe the activities of SAARF and reflect on the nature of the organisation and the contribution it makes towards dissemination and utilisation of research within the industry. We also consider the relationship that one prominent researcher has established with SAARF. In particular, we describe his research at the Bureau for Market Research, University of South Africa, and reflect on his relationship with SAARF and its impact on the industry.

\section{$2 \quad$ SAARF and the media, advertising and marketing industries}

SAARF is a joint industry organisation. SAARF's highest authority is its Board of Directors and these Directors, through their respective industry bodies, represent the marketing, media and advertising industries. The industry bodies represented include: the Newspaper Press Union, now Print Media SA (PMSA); the National Association of Broadcasters (NAB), which includes representatives from the South African Broadcasting Corporation (SABC); the Outdoor Advertising Association of South Africa (OAASA); and Cinemark representing cinema advertising. Similarly, the advertisers are represented through their collective body, the Association of Marketers (ASOM), and the advertising agencies through their industry body, the Association of Advertising Agencies (AAA), which includes representatives from the Media Director's Circle (MDC). Collectively, these bodies represent the scope of membership of SAARF. 


\section{Management and funding}

SAARF was formally established on 4 December 1974 and commenced operations in January 1975. SAARF receives an annual endowment from the Marketing Industry Trust (MIT). The Marketing Industry Trust also supports two other important industry bodies, the Advertising Standards Authority (ASA) and Freedom of Commercial Speech Trust. The MIT is financed via an industry levy on advertising expenditure. The collection of the levy is a relatively straightforward process, as it is media owners collect it on behalf of the industry. The MIT levy is calculated after all discounts and agency commissions have been deducted (SAARF website).

In addition to its Board of Directors there is an independent Board Chairman as well as two full-time directors of SAARF, Mr Paul Haupt, the Managing Director, and Mr Piet Smit, the Technical Director. Four administrative staff that takes on various functions supports the two Directors. These are the only permanent staff members of SAARF.

SAARF operates through a series of councils. Council members represent the interests of their members except for those who are invited to serve in their personal capacity due to the contribution that they can make to the functioning of SAARF and its councils. Ad hoc committees are appointed from time to time for specific tasks, while the Managing and Technical Directors attend meetings of the various members as well as user groups when and if necessary. All these activities are aimed at determining the requirements of the stakeholders, and to ascertain whether the research that is conducted succeeds in its aims (SAARF website).

\section{Relationship with government}

According to Mr Smit, SAARF Technical Director, SAARF has had a close and ongoing relationship with the Government Communication Information System (GCIS). This has entailed mainly providing the GCIS with useful "developmental indicators" derived from the surveys that SAARF manages. These include, for example, access to services and ownership of durable items. Mr Smit explains:

If you don't have electricity obviously you won't have electric appliances in your home. We are now entering a stage where people are actually going beyond the necessary things like stoves, geysers, hot running water and so on, they are now moving into things such as hi-fi's and music centres and microwaves, etc. so there is real development going on and we use that type of thing to give an indication of development (Smit, interview).

Government has been able to use this data as a "monitoring instrument of progress for their Research and Development Programme. Mr Smit also claims that the President has used information from SAARF on several occasions:

You may have heard it but not been aware of the fact that it's our information that Thabo Mbeki used when he opened the ANC congress in Bloemfontein last year. It is our information he used when he opened the parliament this year. He normally says that it's of an independent source so its not political propaganda (Smit, interview) 
Furthermore, at a management level, SAARF directorate serves on the Census Advisory Committee of Statistic South Africa, the government organ responsible for collecting national population census data.

\section{Activities/services offered}

The main function of SAARF is to direct and publish media and product research for the benefit of its stakeholders, thereby providing a common currency for the buying and selling of media space and time. Mr Smit describes SAARF's role and how the research is used:

We do research that is used by the advertising agency - sort of the broker sitting in the middle between the media owner and the client - the marketer or advertiser and the agency use our information to decide firstly how much money is he going to put into which of the media - into radio, TV, magazines, newspapers, outdoor, internet, cinema, etc. - and then finally after they decided how to break the budget out between the media then they go to inside the medium and decide on which print title am I going to use, which day of the week, which radio programme, which time of the day and so on am I going to use to reach as many as possible of my prospects (Smit, interview).

The research referred to above is essentially three major research surveys published by SAARF, namely, the All Media and Products Survey (AMPS), the Radio Audience Measurement Survey (RAMS) and the Television Audience Measurement Survey (TAMS) 12. The actual research work is contracted out to independent marketing research companies and one of the Technical Director's functions is the supervision of these research contractors. The AMPS is published once a year, the RAMS is published six times a year and the TAMS is published weekly.

In addition to these surveys, SAARF has also developed what it calls "segmentation instruments" which allow researchers to group the population around factors other than just demographics. For example, the Universal Living Standards Measure (LSM) is used "to group the population into 10 groups from lower socio-economic groups to the upper end of the scale, LSM I to I0". This measure is described on SAARF website as follows:

It cuts across race and other outmoded techniques of categorising people, and instead groups people according to their living standards using criteria such as degree of urbanisation and ownership of cars and major appliances. Because it is a multivariate segmentation tool constructed from 29 individual variables, it is a stronger differentiator then any other single demographic (SAARF website).

\footnotetext{
12 AMPS, RAMS and TAMS are registered trademarks. For more details of what these surveys entail, see SAARF website: http://www.saarf.co.za/
} 
The Lifestyle Measurement groups the population into people interested in sport, in gardening, in outdoor activities etc, while the Media Group Measure (MGM), groups people together according to the media they use, and then finally the Life Stages Measure, groups people according to the life stage they are at. The significance of the life stages are described by Mr Smit as follows:

When you are single and you live with your parents your needs are different from when you move out of your parents' home and you have to be independent and looking after yourself. Then later on when you get married, your needs change again when your children arrive and as the children grow up, your needs change and then later on the children leave the home and then you are in the era that you can buy timeshare and go overseas. Later on you sit alone, one partner has either left you or passed away. On each of those stages you have different needs and consequently different behaviour patterns (Smit, interview)

The purpose then of introducing these "segmentation instruments" is to enhance target marketing even further. The more the industry knows about behaviour patterns of the population, the better they can plan which products to sell to them and how. The segmentation instruments are published in a SAARF "segmentation handbook".

Another major service that SAARF provides to its members is training in the use of the data:

One of the main activities [of SAARF] is training of our users of our data. In other words, how do you use the data to do your media planning and we offer ongoing courses and we also offer if there is a need for a customised course that we offer in-house for specific members who request it. There is a huge need for instance among the community radio sector who really don't have the money to spend millions of rands on research. So we actually try to assist them as far a we can with advice, how to do qualitative focus group research to get a feel of what your community actually expect from you. That's basically what we try and do, [discuss the survey results], to orientate people with our data and also how to use it (Smit, interview).

The training courses are offered in four modules of three hours each and are attended by media owners, advertisers, marketers, and market researchers. To further assist users of their research, SAARF has also developed a "readership research methodology", which according to Mr Smit, is "worldwide renowned as one of the best methodologies in the world".

From the above descriptions we see that the activities of SAARF centre on the production and utilisation of media and product research surveys. In the next section we consider more closely how SAARF manages and gets involved in these research surveys.

\section{$3 \quad$ SAARF's involvement in research}

\section{Managing research}

SAARF funds, commissions and manages research, which it subcontracts to independent marketing research companies. The Technical Director of SAARF supervisors and 
monitors the research contractors and provides them with detailed specifications of what must be done:

[T] here is not a single research project with such a detailed spec on what people must do and my main job is to monitor to see that they move within the spec. (Smit, interview)

The specifications for the research are developed in consultation with various media committees and councils that SAARF has set up. Mr Smit explains why these councils are necessary:

We have a series of committees which don't make life easy, but for every medium we've got a media committee, we've got a TV council, we've got a radio council, a cinema and print, etc. and those councils are actually because media research, media audience research particularly is extremely complicated. [ ] [T] he first layer or level of councils is a council to assist us to make sure that what we do for print, for radio, for TV is actually what the market wants. And then we have SAARF advisory council, which overrides and makes sure that the one medium doesn't run away with half of the cake. They just make sure there is a balance between what we do for the different media. And then right on top we have SAARF board, which has got the final decision (Smit, interview).

SAARF website provides details of some of the specifications for the surveys. For example, the AMPS survey uses personal in-home interviews of thousands of adults (persons 16 years and older) representative of the total population. Questions asked include the use of the mass media, ownership of durable items and household products as well as the use of financial services. The RAMS survey involves placing RAMS diaries in a large number of representative homes, in communities of all sizes across the country. Respondents enter details of their radio listening behaviour into a diary that is kept for a period of seven consecutive days. The TAMS survey involves installing TAMS meters attached to television sets and other equipment like VCRS and decoders, into a representative sample of homes. Using a remote control device members of the household log in when they start viewing and log out at the end of a viewing session. The data are automatically transferred from panel homes to a central computer every 24 hours.

\section{Research networks}

In its endeavour to stay abreast of international developments with respect to media- and product-related research methodologies, SAARF is affiliated to a number of other research organisations:

SAARF is a member of the European Media Research Organisation (EMRO) (the only member outside Europe) and SAARF's Technical Director is the EMRO country representative. SAARF is also a member of the Advertising Research Foundation of the USA and SAARF's Technical Director is a member of one of their technical committees. One or more of the staff are members of the Southern African Marketing Research Association (SAMRA) and the European Society for Media and Opinion Research (ESOMAR). SAARF recently became actively involved in the establishment of industry media and product surveys in some sub-Saharan African countries. In 
conjunction with these countries, SAARF has formed the Pan Africa Media Research Organization (PAMRO) to promote media and product research in Africa. SAARF Technical Director is currently the Vice-President of PAMRO (SAARF website).

In addition to its involvement in the above organisations, SAARF directorate also regularly attends international symposia dealing with media and product research.

\section{Nature of research}

Mr Smit described the nature of the research commissioned by SAARF as research that must "find applications out there in the market place". Mr Smit gives some examples to illustrate this point:

Think for instance of marketing of electrical appliances. You have to have electricity. If you've got a fridge in your home then you can keep perishable things - maybe buy meat on a weekly basis rather than on a daily basis. You can keep cold drink cool and margarine and those types of things. It has a broad application across many markets - if you've got a fridge or not. If you have a freezer you can now buy meat in bulk. You can buy a quarter of a sheep or a hindquarter of an ox. If you've got a fridge you are in the market for frozen vegetables and so on. If you take our AMPS study I normally say to people what isn't in that study isn't worth knowing. Because, if you are in the marketing business and particularly like us across the board not only certain areas of marketing we must provide information on motor vehicles, of home ownership, on whether you've got a swimming pool, because then you are in the market for pool chemicals and Creepy Kraulys and all that (Smit, interview).

The examples above show that the data gathered in SAARF surveys can have far reaching applications for advertisers and marketers, probably often not necessarily anticipated by the survey designers.

\section{Quality assurance}

Given that the actual research work is contracted out by SAARF, the budget each year contains some provision for validatory and developmental research to check that data are valid and where possible, to improve the [research] tools (SAARF website). Mr Smit describes some examples of external validation procedures that SAARF uses:

For the purposes of the television panel we got audited information on MNET subscription and DSTV [satellite] subscription and then we ask questions when we do our all media study - do you have an MNET decoder and if so is the subscription paid. [ ] And then we compare that with the audited figures from MNET and following statistical requirement if you've got a $0.95 \%$ correlation between the two sets of information you can at a $95 \%$ confidence level say there is no significant difference between the two. We use that, another one that we use is statistics that ESKOM publish in their annual report to their directors on the number of new households that they've connected with electricity, and we ask a question on AMPS and again there is no significant difference. There is a couple of others like cell 
phone usage that we also use. That was external, using bits and pieces of information from somewhere else and compare it with ours (Smit, interview).

SAARF also uses internal validation procedures, by comparing data gathered from one year to another:

We also have regarding durable items a section where we ask [questions] about I 7 durable items - fridge, freezer and polisher etc, do you have such a durable item in your home and if so have you bought that item within the past 12 months or longer ago. And then doing the survey annually, if you take a year ago the incidents of a specific thing a year ago, and you add the new purchases for the past twelve months, you must get to the [number of] incidents now. Provided there isn't duplication. TV's won't work because half of the homes have got two or more TV's. But microwave ovens surely would work and so on. So we aren't sitting back and think that if we've done it so last year, it will work again this year. Every time we publish a survey we actually do a full validation (Smit, interview).

Here we see that SAARF has put in place procedures and mechanisms to ensure the quality and validity of its data.

\section{Relationship with researchers}

SAARF has long-established relationships with researchers through its participation in the South African Marketing Research Association (SAMRA), which is an association of market researchers. This association has monthly meetings and an annual conference that are attended by SAARF executive. Through these meetings SAARF gets to know a range of market researchers and the quality of their work. This is particularly pertinent when SAARF needs to contract out its research work.

SAARF research contracts go out to tender every five years. That means the same researchers will conduct SAARF surveys for five years, after which new specifications are drawn up and new tenders are invited. For the first time this year, SAARF has awarded the tender to two contractors on a 50/50 basis. Mr Smit explains the rationale for two contractors:

One of the reasons why we have opted for two contractors is to create an opportunity for knowledge transfer. Because there is only one company in the country that do AMPS and that is us. RAMS and TAMS - so who else can gain experience. Eventually you are locked in a monopoly. And that is why we decided to deliberately create an opportunity for knowledge transfer by bringing in a second player (Smit, interview).

As the Technical Director of SAARF, Mr Smit's responsibility is to manage these researchers and monitor their progress. He describes how he goes about doing this:

I try to as a professional researcher, not to interfere. We subcontract the work to them and in their professional capacity I don't interfere. I would query them when I don't agree with them but normally by the time we get to a meeting- we work so closely together- that I am on a day-to-day basis completely updated on what they do [ ]. We've got monthly liaison 
meetings. We are on a day-to-day basis telephonically or via e-mail in touch. Once a month we just pull all the ropes together and we see where we are with all the different issues and plan for the next month (Smit, interview).

We see then, that even though the actual research work is done by contract researchers, SAARF plays a strong managerial role that ensures that researchers stick to the brief given by SAARF and that they regularly report on research progress.

\section{$4 \quad$ Promoting research utilisation}

In section 2 we mentioned that one of the main services SAARF offers its members is training in the use of its survey data. This training obviously plays an important role in promoting the utilisation of the research, in particular, by providing training in how to use the data for media planning. In addition to this active promotion of utilisation, SAARF also publishes its survey results in a variety of ways that make them accessible and 'user friendly'. For example, SAARF AMPS survey results are published as follows:

The complete SAARF AMPS database is made available on $C D$, which makes it possible to do custom analyses. Users are encouraged to familiarize themselves with the AMPS Technical Report and specifically to read the questionnaire, in order to get a better understanding of the methodology behind the information which can be accessed via the electronic database. Some of the data from SAARF AMPS surveys are also published in printed format and the printed reports consist of volumes in which the use of the mass media is cross tabulated with other variables such as demographics as well as the use of services and products. SAARF AMPS Condensed Pocket Edition contains a comparative summary of adult data for the most recent five years. Demographic profiles of the users of products are available separately (SAARF website)

SAARF RAMS and TAMS results follow similar publication forms as for the AMPS results. SAARF members, and other users of these research results, thus have access not only to the raw survey data, but also to related data that allow users to do further analyses to inform their own planning with respect to specific marketing, advertising or media requirements.

All the printed reports referred to above are also available in several public libraries: SAARF makes copies of all its printed reports available to the Library of Parliament and the South African Library in Cape Town, the Bloemfontein Library and the State Library in Pretoria. The libraries of some universities and technikons subscribe to the printed reports. All the reports since the inception of SAARF are available in SAARF library (SAARF website).

Another strategy SAARF uses to promote research utilisation is face-to-face meetings with its stakeholders:

Every single meeting we have with our stakeholders at the media level as well as the advertising, the advisory council level these people [the researchers] are invited to those meetings and we expect from them to sit 
there and whenever necessary report back to the industry what they do (Smit, interview)

The researchers are thus encouraged to participate in these stakeholder meetings and contribute towards promoting the utilisation of the research in the relevant industries.

Mr Hennie Steenkamp, a senior researcher at the Bureau for Market Research, University of South Africa (UNISA) has had a long-standing association with SAARF. Mr Steenkamp works in the Demographic Research Unit (DRU) of the Bureau, which SAARF established and still subsidises. One of main functions of the DRU is to update population census data annually and Mr Steenkamp takes responsibility for the submission of this report to SAARF.

In the next section we provide a brief description of Mr Steenkamp's research work in the Demographic Research Unit. We consider how SAARF views his research and also reflect on Mr Steenkamp's interaction with SAARF and its impact on the industry, the benefits he has derived from this interaction, and what he sees as the role and value of SAARF to other researchers in the field.

\section{A researcher's view: Mr HA Steenkamp, Bureau for Market Research, UNISA}

Mr HA Steenkamp has worked as a researcher for 22 years and since 1986 has focused specifically on producing population estimates and demographic research based on available census data. He has done this work primarily through the Bureau for Market Research at the University of South Africa. Mr Steenkamp describes the scope of research that the Bureau undertakes and where his own work fits in:

We actually have seven research divisions that we work in. The one is income and expenditure data that we collect and distribute. [ ] Then we've got the personal, income and market potential division, and then we've got the behavioural communication research that is mostly concentrated on the advertising industry. Then we have economic growth areas looking at where and what is happening as far as that is concerned. Then we have industrial research, commercial research and SAARF demographic research division where this project [population estimates] fits in (Steenkamp, interview).

Producing population estimates involves checking and evaluating national census data produced by Statistics South Africa (Stats SA). Over the last few years, the research produced by Mr Steenkamp and his colleagues has revealed gross undercounting of the population in the national census:

Let me quote a little bit of an example. After the 1996 census, which they estimated the population at 40,5 million, we estimated it at 42 million, which is nearly 1,7 million more because if you remember the 1996 census, they first came out with an estimate of 37 Million, and then they adjusted that and we played a big role in getting them to adjust it to the 40,5 but that was still too low and then when I did the 200 I estimate [ ] I estimated that the difference between us and Stats SA at that stage was 700000 not even less than half, because the growth rates that they use are much higher 
than the growth rates that we use. That is a big problem. So we have an idea that they try and compensate for their lower base, but I can't say that for a fact because it's not written down anywhere (Steenkamp, interview).

These differences in population estimates are particularly significant to the marketing and advertising industries, as Mr Steenkamp points out:

I did a project about two or three years ago where we did a very strict and controlled sample in the Randburg magisterial district to estimate the nonblack population and we proved beyond a doubt that there are huge undercounts in Stats SA data for the whites. Although they are not the higher earners, they still are a huge size of the population with reasonable higher incomes so from a marketing point of view it's very important to have those figures as accurate as possible (Steenkamp, interview).

Accurate population estimates are also crucial for the sampling and weighting procedures that SAARF uses for its surveys:

[SAARF] have to weigh their readership data and their AMPS and TAMS, radio and television audience measurements. They have to weight it to something to say how many people are looking at a specific thing and to draw their samples and to weight their samples and they use it for those purposes, and then of course the added usage of that is the marketers use it as a way of establishing the size of their markets or the potential size of their markets as well from this (Steenkamp, interview).

Mr Smit from SAARF acknowledges the value of the Bureau's research:

You need accurate population information. It doesn't help for us to do a perfectly designed survey and then to gross it up to a population that is wrong. That is our priority and that is why we are involved in the Bureau for Market Research. And why we actually found this demographic research unit that we still subsidise them. [ ] Their first job nowadays has become to evaluate the census and to adjust the census as a benchmark and then from there to annually do the updates. [ ] We found their information very reliable. And then from time to time we use them to do other surveys. (Smit, interview).

Although SAARF is one of the main users of their research, it is not the only users of the research produced by the Bureau. Mr Steenkamp reports that they also give "about 200 reports to the private and governmental sector", which includes reporting to the Statistic Society of South Africa, the Demographic Society of South Africa and the South African Market Association. In the next section we look at some examples of utilisation of the research by SAARF.

\section{Utilisation of the research by SAARF}

SAARF uses the population estimates produced by the Bureau to generalise patterns and trends from the representative samples they use, to the population. For example:

SAARF draws a sample, I don't know whether it's 20000 or 30000 interviews that they do, but then when they have done those samples, they 
must blow it up to say that is the situation of the population. [ ] That forms the basis of the total marketing estimates to say there are 15 million television viewers or what ever the case might be (Steenkamp, interview).

It is for this reason that SAARF relies on accurate population estimates. Mr Steenkamp gives an example of what happens when these estimates are not accurate:

Let us just look at the circulation figures of a newspaper. If we would change the population as what is happened now [with Stats SA] where they differ with virtually a million people from our estimates with the white population and you would put that through to the industry, that would mean that all of a sudden Beeld circulation would drop 100000 to 75000 and Daily Mail from 150000 to 103000 or whatever and that has got huge repercussions in the income streams (Steenkamp, interview).

Mr Smit reflects further on the value of the Bureau's research when it comes to projecting the readership of a newspaper:

You can imagine - the census has changed their demographic or geographic definition of for instance Pietermaritzburg. They've changed the definition of what Pietermaritzburg is and we gross the readership of the Natal Witness up to the Pietermaritzburg magisterial district. And when they [Stats SA] implement a change like they did a couple of years ago, the Pietermaritzburg population goes down with about half and that means the readership of the Natal Witness goes down with about half. That can be the end of the Witness financially. The Bureau of Market Research make sure that those adjustments are taken into account (Smit, interview).

In addition to using the population estimates produced by the demographic research unit, SAARF also uses data gathered by the other research units in the Bureau to compliment its survey data:

There is a growing need amongst our users to have income and expenditure information. We ask a question on household income, but if you want to do a proper income study then it is a full survey in its own right. It is not just a question or two on a specific survey. The Bureau did that type of things, where they go and they interview the guy on every single source of income. On all his expenditure - how much does he pay for his housing or his motor payment for food and that type of things. And what we do now is the Bureau of Market research has implemented our LSM - Living Standards Measure on all their surveys. So you can now via the LSM get the AMPS and the Bureau's income and expenditure studies together. And you can do a breakdown of how much the different [categories of] LSM's earn and how they spend their money (Smit, interview).

From these descriptions, we see that the research produced by the Bureau for Market Research has wide reaching applications for the advertising, marketing and media industries. In the interests of its stakeholders, SAARF is one of the main users of this research and it in turn, makes all this data available to its members. 


\section{Role of SAARF}

SAARF is represented on the Bureau projects committee, the South African Advertising Research Division, that makes decisions about what the different research units at the Bureau will focus on for the coming year and what their budgets should be. This committee includes representatives from Stats SA and from the private sector. While SAARF makes an important contribution in this forum, the most benefit is derived from the subsidy it continues to provide specifically for the Demographic Research Unit: It is very beneficial for us that we get their [SAARF's] financial contribution so that we can still carry on with this research otherwise we would have had to scale down on the time we spent on this and for them of course it is absolutely a necessity that they get more accurate data (Steenkamp, interview)

In addition to formal meetings with SAARF at least twice a year, the Bureau researchers also have frequent informal interactions with SAARF and their other researchers:

We have some of the technical people [from SAARF], [ ] and the actual contractor that at that stage contracts to do the research on AMPS for them. Then we meet with them and discuss our plans and ways and means and D-dates when the information must be ready for them to be incorporated and which survey of SAARF, etc. Those are informal meetings as and when needed, but that is many times more than the formal two committee meetings that we have during the year (Steenkamp, interview)

The Bureau researchers are also regularly invited to make presentations at SAARF organised events, where they report directly to industry members and other researchers. Mr Smit, describes the interactions with the researchers from SAARF's perspective:

We've got a couple of standard events on the calendar annually. [ ] It's a meeting in February/ March, where we just wrap up where they stand and then put together a plan for the rest of the year. And then we have the annual AGM where they report back to all their members. And then there is that planning meeting of the projects committee to decide how to split the budget for the next financial year. That's the three that is scheduled, but as I say when necessary we have additional ones. Within the next few weeks we will have one where they will report back on the census evaluation. [ ] At the moment, the demographer that is doing the demographic adjustments for us, Karel van Aardt, l've involved him in an effort that we drive from SAARF, where we started from SAARF up in Africa. [ ] Karel van Aardt is going to do a conference on our paper in Cameroon in August on the impact of HIVIAIDS on the African population. That is apart from the formal relationship between us which is a couple of scheduled events per year. There is also on a day-to-day basis communication if necessary. So there is that informal liaison also (Smit, interview)

SAARF's role in the Bureau's research is thus part benefactor and part advisor. It does not take on a strong managerial role but does ensure that the research is of benefit to itself and its members. It uses all its resources to disseminate the research widely and to promote the utilisation of the research. 


\section{$6 \quad$ Concluding remarks}

SAARF is an organisation that is committed to directing and publishing media and product research that is of benefit to the media, advertising and marketing industries. SAARF funds, commissions and manages research that it subcontracts to independent marketing research companies. In consultation with various media committees and councils, SAARF provides very clear briefs to researchers of what data should be collected and how, and actively monitors the research progress to make sure that researchers adhere to the brief. SAARF contracts out and then publishes three of the most widely used media and product surveys in the country, namely the AMPS, RAMS and TAMS surveys. SAARF employs a range of external and internal validation procedures to ensure the quality of the research produced. The relationships that SAARF establishes with a variety of researchers, and its involvement in a range of local and international research networks, provides many opportunities for knowledge transfer and enables SAARF to stay abreast of the best practices in media, product and market research. At the same time, the active involvement of stakeholders in its various media committees and councils ensures that the needs of the primary users of the research are taken into account when setting up the research briefs.

SAARF publishes its survey results in a variety of ways that make them accessible and 'user friendly'. Not only are the raw data from the completed surveys made available on CD, additional reports produced in separate volumes provide comparative summary data, and product data cross-tabulated with demographic data. All the printed reports are freely distributed to its members and are available in several public libraries.

In recognition of the wide range of potential users of the research and the varying capacities they have for interpreting the research results, SAARF produces special Technical Reports that contain a comprehensive "readership research methodology" that assists readers to use the data for their media and advertising planning. In addition, SAARF offers ongoing training courses in the use of the data as well as offering customised inhouse courses for members on request.

SAARF establishes many of its relationships with researchers through its participation in the South African Marketing Research Association. Researchers contracted by SAARF benefit primarily from the financial support given, although they also gain experience doing research for a unique joint-industry organisation that serves the interests of the advertising, marketing and media industries. Researchers are encouraged to participate in stakeholder meetings organised by SAARF and whenever necessary, are expected to elaborate on their research directly to industry members.

This case study suggests that SAARF fulfils a significant role as an intermediary agency that: funds, commissions and publishes research that can be utilised by the three industries it represents; disseminates research in accessible and 'user friendly' forms; actively promotes the utilisation of its research through training courses and manuals; and encourages and facilitates interaction between researchers and industry members. 


\section{List of data sources}

Telephonic interviews

Mr P Smit, Technical Director, SAARF (July 2004)

Mr HA Steenkamp, Senior Researcher, Bureau for Market Research, University of South Africa (July 2004)

Website

http://www.saarf.co.za/ 


\section{MINI-CASE STUDY 6}

\section{WASTE MINIMISATION CLUBS}

Companies committed to sustainable industrial development working together to exchange information, ideas and experiences in waste minimisation.

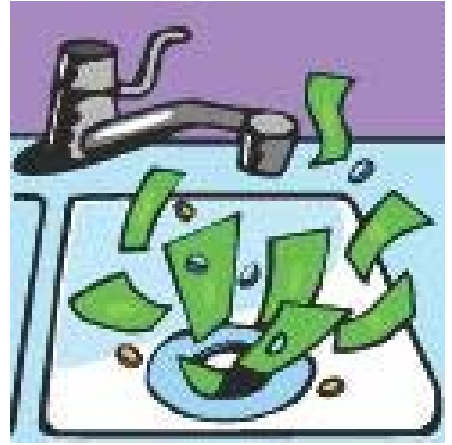

Image courtesy of Sustainabulletin, Issue I, February 200 I

\section{Acronyms}

BECO-ISB

BECO Institute for Sustainable Business

PRG

Pollution Research Group

UN

University of Natal 


\section{Introduction}

The Waste Minimisation Club concept is one that was developed in the early 1990's in Europe and the United Kingdom. They were established as an initiative to reduce the environmental impact of industry operating in the same geographical area and discharging to the same sewer or receiving water body. It was a successful approach, with companies achieving significant financial savings with little investment, and a resultant reduction in their environmental pollution. It was thought that this approach was one that could be used in South Africa to promote sustainable industrial development (Waste Minimisation Clubs, website)

Waste Minimisation Clubs involve a group of companies, either from the same sector, or different sectors, working together to exchange information, ideas and experiences on waste minimisation, and in this way, encourage one another to improve process efficiency, save money and reduce their environmental impact (Barklay et al, 2000). Clubs are generally managed and run by consultants or research organisations who are responsible for facilitating meetings, disseminating information and assisting companies to conduct waste minimisation assessments on-site.

In this case study report we describe the activities of Waste Minimisation Clubs and reflect on the nature of the Clubs and the contribution they make towards dissemination and utilisation of research around waste management. We also consider the relationship that one prominent researcher has established with Waste Minimisation Clubs. In particular, we describe his research in the Pollution Research Group at the University of Natal, and reflect on his views of Waste Minimisation Clubs and the mutual benefits derived from his ongoing relationship with Clubs.

\section{Waste Minimisation Clubs}

\section{Waste Minimisation Clubs and industry}

The first two pilot Waste Minimisation Clubs were established between 1998 and 1999 in two regions of KwaZulu Natal. The first Club brought together 29 companies in the Metal Finishing Sector in Durban, and the second Club was in the Hammersdale region and comprised six textile companies, a chemical manufacturer and a chicken abattoir.

Today, there are over 40 Waste Minimisation Clubs in all parts of South Africa in the industrial, commercial and public sectors. Companies are successfully working together to reduce waste at source ${ }^{13}$, thereby reducing their impact on the environment and saving themselves significant amounts of money (Waste Minimisation Clubs, website).

\section{Management and funding}

Waste Minimisation Clubs are generally managed and facilitated by consultants or researchers. Consultants and researchers are drawn from organisations and institutions that have expert knowledge in waste management strategies. One institution that has vast

13 In other words, preventing the waste from occurring in the first place. 
experience managing Waste Minimisation Clubs in South Africa is the BECO Institute for Sustainable Business (BECO-ISB) ${ }^{14}$.

The founder of BECO-ISB, Mr Bas Kothuis, describes what management of the Clubs entails:

We get the Waste Minimisation Club together; so we invite the companies to join. We administer the Waste Minimisation Club as such; we administer the membership, the membership fees, the attendance of the meetings and all those things. We organise the meetings, we send out the invitations, we make the minutes, we mostly chair the meetings - some Clubs want to have their own independent chair, but mostly BECO chairs the meetings. And we help the individual companies with their waste minimisation assessment so there are a number of consultancy hours involved as well (Kothuis, interview).

Clubs draw on a range of funding options, the biggest proportion normally coming from membership fees. Fee rates are based on the running costs of the Club, which often depends on the services provided by the Club facilitator. Additional financial support to Clubs has come variously from the National Department of Trade and Industry, the Water Research Commission and local, provincial and national Departments of Water and Environmental Affairs. In Cape Town, seven Clubs have received some financial support from the City of Cape Town.

Except for providing the financial support, government officials seem to have minimum involvement in the activities of the Club, but they are kept informed of developments: It is different for every club. [ ] Someone from the City of Cape Town attended the meetings. Sometimes it is the local government that subsidises it but they never show up. We never see anything. They just subsidise it. That's it. They get the minutes and they get the newsletter and things like that (Kothuis, interview).

\section{Activities/services offered}

The main activities that Club members engage in are waste minimisation assessments in their own companies and regular meetings for information sharing and learning opportunities. Mr Kothuis describes how these happen:

What waste minimisation clubs do is every company goes through a full waste minimisation assessment procedure which takes about half a year to a year, and every two months they come together and they exchange experiences about how it is going. And what the results are so far. At these meetings there is an element of training. BECO trains them on how to do a waste minimisation assessment. And there is an element of feedback everybody reports how it's been going and there are sometimes invited speakers. A certain topic might come up about the new Water Act, or the new Air Act or a certain water treatment technology or something like that.

\footnotetext{
14 The only other two institutions from which facilitators of Waste Management Clubs have been drawn are the University of KwaZulu Natal and the University of Pietermaritzburg (Kothuis, interview). BECO-ISB has offices in Cape Town and Johannesburg.
} 
BECO identifies a suitable speaker and invites that speaker to come and talk for half an hour or an hour about a certain topic (Kothuis, interview).

Very often the Club meetings co-inside with on-site tours:

Most of the clubs, not all of them, most of them rotate the meeting location. So every time it is at the facility of another member. So first it is at the factory of the first member, then there is a factory tour involved at the end of the meeting, and then the next time it is at member two at the factory somewhere, and then there is a factory tour again etc (Kothuis, interview).

The two primary benefits to members who engage fully in these activities and apply lessons learnt, are saving costs and reducing any negative impact on the environment:

They save money, by doing waste minimisation - in $99 \%$ of the cases. And they improve their environmental performance. They reduce waste, they reduce water consumption, they reduce energy consumption and they reduce effluents etc. So that's the benefits to the companies (Kothuis, interview).

In addition to these activities, most Clubs also produce their own newsletters, between two and four times a year, which is distributed to all members as well as government organisations and other interested parties.

\section{$3 \quad$ Engagement with research in Clubs}

Waste Minimisation Clubs do not fund, commission or conduct research. They do however, facilitate access to, disseminate and engage constantly with methodological and technological research and innovations that can contribute to improving waste management. The success of this engagement relies heavily, firstly, on how clued up the consultants (facilitators) are with respect to waste management practices and technologies:

The facilitator needs to be somebody who knows about cleaner production, who knows about strategies. It is his task to stay informed about the latest development in cleaner production and waste minimisation. And to inform the members about that, either at the meetings or through the newsletter (Kothuis, interview).

As consultants you are a knowledge source for industry. Industry hires a consultant because the consultant knows something or is able to do something industry is not able to do by themselves. So if you are not up to date with the latest technology and the latest information you are not a good consultant. Industry expects you to be up-to-date with the latest information, the latest knowledge. That's why they hire you. So as a consultant you are required to constantly keep in touch with the people that generate the information - being the universities, reading academic literature etc (Kothuis, interview). 
Secondly, the extent of research engagement in the Clubs depends on how pro-active the facilitators are:

Things in methodology are distributed mainly through the facilitator, and the facilitator's task is to distribute new insights, new tools and these types of things. Apply them and distribute them to the company - results of methodological research. And the same with technological research. If the facilitator hears about it and it is applicable to a problem from a certain company, the facilitator will bring it to the attention of that company (Kothuis, interview).

In some cases, facilitators are also required to respond to issues that members themselves raise:

If there is a lot of members that indicated they've got a problem with let's say steam generation, then we invite a steam generation company to do a presentation and to talk to them, and to visit the members. So if they've got a problem with a certain technology, they've got an interest in a wastewater treatment technology we can invite a wastewater treatment technology person to do that (Kothuis, interview).

Sometimes a member comes back and says I spoke to these and these people, they said there's a niche you think about that I would like to share that with the other members. And we say yes, please come forward and say what you have to say. And sometimes we invite that other person they have spoken to and that has something interesting to say. We invite them as external speakers (Kothuis, interview).

The facilitators thus play a crucial role in providing access to information in the Clubs and encouraging ongoing engagement with new methodologies and technologies for improving waste management.

\section{$4 \quad$ Promoting research utilisation}

Disseminating information is normally the first step towards promoting research utilisation, and as we have seen above, Waste Minimisation Clubs do this constantly, through their meetings and newsletters. Sometimes they adapt their strategy in response to members' needs:

Either it is done through the club meetings or if you know that a certain company has a problem, you know that they don't want to share it for whatever reason, you know there is a certain solution for the problem. In that case you don't bring it into the meeting, you bring it into an individual meeting with the company, not in the general club meeting (Kothuis, interview).

Dealing with an individual company's needs is clearly a more effective strategy towards promoting utilisation within that company.

A commonly experienced barrier to promoting research utilisation is often the theoretical nature of the research and the lack of practical suggestions for implementation. 
Mr Kothuis describes this as one of the big challenges that facilitators of Clubs have to overcome:

Too often academic university research is too far from immediate, applicable, proven to be applicable technology. [ ] There is a big barrier there. There is a clear filtering mechanism that is happening, there is lack of practicality. A lot of academic research is just theoretical academic, far away from being applied immediately tomorrow. And that filter is what consultants filter out fairly quickly. [ ] Consultants pick out those things that are most practical to them at that moment (Kothuis, interview).

Mr Kothuis acknowledges, however, that there have been academics that have produced research that consultants and facilitators have been able to take up and apply immediately.

He cites for example, the research of the Pollution Research Group (PRG) at the University of Natal (UN):

They wrote a manual, a guide about how to run a club that was very useful. What it helped to do was standardisation; it's like a national standard if you want to call it that way, a uniform approach on how you run a Club. The minimum requirements a Club must meet before they call themselves a Club. And that has been very useful (Kothuis, interview).

One of the researchers who were instrumental in the production of this manual is Prof Chris Buckley. He is the group leader of the PRG and initiated the research project that set up the first pilot Waste Minimisation Clubs in KwaZulu Natal. He interacted extensively with those first Clubs and has experience consulting in the United Kingdom around Waste Minimisation Clubs.

In the next section we provide a brief description of Prof Buckley's research on Waste Minimisation Clubs. We reflect on his interactions with Clubs and on what he considers the role and value of these Clubs to industry.

\section{$5 \quad$ A researcher's view: Prof C Buckley, Pollution Research Group, University of Natal}

The Pollution Research Group is located in the School of Chemical Engineering at the University of Natal. As head of this research group, Prof Buckley applied to the Water Research Commission in 1998 for a project that would promote the concepts of waste minimisation, cleaner production and sustainable development in industry, through the establishment of two pilot Waste Minimisation Clubs. As Prof Buckley states, the Clubs were the "rats in the maize" of the research:

They were the subjects of the research. And we were watching how they were reacting, and [we were] learning ourselves so we would be able to better promote and manage clubs (Buckley, interview).

The research process had two dimensions: on the one hand the researchers were assisting companies to do waste minimisation assessments and managing the setting up of 
the Clubs, and on the other hand, they were observing how effectively the Clubs were operating and how members were interacting with each other.

The first Club that was set up was in the Metal Finishing Sector. Selecting this sector was not pre-planned. In fact, the researchers simply responded to what they perceived to be a looming problem within the sector and for the local environmental authorities:

It so happened we initiated our first club because the local authorities had changed the discharged standard for metals to sewer, and so these chaps [in industry] essentially had their bums on the line and they were under extreme pressure to do something. And there were a couple of public meetings and they [industry] were pretty aggressive to the metro people and vice versa. So relationships were terrible. [] We used that confrontation and circumstance to initiate the club. So the metro called all these people to a meeting and laid down the law. And we talked to them beforehand, to the metro that we wanted to form clubs. We didn't have a preconceived idea that we would do it in the metal finishing industry and like that. We took circumstances and there was enough flexibility in the project that we were able to do what we wanted to (Buckley, interview).

The two key motivating factors for the researchers were sustainable development and protection of the environment:

What we want to do is to improve the water environment in the country and this has proved to be a very successful way of doing it. We certainly have empathy for industry and how we can make industry better. And industry is certainly learning that end-pipe treatment is the way you want to go. It's sustainable development. You got to try and reduce your consumption, reduce your production and at the same time not prejudice your standard of living and employment. It does all the right things. There is nothing negative about it. It makes money; it is socially creating sustainable jobs and you protect the environment (Buckley, interview).

Once the first Club had been established, the researchers interacted with members frequently and produced a host of resources:

We gave them training, we gave them manuals. We had monthly meetings; there were manuals, audits, surveys, and all sorts of interactivities like that went on. We showed them how to make the savings (Buckley, interview).

According to Prof. Buckley, their research has had a positive impact on at least two areas. The first is with respect to capacity building or what he calls "technology transfer":

We ended up having the authorities sitting in on the meetings and all sorts of people. We ended up having a whole lot of [different people] - there was immense amount of technology transfer that took place. [ ] There are now over forty clubs in South Africa. We are the Pollution Research Group, but we are not running any [Clubs]. They are being run by consultants and other people, which I consider is technology transfer. We've got to get out of the field and give space to consultants and other people. [ ] We had many of 
our students going off and running their consultancies on what they did their MSc's and PhD's on (Buckley, interview).

In fact, Mr Kothuis, from BECO-ISB, who now manages most of the Clubs in Cape Town as a consultant, was part of this original research team.

The second area that the research has had some impact on, and has the potential for even more influence, is with respect to policy:

If you look at the national waste management strategy, they talk about waste minimisation clubs. There is new strategy and policy coming out for cleaner production in South Africa. I am going to try my darnest to make sure waste minimisation clubs are there. People like Trade and Industry; I would like to see them support it and municipalities. From my side I am trying to make sure it gets into all top policy documents. It's proved itself so therefore I am happy that it is going to get in there (Buckley, interview).

The comments above suggest that Prof Buckley's research group are themselves committed to the promotion and utilisation of the concepts of waste minimisation and sustainable development.

\section{Role of Waste Minimisation Clubs}

Through his interaction with Waste Minimisation Clubs during this project, Prof Buckley has identified an important role that Clubs play with respect to research, and why it is important for groups such as his, to maintain contact with Waste Minimisation Clubs:

It's a two-way trade actually [the relationship between researchers and clubs]. One is yes it is a way of getting the information out, but it is also a very good way of finding out what the needs are in the market. If they have a problem no one knows how to solve it. That's a research need. So it is a two-way thing. [] The Pollution Research Group is a professional research group, so we rely on research projects. So, we are always looking for research needs and we don't try and make them up. We look for real needs with real people. So, it's necessary for us to keep in contact with reality and not make up research problems. They [the clubs] feed us with small problems, but we see a generic problem. So that enables us to have a project (Buckley, interview).

Prof Buckley also describes an interesting role that Waste Minimisation Clubs have come to play in industry:

Initially they [companies] come in because they think they are going to save some money. Then slowly they realise there are other benefits, the authorities, the bankers, the clients. Some of them are even telling their clients, "we are a member of this club, and this is what we've done. Don't go to the plater down the road because he is not a member of the club. He is not going to be in business in five years time. And we will be bigger and better" (Buckley, interview). 
In other words, participation of industries in Waste Minimisation Clubs has become a source of competitive edge to companies. He believes that this is an important step forward in getting more companies to participate in Clubs, and for companies to realise that applying waste minimisation strategies can lead to real cost savings and of course, improving their environmental performance.

Prof Buckley is quick to point out though, that Waste Minimisation Clubs have a limited life, and that they should be seen only as the first steps towards developing a culture of "cleaner production" in industry:

[A Waste Minimisation Club] has a life of two to three years; thereafter it gets engrained within the culture of the company. They really don't need a club after that. [ ] That's on the one side. The other part is that waste minimisation is just one tool of cleaner production. And cleaner production is industry's response to sustainability. This is where my next mission in life is. And that is to establish something that goes way [further], because waste minimisation is really the first baby steps. You want to have some system that is going to give continuous improvement and take people much further forward into places they have never been before (Buckley, interview).

We see here again, a strong motivation for action towards sustainable development in industry. It is worth quoting at this point from a paper written by the PRG, where they elaborate on the concept of 'cleaner production', and describe the role of Waste Minimisation Clubs within a bigger picture of 'cleaner production':

Cleaner Production is recognised as an important approach to reducing environmental impact and leading industries in the direction of sustainable development. Cleaner Production is a general term that describes a preventative approach to industrial activity. It encompasses concepts such as pollution prevention and waste minimisation, but there is also emphasis on a change in attitude in the manner in which products are manufactured. In addition to achieving a lower level of pollution, Cleaner Production results in economic benefits as there is more efficient use of raw materials and less waste being produced. One method of promoting Cleaner Production in industry is through the formation of Waste Minimisation Clubs (Barclay et al. 2000).

\section{$6 \quad$ Concluding remarks}

Waste Minimisation Clubs constitute groups of companies committed to sustainable industrial development working together to exchange information, ideas and experiences in waste minimisation. Clubs are generally managed and facilitated by consultants or researchers who are drawn from organisations and institutions that have expert knowledge in waste management strategies. Clubs draw on a range of funding options, the biggest proportion normally coming from membership fees.

The main activities that Club members engage in are waste minimisation assessments in their own companies and regular meetings for information sharing and learning opportunities. Waste Minimisation Clubs do not fund, commission or conduct research. However, through the initiative of the facilitator, Clubs do provide access to, disseminate 
and engage constantly with research that can contribute to improving waste management. Clubs rely on facilitators to bring relevant research to their attention and facilitators often have to filter the research to highlight practical aspects applicable to members of the Club. Researches are sometimes invited to make presentations to Club members. Facilitators also assist companies to conduct on-site waste minimisation assessments. These on-site visits are used as opportunities to promote and evaluate the utilisation of waste minimisation research and practices.

From a researcher's perspective, Waste Minimisation Clubs serve a dual role. On the one hand, Clubs provide opportunities to disseminate research information to users of the research, and on the other hand, they serve as a potential relay for research needs in industry. Interactions with Club members enables researchers to hear first hand what problems around waste management are being experienced within industries and provide researchers with the opportunity to investigate and seek solutions to these problems.

This case study suggests that Waste Minimisation Clubs play a significant, but limited, role as intermediary agencies: they provide access to, disseminate and engage with relevant research; they actively evaluate and promote the utilisation of waste minimisation research and practices; and they facilitate interactions between researchers and users. However, Clubs are not pro-active in initiating new research or trying to influence policies regulating waste management in industry. Instead, Clubs leave these to the initiative of researchers involved in waste management research. 
List of data sources

Telephonic interviews

Mr B Kothuis, Waste Minimisation Consultant, BECO, Institute for Sustainable Business (July 2004)

Prof C Buckley, Group Leader, Pollution Research Group, University of KwaZulu Natal (July 2004)

Publication

Barclay S, Buckley C, Maharaj D, Thambiran N and Mercer D (2000) Waste Minimisation Clubs: A Route to Sustainable Industrial Development? South African Journal of Chemical Engineering

Websites

http://www.nu.ac.za/wasteminclubs

http://www.beco.nl/en/becolSB.htm 


\section{MINI-CASE STUDY 7}

\section{ARID ZONE ECOLOGY FORUM (AZEF)}

An informal network of researchers, conservationists, farmers and other interested groups concerned with the conservation and sustainable development of arid regions in southern Africa

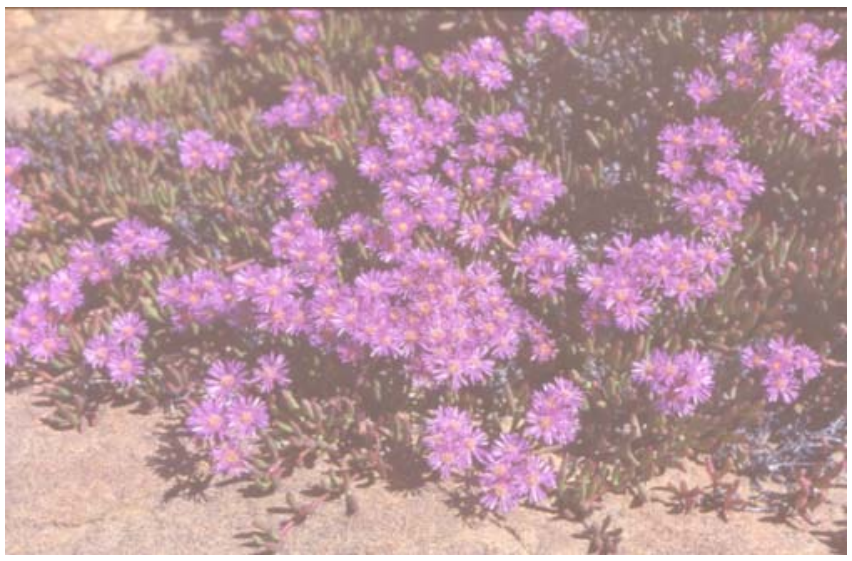

Photograph courtesy of Arid Zone Ecology Forum website [http://www.nrf.ac.za/azef/]

Acronyms

AZEF

NRF
Arid Zone Ecology Forum

National Research Foundation 
1 Introduction

More than half of southern Africa is either arid or semi-arid. Increasingly, agricultural and environmental management policies and research activities have become focused on the potential environmental problems and threats to sustainability that these arid regions will face in the not too distant future. These problems include erosion, land degradation, plant and animal species extinctions, and global climate change, amongst others (AZEF website).

The Arid Zone Ecology Forum (AZEF) is an informal network that brings together, at an annual conference, researchers, conservationists, farmers and other interested groups who are concerned with addressing and finding solutions to some of the above problems experienced within arid regions. In southern Africa, the arid region extends from the Western Cape and the Northern Cape, and parts of the Eastern Cape and Northern Province in South Africa, to Namibia and parts of Botswana.

In this case study report we describe the activities of AZEF and reflect on the nature of the organisation and the contribution it makes towards dissemination and utilisation of arid zone research. We also consider the relationship that one prominent researcher has established with AZEF. In particular, we describe his involvement in arid zone research and reflect on the benefits his involvement in AZEF has had on his ongoing research.

\section{Arid Zone Ecology Forum}

\section{AZEF and the NRF}

The Arid Zone Ecology Forum (AZEF) is one of at least five research related forums, networks or programmes initiated by the National Research Foundation (NRF). The other initiatives include Antarctic research, biosystematics, music and environmental research. All of these initiatives fall within one or more of the NRF focus areas 15 and are geared towards encouraging and supporting research in these areas. Getting this kind of support from the biggest national research funding agency means that researchers in these areas have great potential to develop and flourish into internationally renowned experts in their fields.

\section{Management and funding}

For the past 15 years or so, AZEF has been facilitated and co-ordinated by the NRF. However, since 2004, due to organisational capacity constraints, the NRF provided the funding for the forum ${ }^{16}$, but handed over co-ordination of the forum to a chairperson and an officially appointed co-ordinator.

The chairperson for the past three years has been Mr Mark Anderson, who works in the Northern Cape Provincial Department of Agriculture, Land Reform, Environment and

\footnotetext{
15 The NRF focus areas are: Challenge of Globalisation: Perspectives from the Global South; Conservation and Management of Ecosystems and Biodiversity; Distinct South African Research Opportunities; Economic Growth and International Competitiveness; Education and the Challenges for Change; Indigenous Knowledge Systems; Information and Communication Technology (ICT) and the Information Society in South Africa; Sustainable Livelihoods: The Eradication of Poverty; Unlocking the Future: Advancing and Strengthening Strategic Knowledge

16 R25 000 was given to cover the administrative costs of running the forum, including the salary of the co-ordinator.
} 
Conservation. He is an ornithologist and has had a long association with AZEF. He is not paid to be the chairperson. The role of the chairperson, according to Mr Anderson, is "to make sure that things tick over, to make sure that things run smoothly at the [annual] meeting" (Anderson, interview).

In addition to the funding from the NRF, the forum also gets some income from registration fees at their annual meeting. This however does not amount to much, and, as Mr Anderson explains, AZEF is a "non-profit" organisation:

Each year we just about break-even. Maybe make a little bit of money, which goes into the fund that is useful for other things. It is totally non-profit. [ ] Our registration fees are so reasonable people actually say it is one of the cheapest conferences to attend. We just cover our costs (Anderson, interview).

The NRF funds and registration fees are thus primarily spent on covering the costs of running the annual conference, which includes the salary of the co-ordinator and sending out notices for the meeting. Despite its tight budget, the forum has been able to make good use of some surplus funds:

We do try to keep quite a bit of money in our account because we do sponsor the attendance of students particularly from previously disadvantaged backgrounds. We invite students to submit applications for sponsorship for attendance of the meetings. And we need a letter of endorsement from the supervisor. And we also try to get a couple of invited speakers, really good speakers also (Anderson, interview).

AZEF thus does not have a special budget to commission research or conduct its own research.

\section{Participants}

AZEF is comprised of "an informal network of people from state, provincial, educational and research institutions, as well as farmers and individuals from the private sector" (AZEF website). Researchers and government officials come mainly from agricultural, environmental and conservation departments at their respective institutions. In addition, there are post-graduate students who participate and, according to Mr Anderson, researchers from museums participate in the forum.

Drawing all these individuals together is their common interest in the development, sustainability and conservation of arid zones. The main activity of AZEF is to host an annual conference that is open to all these individuals. They do not have to pay any membership fees, but do pay a small registration fee to attend the conference.

\section{Relationship with government}

Besides being funded and supported by the premier national funding agency, AZEF's relationship with government is established primarily through the participation of government representatives at AZEF annual conference. In most cases, the government representatives are conservationists or scientists who come from national and provincial 
departments of agriculture as well as environmental affairs and tourism departments. No other formal links are established with these departments.

\section{Involvement in research: AZEF Annual conference}

As mentioned above, the annual conference is the primary activity of AZEF. Notices and invitations to attend the conference are sent out widely to higher education institutions, government departments and museums. Researchers are invited to present a paper or a poster. AZEF is also trying to expand the participation in the forum by extending the invitations to other Southern African countries. Mr Anderson explains how invitations are sent out:

The mailing list is so huge that all institutions in South Africa will get it who do work in the Arid Zone. What we have done from this year is to print a little poster as well, which we then send around and ask universities and museums and conservation departments to just hang it up on their notice board. We want to try and let everybody know about the forum and that there are ways in which we can assist them. We actually try and spread into other parts of Southern Africa because it has largely been South African focused with some interest from Namibia. Only recently we started getting delegates attending from Botswana (Anderson, interview).

According to Mr Anderson, the average attendance at the annual conferences has been over 100 participants in the last few years. About a third of the delegates come from national and provincial departments of agriculture, and about $10 \%$ of participants are farmers. The rest come from higher education institutions, museums and nongovernmental organisations.

\section{Location and format}

The conference takes place over three days and is usually held in small towns within the Arid Zone in South Africa, this being mainly the Eastern Cape, Western Cape and Northern Cape provinces. Mr Anderson explains that the location of these conferences is significant:

They are not in the major cities. [ ] And it is quite nice because the meetings are very informal. And getting people together in a small town - they can't disappear to do other things at nights. They are always forced to interact. And the other thing I like about it is taking I00/I 20 people into a small town does quite a lot for the economy. You fill the guesthouses and you get local caterers and hire the town hall, which is quite nice. And what we also do is we have a field trip, in the middle of the meeting. So we go and look at specific projects that are being undertaken in the vicinity of that town. And the researchers will introduce their work and we will all discuss it (Anderson, interview).

The location of the annual AZEF conference thus serves as a strategy to get participants to interact formerly and informally, to network and to engage with on-site research projects. In addition, as Mr Anderson points out, there are economic benefits to the towns hosting the conference. 
In his description of the annual conference, Mr Anderson highlights both the formal and the informal aspects of the conference:

The formal part of the conference is usually two- two and a half days. This year because we got so many papers it will be two and a half days of paper presentations, so talks as well as poster presentations. So that takes two and $a$ half days and we have half a day field trip. That's it. And we have an annual general meeting on the last day, which last about an hour. We also have what we call round table discussions so this year we only have one. But if there is a topic we think needs input and time we will have informal round-table discussions usually in the pub over a few beers. Someone will introduce the topic and it is a more relaxed way. And you find that people who generally wouldn't contribute in the meeting feel much easier about these round-table discussions (Anderson, interview).

In this context, the round-table discussions serve as a specific strategy to get participants to talk and to share research ideas and possibly reflect on practical implications of the implementation of these ideas. Interestingly, none of the conferences so far have had parallel sessions, which means that all participants attend the same presentations.

\section{Nature of research presentations}

Mr Anderson describes the general focus of most of the research papers as follows:

It is very applied. It is how you can sustain and utilise the Arid zone without impacting on biodiversity. And that is what people are mostly interested in. Very little is purely academic. [For example] it is basically how it impacts on overgrazing. How can you change farm management systems to prevent overgrazing - these sorts of things. Studies on specific plants which may be threatened (Anderson, interview).

The applied focus is not surprising, given the broad participation at the annual AZEF conference. Mr Anderson also points out that the research is presented in a way that is accessible to the "layman". This, he states, is particularly important to encourage the input and participation from farmers:

I would say the standard is not that high that the layman would not understand everything. It is not like an academic international conference where only people in that field would understand. [ ] Over the years we always had a number of farmers that attend. [ ] They understand the academic papers. Their input of course is very valuable. Because researchers often go into an area and spend [time] doing the research and they don't have years and years of background knowledge that the farmer may have (Anderson, interview).

It seems then that the nature of research presentations at the annual AZEF conference allows for the optimal participation of all the delegates, ranging from researchers to practitioners. 


\section{Purpose and value of the annual conference}

It is clear from the above descriptions that the annual AZEF conference serves as a mechanism for sharing of ideas around arid zone research and practices. Mr Anderson describes the purpose and value of the conference as follows:

Basically the annual conference is sharing of information. That is really what it is about. People go there to give across the information they collected to other people. The delegates go there to learn. I find one of the major benefits for me is actually the interaction with other scientists you may not get to see very often. You either give a presentation on a certain topic and over tea and over dinner you sit and discuss it and say why didn't you, if you $\operatorname{did} A$ and $B$ it would improve your results or they would ask you questions (Anderson, interview).

Here we see again, the high value that is attached to personal interactions between participants that take place outside of the formal conference programme. It can be argued that the conference fulfils two of the objectives listed on AZEF website, namely "to facilitate knowledge transfer" and "to develop a network of expertise which integrates insight, information, goals and problems of resource managers with those of researchers and educators".

According to Mr Anderson, the intimate and informal nature of the annual gathering of arid zone researchers also benefits the post-graduate students:

For many students it is actually their first break into presenting a paper or a poster at AZEF forum, because it is a smaller meeting, it is very relaxed and you know everybody, which is kind of nice as well (Anderson, interview).

In other words, the informal and intimate nature of the annual conference works positively towards establishing a community of researchers and practitioners interested in arid zone issues, as well as integrating young researchers, like post-graduate students, into this community. In fact, besides sponsoring many of the post-graduate students who attend the annual conference, AZEF also provides some incentives for them to participate:

We have an annual trophy and a money prize that go to the best paper and poster presentation by students. That's been going for a number of years. That is sponsored by the NRF and the Agricultural Research Council (Anderson, interview).

\section{$4 \quad$ Promoting research utilisation}

As its primary activity, the annual conference embodies AZEF's endeavour to promote awareness of problems and threats facing arid zone regions in southern Africa, and to encourage sharing of ideas around possible solutions to these problems and threats. No formal conference proceedings are produced, except for an 'abstract book', which contains basic information about the presentations and contact details of participants. Nevertheless, developing strategies to disseminate arid zone research widely is a concern within AZEF and they are trying out different options:

What we are going to experiment with this year is to produce $a C D$ at the end of the meeting with [the papers of] those who are interested. So people 
who are happy to put their papers on this CD we will [do so], and we will make it available for a small amount - RI5 or R20 (Anderson, interview).

In addition, AZEF is also looking at ways in which its website could be used as a resource for arid zone researchers and practitioners. To this end, it is now encouraging researchers to submit information about their current research projects as well as publication lists to be put on AZEF website, so that those who are interested can contact the researchers directly, or at least get an idea of what literature and research exists on a particular topic.

According to Mr Anderson, promoting research utilisation is an issue that was discussed in depth at the last AZEF meeting. There has been a growing concern within the forum that perhaps not enough is being done by individual researchers to get research information across to practitioners, such as agricultural extension officers, conservationists and farmers, who have to implement the research results and ideas:

It is something we discussed in depth at our last meeting. Are the scientists working in the arid zone getting the information across to the right people? [ ] These would be people like agricultural extension officers and then the nature conservationists working on the ground. So it is really government. There is a concern that the information is not being put across and a lot of the information collected during formal research will be published in scientific journals. We actually had a round-table discussion at the last meeting, chaired by Prof Tim Hoffman, and myself and we want to try and encourage other ways of actually getting information across to the level where it needs to be implemented. And this could be through articles in more popular media, Farmers Magazine. Presentations to conservation departments, agricultural departments and so on - maybe workshops and so on. [ ] You find that people meant to be implementing research results may not be reading the formal scientific literature. But we are definitely looking at it. And I think the delegates that are attending AZEF actually have a fairly good track record of publishing in popular media and holding workshops and so on (Anderson, interview).

There is thus an awareness that disseminating strategies have to be broadened with a view to implementation and utilisation of research results. This means looking at publishing results in popular media and encouraging closer and more regular interactions and dialogue between researchers and practitioners. At the same time, there is an awareness of the constraints on researchers to achieve a lot of this:

At universities in particular it is very competitive as they are competing for funding. A publication in Farmers Weekly doesn't really count as much as a publication in an accredited international journal. So what is the motivation really for university professor to publish in a farmer's magazine? [ ] The problem is time as well. People are busy. Organising a workshop as well, we find the scientific researcher doesn't have the skill to do it. Doing research and writing a paper in a top international journal is very different to organising a workshop in a communal farming area for example. [ ] It is a gap that needs to be bridged (Anderson, interview). 
Although AZEF facilitated and encouraged discussion of this issue of promoting utilisation of research, it has not really proposed a role for itself in ensuring such utilisation. Instead, it is still seen as primarily the responsibility of the individual researchers and practitioners to implement research results:

The forum is open to anybody. Anybody who wants to can attend the meeting, they are more than welcome. So in that way agricultural extension officers, farmers, people in communal farming areas are welcome to attend and learn from the forum. But the problem is it is at a more scientific level and it may not be very appropriate. But the individual researchers and conservationists and extension officers that attend the meeting - it is their responsibility to implement the research findings. And it is not a fault of the people working in the arid zone; it is a fault all over the world. People doing the research very often academic research and often very useful as well. But does it filter down to the people on the ground? (Anderson, interview)

It seems then that AZEF sees its role as encouraging and suggesting ways in which individual researchers can go about promoting their research and making it accessible to those who should implement it, but does not see a role for itself in actually facilitating the utilisation of the research results.

One researcher who has had a long relationship with AZEF is Prof John Skinner, an animal ecologist at the University of Pretoria. Professor Skinner is a pioneering researcher on the springbok species. The springbok is an animal synonymous with arid zones in South Africa. Prof Skinner has been a regular participant at AZEF annual conferences since its inception, where he has presented various aspects of his research on springboks.

In the next section we provide a brief description of one of Prof Skinner's research projects, namely "Reproduction in the springbok". We consider how AZEF views his research and also reflect on Professor Skinner's interaction with AZEF and its impact on the industry, the benefits he has derived from his involvement in AZEF and what he sees as the role and value of AZEF to other arid zone researchers.

$5 \quad$ A researcher's view: Professor JD Skinner, University of Pretoria Professor JD Skinner started his research into the springbok as early as 1968. He has investigated various aspects of the species and in 1996 got funding for four years from the NRF for a research project looking specifically at "Reproduction in the springbok Antidorcas marsupialis". He led a team of researchers that included his son, who is a research fellow at Cambridge University, one post-graduate student and two assistants. The project focused on husbandry practices of the springbok with a view to improving the reproduction of the species. In particular, the project was interested in determining the factors that would enable the springbok to breed more frequently in one year. Professor Skinner describes some of the aims and objectives of the research:

The broad aims of that project were to delve into the Springboks secrets because the Springboks are a very interesting species in the sense that [ ] it's an a-seasonal breeder, so you can breed with the Springbok at any time of the year, unlike many of the game animals who are very fixed in their seasonal breeding so you can't do anything about improving the breeding. 
Springbok for example can have two lambs in one year, because there gestation period is only 6 months so you can exploit the species heavily if you know all the secrets of what switches it on and off and this was one of the aims of this project to delve into that and in fact we found very startling results which were the first ever discovered in this context. [] The intention was to improve the husbandry methods so that the farmers could get a better production per hectare, to get the animals to breed as fast as possible all the time (Skinner, interview).

Prof Skinner describes this research as "eco-physiological" research which is both basic, in that it looks at reproductive physiology of the springbok, and applied, in that it looks at the application of husbandry practices to springbok. Mr Anderson from AZEF, acknowledges the value of this research, particularly to game farmers, especially those who breed springbok for the export market:

The springbok is obviously a very important animal in the arid zone. They use farm width quite extensively and more and more farmers are using them for [meat exports]. [ ] And the knowledge about the species is very important in order to have a successful farming operation. Things like sex ratios and how many males to females and so on. So the information Skinner has gathered over the years have contributed towards the success of many of these. I don't think there is a single farmer in the Karoo that doesn't have springbok (Anderson, interview).

Prof Skinner points out that the application of the research results has also ensured that the springbok has never been under threat of extinction:

In 1962 when they did a big survey of Springbok in the Karoo, there were some 80 thousand and the estimate is that there are [now] about I.2 to I.3 million and this is largely because of the heavy research that has gone on about the species and we've given feedback to the farmers (Skinner, interview).

Ensuring the application and utilisation of the research was thus always an integral part of the research process. Prof Skinner describes having ongoing discussions with big farmers in the game industry and holding regular 'springbok workshops' with farmers. According to Mr Anderson, Prof Skinner also publishes extensively in the popular media such as farmer's magazines and environmental magazines. In addition, he consistently presented his research results at $A Z E F$ annual conferences.

\section{Role of AZEF}

It seems that Prof Skinner is perhaps exceptional in the strides he has made to get his research results popularised and implemented. Nonetheless, he does appear to value the interactions he has had with researchers in AZEF and gives some credit to the role AZEF plays in providing a space for him to disseminate his research, particularly to potential users of the research:

[The benefit of AZEF] to me it is that I have a forum in which I can express and show my results and discuss those results and get feedback from people belonging to AZEF who are interested in these results. So I get feedback and 
criticism and comments and constructive suggestions and that sort of things. But [AZEF] don't utilise the results of my research, they merely provide a forum where $I$ can tell the utilisers about it. The utilisers are the research scientists as well so there would be people who are interested in Springbok research and game ranching, etc. and they would be attending these meetings. Professor Skinner also acknowledges the role AZEF plays in keeping people informed about current research: Well [AZEF's] role would be largely to keep all the researchers informed and co-ordinate, informally, but so that you know what everyone else is doing so from this point of view it is highly advantageous and it is highly beneficial to belong to them. [ ] Yes, it is a very significant role that AZEF plays keeping everyone very well informed. We will know about the research long before it may be published for example (Skinner, interview).

Prof Skinner further highlights the added value of the informal nature of AZEF gatherings: $A Z E F$ is a hugely important body for informally co-ordinating research, without rules in AZEF, but just by mixing with your fellow scientists and colleagues on a very friendly basis and listening to them and perhaps offering some constructive criticism on their projects and they on yours, you reach a much more effective goal, your results are being much more effective in the overall end and AZEF plays a major role in this and it certainly is growing amongst the Arid Zone scientists and the farmers who are qualified and can benefit from this sort of meeting. AZEF is certainly increasing in stature and it is shown by the numbers who are attending these meetings every year. (Skinner, interview)

These sentiments by Prof Skinner resonate with those expressed by Mr Anderson from AZEF, and reflect an aspect of researchers' professional lives, the informal interactions with other researchers, that is perhaps very often underestimated when considering factors influencing knowledge production and utilisation.

\section{$6 \quad$ Concluding remarks}

AZEF is an informal network, initiated by the NRF, that provides a forum for arid zone researchers and practitioners to get together to share ideas around innovations and debate solutions to commonly experienced problems within arid regions. It gets limited funding from the NRF which is used primarily to cover the cost of hosting an annual research conference. Participants at the conference include researchers, government officials from agricultural, environmental and conservation departments, and about $10 \%$ of participants are arid zone farmers.

Much thought is given to the location and format of the annual conference. The conference is usually located in small rural towns, with little to distract participants from conference activities. Formal and informal interactions between participants are equally valued and hence many opportunities for both forms of interaction are created. These include formal presentations, field trips, formal and informal round-table discussions and general socialising. The nature of the research presentations usually allows for the optimal participation of all the delegates, ranging from researchers to practitioners. The informal 
and intimate nature of the annual conference contributes towards establishing a community of researchers and practitioners interested in arid zone issues, as well as integrating young researchers, like post-graduate students, into this community.

AZEF sees itself primarily as a forum that promotes awareness of problems and threats facing arid zone regions, and that encourages sharing of ideas around possible solutions to these problems and threats. Conference activities are only reported in a booklet with abstracts of the research papers and it is only recently that AZEF is beginning to develop space on its website to publish some of the research papers and compile CDs of full conference proceedings. With respect to promoting research utilisation, AZEF sees its role as encouraging and suggesting ways in which individual researchers can go about promoting their research and making it accessible to those who should implement it, but does not see a role for itself in actually facilitating the utilisation of the research results.

From the perspective of researchers, AZEF provides a space for them to disseminate their research, particularly to potential users of their research, and to network and establish relationships with researchers and practitioners in the field. The value placed on informal interactions within the forum creates a picture in which participants are made to feel at ease and part of a family. In other words, AZEF becomes a sort of 'home' for arid zone researchers and practitioners, where they feel comfortable talking about their work to people whom they know are interested in what they do and can give them constructive feedback on their work.

This case study suggests that AZEF plays a limited role as an intermediary agency: while it creates a forum for dialogue between arid zone researchers and practitioners, it has not yet developed particular strategies to include more arid zone farmers or to give voice to their particular research needs; it is still exploring ways to disseminate research findings more widely; and it is yet to carve a role for itself to actively promote the utilisation of research. 
List of data sources

Telephonic interviews

Mr M Anderson, Chairperson, Arid Zone Ecology Forum (July 2004)

Prof JD Skinner, University of Pretoria (July 2004)

Website

http://www.nrf.ac.za/azef 
MINI-CASE STUDY 8

SOUTH AFRICAN COMMUNITY EPIDEMIOLOGY NETWORK ON DRUG

USE (SACENDU)

A network of researchers, practitioners and policy makers concerned with establishing trends, risk factors and consequences of alcohol and other drug use

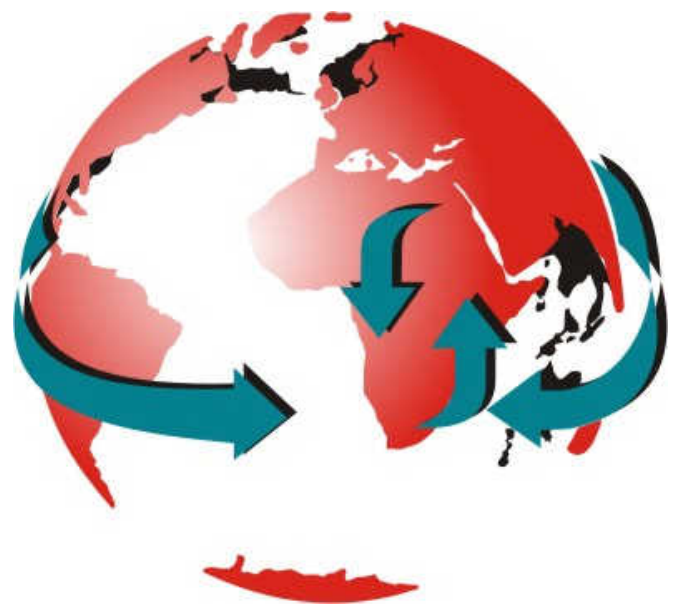

Logo courtesy of South African Community Epidemiology Network on Drug Use

\section{Acronyms}

SACENDU

AOD

MRC

NIMSS

ADARG
South African Community Epidemiology Network on Drug Use

Alcohol and Other Drug

Medical Research Council

National Injury Mortality Surveillance System

Alcohol and Drug Abuse Research Group 
It is perhaps not a well known fact that the economic cost associated with alcohol abuse in South Africa is estimated to be in excess of $\$ 1.7$ billion per year (Parry, 2004). If we include the cost of the abuse of other substances, this figure will be dramatically higher. What costs, you may ask, contribute to this figure? Local and international research have shown that substance abuse is a contributing factor in many chronic medical disorders, which often leads to long term medical care, treatment and costs, which in turn can lead to loss of employment and income, and even early mortality. In addition to the medical effects, the abuse of alcohol and other drugs has increasingly been associated with incidents of violence and crime in society, which also carry economic costs. Perhaps more difficult to quantify is the effect that the abuse of alcohol and other drugs has on the general fabric of society, for example, the social and psychological impact on families and the youth in society, and the general health of the population.

There are of course many organisations that are involved in treatment, monitoring and research, related to alcohol and drug abuse. The South African Community Epidemiology Network on Drug Use (SACENDU) is one of these organisations. SACENDU is a network of researchers, practitioners and policy makers that contribute to providing community-level health surveillance of Alcohol and Other Drug (AOD) use trends and associated consequences, through the presentation and discussion of both quantitative and qualitative research data (SAhealthinfo website). SACENDU provides descriptive information on the nature and pattern of AOD use, emerging trends, risk factors associated with AOD use, characteristics of vulnerable populations, and consequences of AOD use in South Africa (SAhealthinfo website).

In this case study report we describe the activities of SACENDU and reflect on the nature of the network and the contribution it makes towards dissemination and utilisation of substance abuse research. We also consider the relationship that one prominent researcher has established with SACENDU. In particular, we describe his research in the National Injury Mortality Surveillance System, at the Medical Research Council (MRC), and reflect on his relationship with SACENDU and the mutual benefits of this relationship.

\section{South African Community Epidemiology Network on Drug Use SACENDU and the MRC}

The MRC has structured its research into six National Programmes according to highpriority areas identified by Government and in keeping with international trends. Further focus areas have also been identified within each National Programme (MRC website). One of these National Programmes is titled Environment and Development ${ }^{17}$. Within this programme, there are five research groups, one of which is the Alcohol and Drug Abuse Research Group (ADARG). SACENDU is a special project of the ADARG. The head of this research group, Dr Charles Parry, is also the National Director of SACENDU project. The MRC and the School of Psychology at the University of Durban-Westville established SACENDU in 1996 with technical support from the United States National Institute on Drug Abuse (NIDA). The United Nations Development Programme (UNDP) initially

17 The other National Programmes are titled: Health Systems and Policy; Non-Communicable Diseases; Infection \& Immunity; Molecules to Disease; Women \& Child Health 
provided financial support for this project. Financial support for Phase 8 (January - June 2000) was provided by the Gauteng Department of Welfare and Population Development, and the Mental Health and Substance Abuse Directorate of the National Department of Health (MRC website). The financial contribution of the MRC to the salaries of the National Director of SACENDU and researchers within the ADARG, serves to subsidise part of SACENDU project.

Dr Parry describes the relationship between SACENDU and the MRC as follows: SACENDU is a network. It doesn't have a bank account; it works through the MRC really. [ ] The MRC is clearly the driving partner behind SACENDU. We set up quite closely with a guy called Arvinc Bhana at the University of Durban Westville and Arvinc now works for the Human Science Research Council. And I have always really seen him as a co- director of this project. When we write proposals there is myself and a colleague at the MRC and Arvinc. So it goes out under the banner of the MRC but SACENDU is more than just MRC. [ ] The ownership [of SACENDU] is bigger than us [MRC] and there are different levels I suppose (Parry, interview).

\section{Management and funding}

In addition to a National Director, SACENDU activities are managed by regional coordinators who are located in the five 'sentinel urban sites' in which SACENDU data is collected, namely, Cape Town, Durban, Port Elizabeth, Mpumalanga and Gauteng. Funds are used primarily to cover the costs of collecting data in these different sites, conducting six-monthly regional meetings in different centres and producing reports every six months to disseminate the data.

\section{Members of the network}

SACENDU comprises a network of researchers, practitioners and policy makers that make up a group of people who either contribute information to the network or use information from the network:

They would principally be people who could provide information about patterns of alcohol and drug use in the country or the consequences of the abuse of alcohol and drugs, and also people, if they can't provide the information, it might be people who use the information such as people in national and provincial government (Parry, interview).

Interestingly, not only researchers contribute information:

The information mainly comes from alcohol and drug treatment centres. There are about 55 of them. Those people would be people who manage or who work in the treatment centres. They may or may not be researchers. We also get information from psychiatric hospitals, from the police. They do forensic analysis of drugs in South Africa. So they are more chemists rather than researchers. There are researchers that do school surveys, community surveys and so on. It is a broad mix of people including government officials and people who fund treatment centres and people who work in NGO's (Parry, interview). 
There is no membership fee attached to the network. Dr Parry describes the network as "an open system", in which there has always been a core group of people involved, with additional people coming in and out at different times. The latter are particularly researchers who do short studies or surveys on some or other substance abuse within specific groups of the population, say school students. They are then involved in the network for the duration of their study.

\section{Relationship with government}

SACENDU's relationship with government has not only been about receiving financial support in the past from both the National Department of Health and the Gauteng Department of Social Services. Data from SACENDU project have been presented to a range of sectors within government and have not gone unchallenged:

It's been challenged sometimes by government. We presented it to parliamentary groupings; I presented it to Minister of Health. We presented it to the speaker of the provincial government in the Western Cape. They are doing a special section on methamphetamine, and we just pulled out the "Tik" data and we looked at what has been happening in Cape Town over the last three years with Tik. So it has been very versatile (Parry, interview)

In addition to these presentations, for the past two years, the National Department of Social Development has also provided funds for a small contract that involves the use of SACENDU data:

South Africa reports to the United Nations on drug trends and the last two years we were commissioned to fill in the annual report to the United Nations using SACENDU data amongst others. [ ] It is a reasonably close relationship [with government] and I don't want to blow it up more than it is (Parry, interview)

National and provincial government departments thus form a significant proportion of users of SACENDU data and it is encouraging to find that some of them are prepared to commit financial resources to the continued collection of data for this project.

\section{Activities/services offered}

SACENDU activities can be directly related to its objectives. The first of these objectives is "to develop networks of local role players in the substance abuse area" (MRC website). To this end, SACENDU organises meetings every six months in its five sentinel sites across the country. At these meetings, the diverse members of the network have an opportunity to interact with each other and share information around drug use and abuse:

The benefits for them are things like networking because they get to mix with people they wouldn't normally interact with. So a treatment provider may interact with a chemist or a police officer or a researcher who has done community research. So there is networking and they get exposed to the latest information because we collect information on a six monthly basis. [ ] That is quite fresh and they feel they are on top of getting the best information. And I suppose there is an opportunity to contribute and learn from others (Parry, interview). 
The second and third objectives of SACENDU are "to identify changes in the nature and extent of AOD abuse and emerging problems" and "to identify changes in alcohol and other drug-related negative consequences" (MRC website). In order to achieve these objectives, SACENDU collects, and then collates and analyses, data from a range of sources.

Dr Parry lists some of these data sources and describes what they are used for: We want to look at changes in patterns of alcohol and drug abuse. So we look at the treatment data and the police data and if there is survey data but there usually isn't survey data. And we use that and how people are using that and how is that changing over time. And we are also very interested in consequences of drug use. So we look at the mortuary data and at the arrest data and the trauma unit data and people with foetal alcohol syndrome. So we are looking at use patterns and consequences. Then we draw up on that and identify risk groups and policy recommendations and things (Parry, interview).

The treatment data referred to above include substance abuse data reported by specialist AOD treatment facilities as well as acute psychiatric treatment facilities. Police data include "data obtained from local branches of the South African Narcotics Bureau (SANAB), Crime Information Analysis Centre (CIAC) and the Forensic Science Laboratory (FSL)" (MRC website). In a later section we will look more closely at how this data gets collected.

The fourth SACENDU objective is "to inform policy, planning and advocacy efforts at local and other levels" (MRC website). This objective is achieved through the many presentations of SACENDU data to government officials described earlier. Dr Parry gives an example of how SACENDU responded recently to a special request from the Deputy Minister of Social Development:

For example we had the new Deputy Minister of Social Development - Jean Benjamin. And she is now big on dealing with Tik 18 in the province here [Western Cape]. And she came to us and said what has your research got to offer me as a deputy minister trying to do something. And we sent her one of our reports that was already finished. [ ] What she said is this is now six months old, I need fresh stuff, so then what we did is we quickly analysed the first half of this year, quicker than we would normally have done and we produced a special briefing document which we presented to the provincial legislature last week, which looked specifically at what is happening now and we incorporated policy recommendations. [ ] I went to the States last month, in June. And with Tik coming up from out data system I used that opportunity to ask people so what should we be doing about Tik. And then we were able to make a tailor-made report for her, including SACENDU data and take it a little bit further and offered policy suggestions. So we have done that quite a bit (Parry, interview).

18 Tik is the local name given to methamphetamine. 
The last two SACENDU objectives relate to stimulating "research in new or underresearched areas" and to participating in "international fora focusing on the epidemiological surveillance of drug abuse" (MRC website). With respect to the former, Dr Parry claims that it is through the lobbying from SACENDU that research studies relating to 'drugs and trauma', 'drugs, crime, violence and injury' and 'drugs and school students', have been undertaken by other researchers at the MRC and researchers associated with SACENDU. With respect to participating in international fora, Dr Parry mentions quite a few visits overseas, for example to the United States and to Vienna, but these do not seem to be through formal links with SACENDU.

\section{SACENDU's involvement in research}

SACENDU's core involvement in research is commissioning the collection of data, which it usually sub-contracts to researchers 19 in its various sentinel sites. In addition, particularly through the participation of the ADARG, SACENDU also conducts research, sometimes based on the collected data, and sometimes based on new data. Occasionally, SACENDU has also lobbied successfully for funds to commission research outside of SACENDU brief, but still related to substance abuse.

\section{Collecting data}

SACENDU data are collected every six months in the five identified sentinel sites. Data are collected from a variety of sources, some primary and some secondary sources. The biggest set of primary data comes from treatment centres:

The main core is the collection of treatment data. It is the demand for treatment services. Every six months, maybe 5000 or 6000 people go to treatment in the 55 treatment centres where we collect data. We have a standardised form and it gets collated and that is the core research. And we access police data and we get data from psychiatric hospitals that are more secondary data (Parry, interview).

Collecting the data from the treatment centres takes a lot more organising than accessing, for example, police data:

We print forms and we deliver them to the treatment centres every month or so. And they fill them in and we either put the data on our computer here or our sub contractor e-mails us the data. That is primary. But the police data is part of their system and they just send us a summary one-page report, which collates all their data for the six-month data collection period. We are just accessing other people's data in that sense (Parry, interview).

It is the collection of the treatment data that is most expensive, and so there are always attempts to save costs where possible:

Cape Town is easy - I am based in Cape Town so my staff already contacted the treatment centres and collect the data and analyse the data as part of our own expenses. We are in charge of that. But then in Gauteng it is quite a big job. Long distance is involved. We actually commission someone who has been doing it for five or six years to do that for us. The

19 Researchers are actually sub-contracted to the MRC to do this research. 
same in Port Elizabeth and Durban. In Mpumalanga our facilitator there runs it. She works for the government so she can collect the data from the treatment centres as part of her job. So there is no real need to fund her (Parry, interview).

Other members of SACENDU network are drawn into the research process by providing data that they collect for themselves:

Some other people are collecting data as part of their own work like the Mortality Surveillance System ${ }^{20}$ and so we just draw them into the network and get them to present and in a way donate their information. Then we pull it all together and compare data across different sources. We have got our core data, which is treatment data and police data and psychiatric data, and we add in other things (Parry, interview).

Even though SACENDU is more interested in longitudinal data in order to observe patterns and trends, occasionally they do incorporate data from 'snap-shot' surveys:

If you look through the proceedings you will see there is all kind of school surveys and community surveys. People from an organisation called "RAVE save" we quite often get them to present. They collect data at Rave parties. And so we are always on the look out for people to present their information. Obviously it is nicer if it is like the Mortality Surveillance survey, which is not just once off. We are open to once off surveys as long as they took place during the six-month period we are reporting on. [ ] Someone gave a presentation on Alcohol and HIV, a one off snap shot. That is interesting in its own right because it tells us about alcohol abuse in a certain group of people, HIV patients and the burden on them. They have more alcohol dependence than non-HIV patients. But that is not our first prize. Our first prize is for it to be longitudinal data. (Parry, interview).

The biggest challenge to SACENDU is collating the data from the different sources and putting them together in ways that can be meaningfully analysed and reported. For example, even adding together data from different treatment centres within the same province can pose a challenge:

You can loose a lot by adding data and what we find with our study, if you add all the data you miss local variations. [For example], your cocaine was used by criminals in Sea Point but they are using dagga in Khayelitsha. Adding them all together you get data that wouldn't be very useful. We are sensitive to differences. We do analyse the data for example we used to do it all in one group but now analyse it separately again for people under twenty. And we find that is quite useful because they are a unique group of people. And we do analysis by gender and age and race. We even look at the data by suburbs sometimes (Parry, interview).

20 This is data collected from mortuaries. 
The data from other surveys are perhaps the most difficult to deal with and occasionally, special requests have to be made for this data to be included in SACENDU reports:

We do emphasize certain things. We don't want them to report on the whole country combined. We want them to fit in with our geographic area. [ ] So we will say: "please present on Cape Town" in our Cape Town meeting. They will then pull out all the Cape Town data. [ ] Every year the [Injury Mortality Group] presents on their trends. But we tell them to focus on the alcohol stuff and not tell us all the other things that will take time. [ ] Someone else did a study of sexual risk behaviour - it was the WITS reproductive health unit. They included a few questions on substance abuse. I will for example go back to them and say can you please give me more data on substance abuse and would you like to present it at our meeting (Parry, interview).

While collecting data from so many different sources is challenging, it is a crucial component of SACENDU's mission since the data enable SACENDA to report quite extensively on alcohol and drug use patterns and trends (taken from its treatment data and other surveys), as well as the consequences of alcohol and drug use (taken from its police and mortuary data). In the next section we look at how SACENDU reports on this data.

\section{Reporting on the data}

SACENDU data are reported in three main forms - oral presentations, published reports, and journal articles.

Every six months new data is presented orally in each sentinel site and compared to the data from the previous six-month period. The presentations are standardised across sites and take the form of normal conference presentations. Dr Parry describes the focus of these presentations:

We try to compare it to the previous six-month period. So you can look at trend data, across different sources, across treatment centre data and then looking at how that compares to police data and to the mortality data and survey data. [ ] And there are graphs, which plot the demand for treatment by different drugs, the changes in terms of age, gender, racial differences between the population and people in treatment, so they can identify absent policy implications. (Parry, interview).

All network members in these sites attend the meetings and have an opportunity to discuss and critique the findings. A range of SACENDU associated researchers do presentations. After these meetings various reports of the data are published on SACENDU website. The reports include summarised and aggregated data, as well as the raw and disaggregated data:

There is a report that goes out about three weeks after the meetings was held, which is a two page summary which is called a SACENDU Update. And then it takes a bit longer to produce - we put a twelve-page overview by sites and by drug and so on, in tables. That twelve pages goes out about two and a half months after the meeting. And then at the 
same time we mail the full proceedings of all four meetings ${ }^{21}$. They can look at the raw data in a sense. They are called SACENDU Brief and the longer one is SACENDU Proceedings. So you will see those also on the website (Parry, interview).

The authors of the reports are the researchers who do the collation and analysis of the data, as well as the co-ordinators in each of the five sentinel sites responsible for the collecting of the data.

SACENDU associated researchers have also produced at least ten journal articles, individually and collaboratively, based on the data collected over the years. The articles have focused on different aspects of the data:

They have written papers on for example individual drugs. There is a paper on dagga and mandrax and ecstasy and then there is one looking at the youth data over time, which just came out in the Journal of Adolescence. So you look at particular age groups across the different sources of data and we had done one on alcohol and injury (Parry, interview).

In addition to the above, SACENDU data have also been reported less formerly in the media. Dr Parry claims that they do between "30 and 40 interviews a year for radio, newspaper and TV'.

\section{$4 \quad$ Promoting research utilisation}

Key to the promotion of utilisation of research is identifying who the primary users are and then interacting with them in ways that make the research accessible and usable in their contexts. Dr Parry's views on utilisation of SACENDU's research reflect a heightened awareness of whom the primary users of the research are, how they can use the research and what SACENDU does to promote this utilisation.

Firstly, Dr Parry identifies people working in treatment centres:

The groups of users are endless, but let me give you primary users. Clearly I think treatment centres are very key so they can use it to inform the training of staff. If there are more of certain drugs being abused, like Tik [methamphetamine] what should they do differently? Maybe they should come up with treatment strategies for Tik. If the patient is getting younger they need to deal with that. So treatment centres and people involved in prevention work. Because there is not very good survey data they use our data to inform some of the things they do in terms of prevention (Parry, interview).

Often, individual treatment centres only see the value of their data when they are reflected in a SACENDU report:

Most treatment centres would not be collecting the data if it weren't for us. [ ] We added their data to the data of all the other treatment centres. [ ] Hopefully we are empowering them somehow. Sometimes they

21 Gauteng and Mpumalanga sites are combined into one meeting. 
do feel disempowered, the small treatment centre - I mean there are 22, 23 we are collecting data from in Cape Town. But then when we add it together and it gets fed into the media. They read the front page and see their data is part of it. I am not just talking about I 50 people; we are now talking about 3000 people treated in Cape Town. And 20\% have Tik as their drug of abuse, it becomes a lot more powerful and we can perhaps lobby for resources (Parry, interview).

A second group of users identified by Dr Parry are policy makers. Here he explicitly talks about adapting SACENDU presentations for policy makers:

Policy makers at a provincial level they use it, in health and welfare. [ ] We were able to make a tailor-made report for [the Deputy Minister of Social Development], including SACENDU data and take it a little bit further and offered policy suggestions. So we have done that quite a bit. I suppose it is helping to make up the gap between research and policy - I presented it to one of the committees in parliament. You obviously have to tailor make what you give to them. You can't just use the same presentation that you would [in other places]. So I think SACENDU does try to help translate research for policy makers. And we are also now producing some policy briefs (Parry, interview).

A third group of users are researchers:

People say they want to do a research project - every six months we identify research needs coming out of the project [SACENDU] and so we now have $a$ whole list of things people now want to do, masters students and so on. And we say here are the topics that have been identified as gaps; we don't know the answers to these questions. That is another group of users (Parry, interview).

Dr Parry acknowledges that, in addition to the groups mentioned above, all the network members are users of the research, including those who contribute from their own data. As such, the interaction with network members at the six-monthly meetings also constitutes feedback from users. In this regard, SACENDU have always been responsive to comments and suggestions from network members at these meetings:

The forms have gone through many changes over the years up to about 22 questions. But now there are about 18. But some of the questions don't work. They [network members] say drop this question because you will be getting useless information or add this. So we need to add information on who is paying for treatment and so we added that. We are very responsive. [ ] There is a lot of time for discussion. So a presentation is given and there is time to critique the information and people would say you really need to add this. And it is changing - even how we report data. We used to report methamphetamine on its own. It went under "other" because it was so rare. But now we are actually reporting it as a separate category. So it evolves (Parry, interview). 
Being responsive to users is often a very effective strategy to promote research utilisation. An equally effective strategy is to get users to 'buy in' to your research ideas before you implement them. Dr Parry gives an example of how he has done this in the past:

Sometimes I will go overseas and come back with a nice interesting report on how to deal with certain drugs. And we will photocopy it and when Pam goes to collect the forms [from treatment centres] she will hand it out as well. We try to make people feel part of an end group who are sharing this information. We got to have some standardisation. We can't change things too much (Parry, interview).

Finally, the way that SACENDU invites new researchers to share information and become part of the network, can be viewed as another strategy it uses to promote research utilisation in that, it expands the scope of its data and the number of potential users. Dr Parry describes for example, how researchers working with injury and mortality data at the MRC, became involved in SACENDU:

Basically we heard about the study and invited them to one of our six monthly meetings. And realised this is a very useful source of information and the people who presented was also useful people to have in the network. So we had Deon Knobel the forensic pathologist for Cape Town and Richard Matzopoulos, and they could not only present data but they could also enter into the discussions that we have every six months (Parry, interview).

In fact, one of these researchers, Mr Richard Matzopoulos, has been working on the National Injury Mortality Surveillance System (NIMSS), set up at the MRC, since 1998. The NIMSS collects data specifically from mortuaries and records causes of deaths for non-natural deaths. It uses this data to develop indicators for injury and mortality, one of which is the presence of alcohol in the body, and it is this data specifically that has been used by SACENDU.

In the next section we provide a brief description of Mr Matzopoulos' research work in the NIMSS. We consider how SACENDU views this research and reflect on Mr Matzopoulos' interaction with SACENDU.

A researcher's view: Mr R Matzopoulos, National Injury Mortality Surveillance System, Medical Research Council

In 1998, with funding from the Department of Arts, Culture, Science and Technology's Innovation Fund, the MRC initiated the NIMSS project. Mr R Matzopoulos has been one of the researchers on this ongoing project since it started. The main objective of the NIMSS is to monitor non-natural deaths from 17 urban and 14 rural mortuaries in South Africa in order to provide ongoing and systematic information about the incidence, causes and consequences of non-natural deaths. This data was seen to be valuable for a number of reasons:

Nobody was collating this routinely collected information that would be very useful for prevention agencies and there were examples from elsewhere in the world where this information has been put to good use and we decided to follow that example. [] The database would also be expected to help 
forensics services with their planning and service delivery. It would have tied into the national crime prevention strategy as well. It was obviously going to be very useful for prevention agencies because they didn't have that quality of information available from other sources (Matzopoulos, interview).

Mr Matzopoulos explains why this kind of data was not routinely collected before: In 1999 there was a bill passed to remove detailed information of the external cause of injury from vital registration so if it was a natural cause of death it would have detailed information about the disease. [ ] But for external causes it would just be marked as unnatural or not natural. [ ] And they were relying on people completing page two of the death certificates where they would get into specifics. [ ] Also there was reluctance on the part of some pathologists to fill in that information under the Inquest Act because it was seen as a legal document. There were some problems with it. So we basically were trying to fill a gap and provide information for the injury prevention sector (Matzopoulos, interview).

The research process involves all the participating mortuaries filling in data collection instruments prepared by the NIMSS researchers. In some cases, mortuaries complete these forms electronically, and in other cases they forward the data to the MRC. The NIMSS researchers clean the data and then produce quarterly descriptive reports for each mortuary and an annual report that reflects data from all the facilities. The reports contain a range of information:

On different types of injuries, what the caseload was, how many pathologists, which pathologists did cases and how many toxicology analysis, main causes of injuries. The scene and location of most of the injuries, dates and times of injuries - all the variables that are on the NIMSS form (Matzopoulos, interview).

According to Mr Matzopoulos, more than 50 agencies have used their data so far. SACENDU is one of those agencies. Mr Parry describes why the NIMSS data has been a valuable contribution to SACENDU:

Basically to provide another source of information, in particular, on the burden from alcohol use. They provide data on the proportion of deaths that are alcohol positive or above 0.05 and they break that down by certain causes of death. So you see there is a higher rate of fatality for traffic deaths versus accidents versus homicides. So we compare that with what is happening with alcohol from our treatment centre data or the injury data from surveys (Parry, interview).

For the NIMSS researchers, it is not unusual for agencies to be interested in only certain sub-sets of their injury and mortality data. In fact, they frequently produce "customised reports" for smaller prevention agencies:

[A] group of people are looking at child injuries and burns which are major causes of injury among young children. Pedestrian injuries among children, car seats programmes, poisoning data, we have done customised reports on drowning. Each industry cluster or gender as well, some of the variables, 
cross cutting variables would prompt prevention agencies to want customised specific analysis. So we cater to quite a wide variety of agencies (Matzopoulos, interview).

In their report to SACENDU, the NIMSS researchers responded to a request "for a city level analysis of alcohol data, which is a very routine thing, which we have supplied to them in the past" (Matzopoulos, interview). Mr Matzopoulos insists that in these reports to outside agencies, the NIMSS researchers only provide statistics:

We don't provide data. We just provide statistics. We hold on to the data and we have a request form, which people would need to fill out for data. [ ] And we evaluate those on the merits and obviously it's got to be used for prevention and not for personal gain or profit. [ ] We seldom give out raw data. It is subject to ethical approval and that kind of thing. Obviously there is confidential information in there, and typically if we would release it we would "anonomise" it as well. We don't routinely give out data (Matzopoulos, interview).

According to Mr Matzopoulos, the statistics are used particularly by lobbying agencies, such as Gun Free SA22 for example, and are useful for press releases because of the impact they often have in the public domain. From Mr Matzopoulos' comments, it appears that the NIMSS researchers are very conscious of the potential users of their research and are more than willing to accommodate users' needs in the ways that they report on the injury and mortality data.

\section{Interaction with SACENDU}

Mr Matzopoulos claims that there is no formal relationship between NIMSS and SACENDU and reports on the interaction between NIMSS researchers and SACENDU members mainly at the regional meetings of SACENDU:

[SACENDU] have meetings I think a couple of times a year at least. We would be invited to those meetings whenever we had new data to present. They would collate and compile it and show trends and stuff like that. We would just present the latest findings (Matzopoulos, interview).

Mr Parry however, reports on other forms of interaction as well with NIMSS researchers:

I have lunch with Richard [Matzopoulos] quite often. But we let them get on with their stuff. We obviously have been involved in writing journal articles with them. Sometimes they got to write an article, which they wouldn't have done if we hadn't worked with them. We had to re-analyse their data and they get co-authorship. And influence their methodology. [ ] We wrote a paper on alcohol. And then we got the data from the treatment centres, from the mortuary data, the school data, [ ] and the injury data and wrote it up in one single paper. And then they get co-authorship (Parry, interview).

\footnotetext{
22 See Seedat and Nascimento (2003) for a discussion on how Gun Free SA used NIMSS statistics in their lobbying programmes.
} 
It would seem that, while NIMSS researchers gain extra publications from working with SACENDU, SACENDU is the main beneficiary of this association with NIMSS researchers. SACENDU is able to expand the scope of its reports to include alcohol related injuries and deaths, it gets additional information against which to compare its treatment data, and SACENDU researchers are able to extend the repertoire of articles they produce on the consequences of alcohol abuse.

\section{$6 \quad$ Concluding remarks}

SACENDU is a network of researchers, practitioners and policy makers concerned with the uses and consequences of abuse of alcohol and other drugs. Members of the network comprise both users of, and contributors to, SACENDU data. The network is driven from within by a strong research group at the MRC, which accounts for the emphasis that SACENDU places on the systematic collection of appropriate data and the analyses of patterns and trends of the uses and consequences of abuse of alcohol and other drugs. While the MRC subsidises SACENDU, it also receives some funding from the National Department of Health.

SACENDU collects, collates and analyses primary and secondary data from a range of sources. Data sources include members within the network and researchers outside of SACENDU. The range of data that SACENDU collects enables it to report quite extensively on alcohol and drug use patterns and trends (taken from its treatment data and other surveys), as well as the consequences of alcohol and drug abuse (taken from its police and mortuary data).

Updated SACENDU data are reported at specially organised meetings in different regions across the country every six months. At these meetings researchers, practitioners and policy makers have the opportunity to interact with each other and network, as well as discuss and critique SACENDU data and research results. The interaction with network members at these meetings provides valuable feedback from users and enables SACENDU to be responsive to comments and suggestions from network members. This often results in the addition of new data or the initiation of new research projects.

Subsequent to these meetings, SACENDU data are disseminated on its website in three different forms: two page summaries; longer overviews of results by sites and by drugs; and full proceedings containing all the raw data. In the past few years, several journal articles have been written based on SACENDU data and the data are also regularly reported on in the popular media.

SACENDU promotes the utilisation of its research particularly to practitioners in treatment facilities and to policy makers. This is done primarily through ensuring firstly, that they all have access to the data and secondly, that aggregated and disaggregated data are presented which can inform treatment and policy actions. With respect to policy makers especially, SACENDU prepares special policy briefs and makes explicit policy recommendations based on its data.

From a researcher's perspective, being a part of the network, even for an interim period, presents an opportunity to disseminate research that could potentially be utilised by 
practitioners, policy makers and other researchers in the field. Researchers often benefit from co-publications with SACENDU researchers.

This case study suggests that SACENDU plays a significant role as an intermediary agency that: collects, collates and analyses data on alcohol and other drugs from a range of sources; provides access to, disseminates and engages with related research; is responsive to the needs of practitioners and policy makers in the field; promotes the utilisation of research; and facilitates interactions between researchers and users. 
List of data sources

Telephonic interviews

Dr C Parry, National Co-ordinator, SACENDU (July 2004)

Mr R Matzopoulos, Researcher, National Injury Mortality Surveillance System, Medical Research Council (July 2004)

Publications and documents

Parry, C (2004) The need for a science-based approach to addressing substance abuse in the Western Cape, MRC e-publication

Plüddemann, A (200I) The South African Community Epidemiology Network on Drug Use - SACENDU (Phase 8) - A Gauteng focus, MRC e-publication

Seedat, M. \& Nascimento, A (2003) The Use of Public Health Research in Stimulating Violence and Injury Prevention Practices and Policies: Reflections from South Africa, Journal of Prevention \& Intervention in the Community, Vol. 25 No. I, Hawthorn Press

Websites

http://www.sahealthinfo.org/admodule/aboutsacendu.htm http://www.mrc.ac.za/urbanbulletin/march200I/sacendu.htm 


\section{MINI-CASE STUDY 9}

\section{NELSON MANDELA FOUNDATION (NMF)}

An organisation committed to supporting social development research and programmes and creating platforms for dialogue between different social groups and agencies.

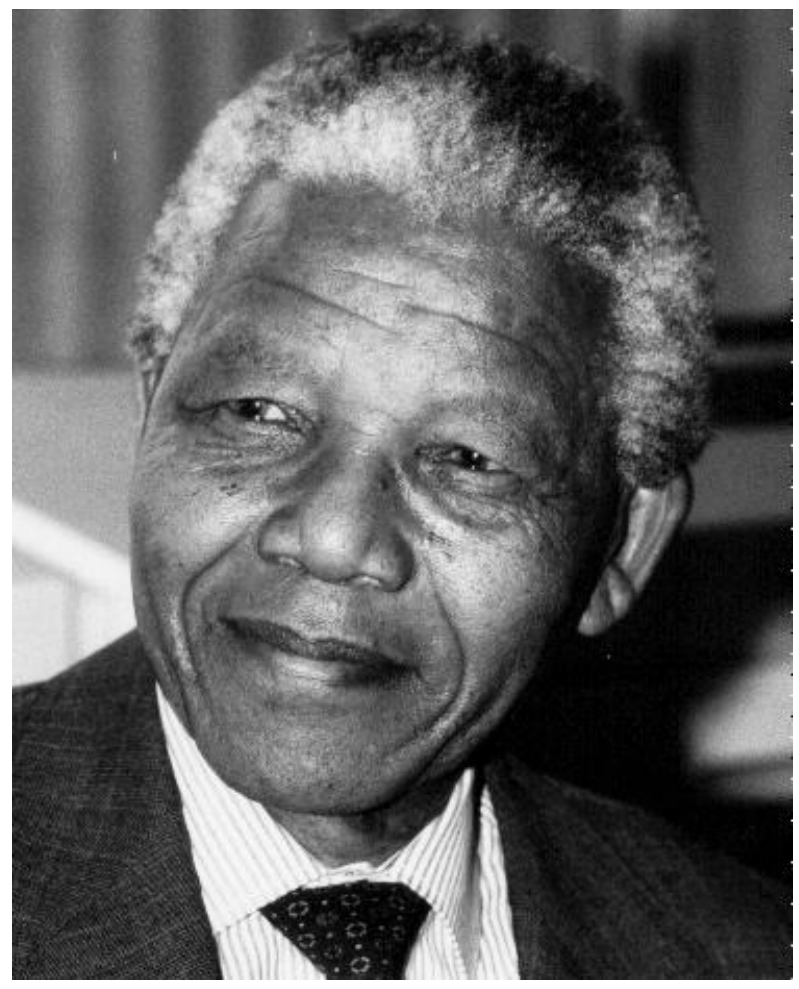

Photograph courtesy of the ANC website [http://www.anc.org.za/people/mandela/index.html]

\section{Acronyms}

$\begin{array}{ll}\text { NMF } & \text { Nelson Mandela Foundation } \\ \text { HSRC } & \text { Human Sciences Research Council } \\ \text { ARV } & \text { Anti-Retroviral } \\ \text { NGO } & \text { Non-Governmental Organisation } \\ \text { MEDUNSA } & \text { Medical University of South Africa } \\ \text { UNAIDS } & \text { United Nations AIDS Project } \\ \text { SADC } & \text { Southern African Development Community }\end{array}$




\section{$1 \quad$ Introduction}

According to the UNAIDS Report of 2002, it is estimated that more than 60 million people worldwide have lived with HIVIAIDS since it was first diagnosed in the 1980s, and 20 million of these people have died. The continued spread of HIVAIDS and the absence of a cure have compelled every country in the world today to implement policies and programmes to monitor the spread of the disease and to support the prevention and treatment of HIVIAIDS. In South Africa, over the last decade, HIV prevalence estimates have been largely derived from an annual survey by the Department of Health of pregnant women attending antenatal clinics, supplemented by additional estimates from workplace and other studies (Shisana \& Simbayi, 2002). Until 2002, there had been no studies that could provide estimates of HIV prevalence in the general population. There are studies, based on limited samples, which investigated risk factors for HIV infection, sexual behaviour patterns and level of awareness of the disease. The limitations of these studies make it difficult to make very accurate inferences to the general population.

This lack of information that could inform public health policies and programmes for the prevention and treatment of HIVIAIDS was recognised by the Nelson Mandela Foundation (NMF). The Foundation then initiated a major study that involved household surveys to determine HIV prevalence, behavioural risks and levels of knowledge and awareness of the disease. The initiation and support of this study is just one example that reflects the commitment of the Foundation to support social development research and programmes that "build capacity, influence policy, model innovation for social improvement and create platforms for dialogue between different social groups and agencies” (NMF website).

In this case study report we describe the programmes and activities of the NMF and reflect on the nature of the organisation and the contribution it makes towards dissemination and utilisation of social development research. We also consider the relationship that one prominent researcher has established with the NMF. In particular, we describe his involvement in a HIVIAIDS research project at the Human Sciences Research Council (HSRC), which was commissioned by the NMF. We reflect on his relationship with the NMF and the mutual benefits of this relationship.

\section{$2 \quad$ Nelson Mandela Foundation}

\section{The Foundation and its legacy}

Nelson Mandela founded the Nelson Mandela Foundation after he retired as President of South Africa in 1999. The purpose of the Foundation was to lead and direct the development of a living legacy that captures the vision and values of Nelson Mandela's life and work and through this contribute to the development of a just, peaceful and democratic world. The Foundation was to become the primary vehicle for Mr Mandela's continued pursuit of the ideals and goals he set while serving as South Africa's first democratically elected leader. Mr Mandela' involvement in health and educational development, his consistent voice on matters of public interest and his role as mediator in world conflict situations helped to shape and inform the planning for the Foundation. The immediate goal of the Foundation was to identify and work in programming areas where Mr Mandela could provide leadership and initiative. (NMF website). 


\section{Management and funding}

Nelson Mandela and a Board of Trustees lead the Foundation. The Board consists of individuals who have worked closely with Mr Mandela in the past and who are themselves well known for their contributions to the political, economic and social transformations that have taken place in South Africa. A Chief Executive Officer sees to the day-to-day management of the Foundation. An Executive Committee, five programme managers and of course administrative staff supports him in this task.

The Foundation embarks on regular fundraising campaigns, often led by Mr Mandela himself. Fundraising is normally focused around specific projects or programmes. Longterm donor funds for specific projects or programmes sustain the Foundation.

\section{Relationship with government}

The Foundation has no formal relationship with government. However, it frequently interacts with different spheres of government to inform the Foundation's programme planning, to support health, education and social development initiatives of government and, to influence government policies and interventions. Ms Bridgette Prince, the Programme Manager for HIVIAIDS at the Foundation, describes two very different examples of how the Foundation interacts with government - either to support government initiatives or to initiate interventions from government:

If you look at AIDS and Education - what the Foundation did was it did a situation analysis in the Free State because that has a very high prevalence [of HIV|AIDS]. And we did a situation analysis on what is currently in school, what are the mechanisms we can put in place to ensure that those children are protected and those who are affected are taken care of in the school. We are not going to do any of this, but what we are going to do is to present this to the Free State government and say these are the outcomes and the recommendations. This is how we can assist to bring you together with other stakeholders enabling that process to happen (Prince, interview).

[Government] started like a men's [HIVIAIDS] program, where they worked with men- through traditional leaders, churches etc. Now for this particular program we have partnered with the National Department of Health, because they don't have the money to do training for these guys, which the Foundation was able find. So we partnered with them at national level and we have a joint partnership in terms of the project (Prince, interview).

The Foundation also frequently interacts with government to disseminate and promote the utilisation of its research.

\section{Activities}

The role that the Foundation sees for itself in terms of its activities is described as follows in its Mission Statement:

The Foundation sees its role as a catalyst. It develops strategic alliances and partnerships in order to foster community engagement, community projectownership and community benefit in carefully selected sites. The 
organisation does not function as a traditional grant-making agency. Instead, using established programming parameters, the Foundation conceptualises and launches projects with credible and experienced implementation partners (NMF website).

According to Ms Prince, the Foundation has for example, used its research agenda to take on this role as 'catalyst':

Through research, the Foundation is able to put issues on the table that people are trying to ignore. Poverty is a good example. You see people reflect on yes there is still poverty, but it is not as it was in 1980's where it appeared on every single person's agenda. Access to health and education - and our focus within the Foundation is in the rural, poor and undeveloped areas (Prince, interview).

The Foundation also acts as a 'catalyst' when it launches new programmes and invites people from different sectors and perspectives to become involved:

When we entered into the AIDS arena, AIDS was extremely territorial because everybody is fighting for their little bit. And nobody wants to share. And through the utilisation of Mr Mandela's name we are able to bring together people that would ordinarily never speak to each other. So part of how we conceptualise the living legacy of Madiba is to be facilitative, a catalyst, coordinating mechanism so to us that is quite critical in the way we work (Prince, interview).

Developing models of best practice is another strategy the Foundation uses as a 'catalyst' for social interventions:

Before government rolled out Anti-Retroviral treatment the Foundation developed two models of best practice. One in Dzikiziki in the Eastern Cape because it is completely under resourced and very very poor. And our reasoning was very simple. Let's start this pilot site, let's start up this model. If this model works, government can replicate it very easily. And two: other organisations can too. What we did is we developed a model where nurses run $A R V$ treatment sites because essentially we are saying, if you are going to de-stigmatise the disease [AIDS] to say an ordinary chronic disease, then nurses must be able to manage it. And that is essentially what we have done in Dzikiziki. So in twelve clinics, there is one doctor that sees patients - only complications. The nurses have been trained to do the rapid test, to do counselling, to do identification and treatment of opportunistic infection as well as ARV treatment. So what we are essentially saying to the Eastern Cape is, here is the model, you can replicate it - it works (Prince, interview).

Currently, the Foundation has four lead programmes: Social Development, especially in HIV/AIDS and education; Peace and reconciliation; Leadership, governance and democracy; and Social giving and volunteering. The nature of the programmes is described as follows on the Foundation website:

Programmes are well-grounded in research and information, and are piloted, monitored and evaluated for impact. New knowledge gained from 
programme experience is disseminated appropriately so that valuable lessons can be learnt. In the process the Foundation develops capacity, influences policy through research and advocacy, builds institutions, models innovation for social improvement and creates platforms for dialogue between different groups and agencies (NMF website).

The programmes are run by Programme Managers who take most of the responsibility for: monitoring the progress and impact of the programmes; initiating new projects; finding appropriate partners to collaborate with; and for initiating interactions with government officials and other stakeholders. Collaborators on projects or programmes include researchers and implementing agencies like NGOs and government departments.

\section{The Foundation's involvement in research}

\section{Commissioning research}

The Foundation commissions and funds a wide range of research projects that fit in with their core programmes. Ms Prince alludes to at least two criteria for the types of research projects that the Foundation commissions. The first criterion relates to the value of the research for social policies and interventions:

Part of why we do research, and we will probably get to that later is the fact that we believe it has to impact on policy and it has to be incorporated into program planning. Because if it doesn't then it just becomes another book on a shelf. [ ] I can't repeat the fact enough that the Foundation will not engage with research that is just research. Just research that doesn't have any impact and use. Because we are not an implementing organisation so we can't use the research directly. But what we can do is do research on behalf of those organisations that can't do research and get them to internalise the findings and recommendations of that research to utilise in their programming or whatever (Prince, interview).

Here we see that research utilisation is an issue that is at the forefront of the Foundation's programme planning. The second criterion for the types of research projects commissioned by the Foundation relates to filling gaps and being innovative. Ms Prince describes for example, why the Foundation initiated the HIVIAIDS study:

We cannot also be seen as doing mediocre research. There is a lot of research going on. What we try and do is to focus on that that hasn't been done ever before, like your household studies [on HIV prevalence]. [ ] At the time nobody thought it would be humanly possible to do it. And the reason why the Foundation did it was because there was no accurate HIVIAIDS statistics. There was none - we were working off antenatal data here and there and workplace prevalence studies that have been done. [ ] I think the Foundation would spend a lot of time identifying something that will alleviate a serious problem in South Africa. [] So it's about taking things that are not normally done but that are able to give insight into a critical problem in South Africa (Prince, interview). 
The Foundation does not have a particular group of researchers that it commissions work to. Researchers are selected based on their expertise:

We don't have [particular researchers we work with] because it depends on the area of research and their track history in terms of doing it. A good example is we needed to have our treatment site evaluated and some research needed to be done for example is it fully operational and what is happening there. And we outsourced it to MEDUNSA - somebody based in Botswana (Prince, interview).

In the case of the HIVIAIDS project, the researchers came highly recommended: Madiba approached the HSRC and I can understand why. Because Professor Gerwel is the chair of the HSRC, he is also the chair of our board. $\mathrm{He}$ is also somebody who has worked quite extensively with Madiba. So Madiba would have felt that he is more familiar with the HSRC, and also it is a government institution. It is not like he would just be outsourcing it (Prince, interview).

When initiating a research project, the Foundation sets up a panel of experts who serve as advisors and quality controllers of the research:

When [the Foundation] engages in a particular area of work it sets up like an expert panel because we believe we don't have all the answers but we can get it. We have been very successful in putting people together who in fact don't get paid. All they do is they advise us. [ ] And normally when you need something done, out of those experts somebody will know someone who is very renowned in that particular area. [ ] We source these experts, we approach them, and we put together the actual panel. [ ] They ensure that the research that is being done is one: methodologically sound and two: that the process as it unfolds is correct and before the report is being finalised they put critical research questions to the people who do the research. So it becomes like a quality control check for the Foundation (Prince, interview).

Once the research process is underway, the Programme Managers become involved in different ways. In the next section we look specifically at Ms Prince's involvement in the HIVIAIDS research project.

\section{Involvement in the research process}

As Programme Manager of the HIVIAIDS project, Ms Prince set up offices at the HSRC, bringing her physically closer to the primary researchers on the project. This enables her to attend all the working committee meetings throughout the research process:

I serve on all the committees so there is a weekly meeting and monthly meeting at which different people are drawn in and I serve on all of those. So I get feedback directly from the people who work. [ ] We have a weekly meeting, now because research is kicking in. And that is just to make sure everything is on track. Then there is a two-weekly meeting which brings in the program manager sitting in Pretoria, HSRC whatever, whatever. And the monthly meeting pulls together all the work that has been 
outsourced to other researchers. So in this particular case the HSRC is working with the Centre for Aids Development Research and Evaluation and working with the Medical Research Council. So I am physically part of those meetings (Prince, interview).

Ms Prince gives some reasons why she feels it is important for the Foundation to work closely with researchers:

The thing is ultimately we have had lots of discussions and the point is very simple. If you have no input researchers can also go off on their own tangent and do what they want to do. Because that is unfortunately what researchers tend to do. And for us we feel that [the research] has to inform someone of something. It is not for us and it is not for the research institution. [ ] I am unfortunately for the researchers based here. [ ] And when we commission research we expect people who do it on our behalf to treat the people they are interviewing with utmost respect. To treat the communities [with respect] and do [their] research with extreme compassion. And I suppose that is the good thing about working this closely with them. You are always there as a reminder. [They] are not doing research for someone who is out there and [whom they] don't have any dealings with, and so they [become] more interested in the final project (Prince, interview).

Ms Prince does not only sit on 'feedback' meetings, she also gets involved in the development phases of the research:

The past two days are a good example. They [the researchers] were finalising questionnaires, quite frankly if you think about it did I have to be part of it? I think I did - because those questionnaires could give rise to data that we could either use or not. So I actually prefer to be part of the meetings (Prince, interview).

We see then that through the Programme Managers, the Foundation takes an active role in shaping and monitoring progress of the research it funds.

\section{$4 \quad$ Promoting research utilisation}

One of the Foundation's main strategies to promote the utilisation of its research is to involve stakeholders throughout the research project. Ms Prince describes for example how this happened with the HIVIAIDS project:

If you take that household survey, the first one that was done. Because it was prevalence in terms of HIVIAIDS the foundation convened meetings with AIDS stakeholders, AIDS institutions, AIDS organisations. We first of all started putting the proposals to them - this is what we would like to do. Some of those organisations gave input and said why can't we add that. It would be more beneficial to some organisations if you could do this. So they actually added to the design of the proposal before the research even started. And then on an ongoing basis we met with them, the HSRC would come and give a report on where we are, what they are doing. [ ] They receive reports, they receive the findings, the recommendations. [ ] And 
eventually we had a special briefing with just those organisations when the [final] report became available (Prince, interview).

To make an even greater impact and appeal to stakeholders to utilise the research, the Foundation gave special reports to sub-groups of these stakeholders:

Subsequent to that we broke up the report into components, there is a treatment component, there is a children component, there is a woman's component. [ ] And what we did was we grouped the organisations that made up this - there was like a 100 odd organisations. We grouped them in terms of their expertise and their experience and we broke up the report and we presented that particular component of the report to them so that they could see how they could change program design or change current initiatives (Prince, interview).

Given the Foundation's position that its research should inform social policies and interventions, it is not surprising that the Foundation considers government to be key stakeholders to whom it should disseminate research information and promote the utilisation of its research. Ms Prince uses the HIVIAIDS research project as an example:

Then we had government and government served on here [the stakeholder meeting], but we didn't just want the Department of Health and Social Development, which usually comes. So what we did is we identified who is able to use these findings: there is the presidency, there is treasury, there is Social Development there is Health, there is Education and there is Science and Technology. Now what we did, Olive [the principal investigator] and I physically addressed the ministers and the presidency [regarding the research] where we actually one tell them what we are doing and secondly highlighting [the findings] (Prince, interview).

She gives examples of some of the repercussions of presenting the research findings to the ministers:

Treasury changed their allocation to AIDS, based on our statistics. Social Development, the Department of Education - they subsequently had an educator study that they commissioned based on the fact that our statistics showed that the school is a primary force where children are educated on HIV and AIDS [prevention] (Prince, interview).

Ms Prince believes that the role the Foundation played in disseminating this research and promoting the utilisation of the research contributed enormously to the impact that this research has had:

[The impact of the research] was way beyond what we ever imagined. But it was because of the fact of us driving and being involved throughout. You must remember research institutions in particular can't do some things; they can hardly get a meeting with the presidency. They [need us as] facilitators. So the reports went to the presidency. So it is important to work together in that kind of way (Prince, interview). 
The final report of the HIVIAIDS study was released under the title: Nelson MandelalHSRC Study of HIVIAIDS ${ }^{23}$ and published by the HSRC.

Although the Foundation initiates many of the interactions with potential users, it always encourages the researchers to present the research themselves:

We deal with people that very few other people would have access to. Not necessarily around research. But what we have done is we make use of every opportunity. So we have presented this to a German delegation, to an African delegation and I could go on and on. [ ] When the Sahara conference was happening I flew out to do a presentation to a German delegation. It was me, but then I also got someone from the HSRC in Pretoria to come and do a presentation on the impact on HIVIAIDS in the workplace. So it depends on who the delegation is - I present it to the Board with someone else. It depends on the occasion and what level of intensity the discussion is. Sometimes it is just better to take one of the researchers that are able to explain (Prince, interview).

While most of the Foundation's efforts are dedicated to its own programmes and projects, occasionally the Foundation also disseminates and promotes research from other organisations that they feel can also make a valuable contribution to social development research, policies and interventions:

When Love Life's [an NGO] report came out before it was made public. We have a relationship with Love Life through other work that we do. The Foundation commissioned a round table on research where Love Life's findings were presented. We had nothing to do with their research, but what we can do and what we did do is to pull together a group of researchers that hate each other because they all think they are doing the best. So we had Prof $X$ present those findings. Olive presented things on the similarities because you know their research gave exactly the same findings than the research that we did. Maybe one or two percent out. Then we had Ms $Y$ - so essentially we arranged a round table bringing all these people together around "Love Life". But it is something that Love Life wouldn't be able to do necessarily on their own. [ ] But what we did is making it neutral and saying look there are four or three sets of work that has been done around this area focusing on different things. All of you come here and present me with media and let's see what is relevant, what are the similarities in terms of methods and process (Prince, interview).

Ms Prince regards the case of 'Love Life' above as an example of how the Foundation fulfils its role as facilitator and catalyst of social development interventions:

If we call people to meetings they see it in a very particular different spirit. So there is that component because it again shows the power the Foundation has in terms of being that facilitator, catalyst. But the second thing is that the bottom line for me is that people are dying out there [from

23 The full title is: Nelson Mandela/HSRC Study of HIVIAIDS: South African National HIV Prevalence, Behavioural Risks and Mass Media: Household Survey 2002. The authors are Shisana and Simbayi, the respective Principal Investigator and Project Director at the HSRC. 
AIDS]. We could all choose our personal things what we would like to know, but it doesn't provide answers. And that is very much where the Foundation is kind of located. All of these things have a role. Whether it is antenatal and some people argue around antenatal. Where there is modelling and protection then some people argue around that. All form some way of dealing with the epidemic. Our interest is to deal with this epidemic. It is not about personal traces - if we feel that somebody is relevant to making a change, then those are the people that we will join.

In this and the previous section, we can see that Ms Prince took a very 'hands-on' approach in her role as Programme Manger for the HIVIAIDS project at the Foundation. She has worked closely with the primary researchers, not only in the research development and monitoring process, but also in disseminating and promoting the utilisation of the research. The HSRC Principal Investigator on this project was Dr Olive Shisana and the Project Director was Prof Leickness Simbayi.

In the next section we provide a brief description of the project again and reflect on Prof Simbayi's views of the project, his interaction with the Foundation and what he sees as the role of the Foundation in disseminating and promoting the utilisation of the research.

\section{A researcher's view: Prof LC Simbayi, Human Sciences \\ Research Council}

In 200 I the Foundation commissioned and provided the funding for a study of HIVIAIDS prevalence, behavioural risks and the mass media. The HSRC was identified as the primary researchers, but it was in fact to be a collaborative research project. Prof Simbayi was the Project Leader for this project at the HSRC. He explains who the collaborators were and what the research brief was:

In 200 I [the Foundation] called this meeting where everybody attended and it was at that meeting that the HSRC was identified as the one which would spearhead the project. It is part of a consortium that draw in the Medical Research Council as well as an NGO called CADRE (Centre for Aids Development, Research and Evaluation), which is part of Rhodes University. [The Foundation's] needs were to have a household survey to answer a lot of questions at a time to which people felt there were no answers available. (Simbayi, interview).

The study is described as follows in the final report:

This is the first systematically sampled national community-based survey of the prevalence of HIV in South Africa. In addition, it considers issues of risk, risk reduction, HIVIAIDS knowledge and communication, psychosocial and socio-cultural aspects of HIVIAIDS, providing important baseline data for programme development (Shisana \& Simbayi, 2002). 
Elsewhere we related some examples from Ms Prince about the impact of the research results and how it has been utilised. Prof Simbayi in contrast draws attention specifically to the utilisation that has been triggered by the research methodology:

It has created a lot of discussion about the methodology. To the extent that even the World Health Organisation and UNAIDS have been adjusting their statistics on the basis of amongst others that it is like ours - household surveys. At the moment we are working with UNAIDS on a [protocol] for use of our surveys. So the methodology is being accepted. And therefore the contribution goes beyond the borders of this country (Simbayi, interview).

He further describes a follow-up study initiated by the SADC HIVIAIDS Unit:

[SADC] put out a tender for various projects that are funded by the EU and we had requests from member countries, in fact Botswana expressed interest in what we have done and they wanted to learn from us. We had Mozambique and Swaziland also attending a workshop in Pretoria, where the idea of sharing, providing technical assistance was mentioned. [ ] The project is to conduct household surveys in each of the countries so we can get a better understanding of the HIV situation in each country. We basically help with what they need help with. We provide technical assistance and this varies depending on the countries' capabilities or expertise. So different countries ask us for different things. [ ] We share with them our [questionnaires]. We share with all of them what we have done. And it is up to them to look at their situation (Simbayi, interview).

Locally, the utilisation of the research by government has also led to an ongoing involvement of the HSRC researchers in monitoring and evaluating HIVIAIDS intervention programmes:

The government also released that report [Nelson Mandela/HSRC Study] acknowledging the importance of the study and actually specifying that they were increasing their budget even more in their fight against AIDS. Subsequently during the development of the comprehensive response [from government] which includes providing anti-retroviral in the public sector, the HSRC has been part of the process and in fact even now when they are looking at issues pertaining to monitoring and evaluation of that programme we are part of committees that are involved in that (Simbayi, interview).

While Prof Simbayi also acknowledges the important role the Foundation has played in disseminating the research, particularly to government, he and his research team have also disseminated the research widely through publications and conferences:

We have published some articles in international journals with the majority of publications going into the South African Medical Journal. And also conferences of course. I for example presented the findings at the National Institute of Mental Health in Washington last year. Then we have travelled to research institutions. We have a partner in France- the national research [institute] for HIVIAIDS in France. We had a conference in Bangkok two weeks ago, we presented some papers and we will be going to China this weekend. Next week I will be presenting a paper based on that. Even the 
SAHARA conference is next month - I would present something just for them (Simbayi, interview).

According to Prof Simbayi he has also been interviewed many times by the media and written a few newspaper articles based on the research results.

\section{Role of the Foundation}

Prof Simbayi describes the Foundation as "the main driver of the dissemination strategy". He refers for example to the meetings with stakeholders facilitated by the Foundation:

What the Nelson Mandela Foundation fund does as the main funder of that project, they actually call meetings of stakeholders. These are drawn from government and non-government organisations, donor organisations and multi lateral agencies and they feed the information back to them. We sure hope that they are able to take what they are to help improve what they do (Simbayi, interview).

He also refers particularly to the efforts the Foundation made to disseminate the research to government and how the researchers were included in this process:

Making it available to particularly government, which then use it as they see fit. The information has been shared with most departments in government, in particular health. We were called after presenting to them, before the report was just released. [ ] There was another meeting where they wanted to find out as much as they could so that they could use it in planning their work for last year and subsequent year. Department of Education the same, the minister there was very keen and because we included children, there were aspects of looking at how effective the programs [could be] $n$ the schools (Simbayi, interview).

The Foundation, he says, always goes a step further than the researchers when it comes to disseminating the research:

We are the technical experts, then there are meetings at which we present the results. But [the Foundation] also tries to re-package the press release in such a way that it is user friendly for different categories of stakeholders. So that it is not too technical particularly for those working at grassroots level (Simbayi, interview).

The comments by both Prof Simbayi and Ms Prince earlier, suggest that there is mutual acknowledgement of the roles that the researchers and the Foundation can play in disseminating and promoting the utilisation of the research.

\section{$6 \quad$ Concluding remarks}

The Nelson Mandela Foundation is an organisation committed, amongst other things, to supporting social development research and programmes and creating platforms for dialogue between different social groups and agencies. It sees itself as a kind of catalyst that can inspire people, who wouldn't normally collaborate, to work together towards social change. It encourages social alliances and partnerships that will foster community engagement, community project-ownership and community benefit. 
The Foundation relies on donor funds for specific projects to sustain it. It commissions and funds research that is innovative and will have some impact on social development policies and interventions. The Foundation considers the researchers to be their partners and where possible, it actively participates in the development phases of the research and monitoring research progress.

The Foundation is instrumental in disseminating and promoting the utilisation of its research. One of its main strategies is to involve key stakeholders at the outset of a research project, getting their input at the research design stage, and then keeping them updated throughout the research process. Once the research is completed, the Foundation makes special efforts to tailor reports for specific groups of stakeholders and specifically targets different pillars of government that it feels can utilise the research to make a difference to the future of the country.

From a researcher's perspective, working with the Foundation presents many opportunities that he/she would not normally have to disseminate the research. Having the name, Nelson Mandela Foundation, attached to the research, also brings status and power to the research, and hence more credibility, in the eyes of potential users.

This case study suggests that the Foundation plays a significant role as an intermediary agency that: commissions and funds social development research that will impact on policy; participates in the development and monitoring of the research; facilitates interactions between key stakeholders and researchers; and adopts different strategies to disseminate and promote the utilisation of its research. 
List of data sources

Telephonic interviews

Ms B Prince, Project Manager: HIV/AIDS, Nelson Mandela Foundation (July 2004)

Prof LC Simbayi, Project Director: HIVIAIDS, Human Sciences Research Council (July 2004)

\section{Publication}

Shisana, O \& Simbayi, LC (2002) Nelson Mandela/HSRC Study of HIVIAIDS: South African National HIV Prevalence, Behavioural Risks and Mass Media: Household Survey 2002. HSRC

\section{Website}

http://www.nelsonmandela.org/ 

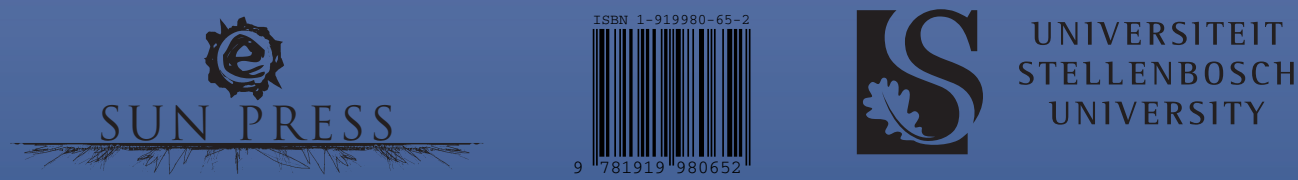